NOTE: This is a postprint of the study Katz, B. A., Matanky, K., Aviram, G., \& Yovel, I. (2020). Reinforcement sensitivity, depression and anxiety: A meta-analysis and meta-analytic structural equation model. Clinical Psychology Review, 101842, doi:

\title{
Reinforcement Sensitivity, Depression and Anxiety: A Meta-Analysis and Meta-Analytic Structural Equation Model
}

\author{
Benjamin A. Katz*, Kathryn Matanky, Gidi Aviram \& Iftah Yovel \\ The Hebrew University of Jerusalem
}

\begin{abstract}
Reinforcement Sensitivity Theory (RST) posits that individual differences in reward and punishment processing predict differences in cognition, behavior, and psychopathology. We performed a quantitative review of the relationships between reinforcement sensitivity, depression and anxiety, in two separate sets of analyses. First, we reviewed 204 studies that reported either correlations between reinforcement sensitivity and self-reported symptom severity or differences in reinforcement sensitivity between diagnosed and healthy participants, yielding 483 effect sizes. Both depression (Hedges' $\mathrm{g}=$ $.99)$ and anxiety $(\mathrm{g}=1.21)$ were found to be high on punishment sensitivity. Reward sensitivity negatively predicted only depressive disorders $(\mathrm{g}=-.21)$. More severe clinical states (e.g., acute vs remission) predicted larger effect sizes for depression but not anxiety. Next, we reviewed an additional 39 studies that reported correlations between reinforcement sensitivity and both depression and anxiety, yielding 156 effect sizes. We then performed meta-analytic structural equation modeling to simultaneously estimate all covariances and control for comorbidity. Again we found punishment sensitivity to predict depression $(\beta=.37)$ and anxiety $(\beta=.35)$, with reward sensitivity only predicting depression $(\beta$ $=-.07$ ). The transdiagnostic role of punishment sensitivity and the discriminatory role of reward sensitivity support a hierarchical approach to RST and psychopathology.
\end{abstract}

Highlights: Sensitivity to punishment positively predicts both depression and anxiety. Sensitivity to reward discriminates between them, negatively predicting depression. This pattern was observed even when directly controlling for comorbidity. Depression's effect sizes are uniquely sensitive to clinical state. Depression's effect sizes are also moderated by method of clinical assessment.

Data, analysis code, supplementary material: https://osf.io/n6gv4/

Keywords: Reinforcement Sensitivity Theory, Depression, Anxiety, Meta-analytic structural equation modeling, Reward processing

Gray's Reinforcement Sensitivity Theory (RST; J. A. Gray, 1970, 1987; J. A. Gray \& McNaughton, 2000) posits that sensitivity to appetitive and aversive stimuli

\footnotetext{
This research was partially supported by the Israel Science Foundation grant 886/18 awarded to IY. Author BAK was involved in all parts of the current research. Author KM assisted in literature searches, coding of data and editing of the manuscript. Author GA contributed to writing of the manuscript. Author IY supervised study design, analysis and writing of the manuscript. All authors have approved the final manuscript. The authors have no conflicts of interest to report. The authors thank Avraham N. Kluger for his input regarding the formulation and analysis of this project and Deborah Schwartz for her assistance in editing the manuscript. We also thank the researchers who took time to provide unpublished data and additional information that improved the quality and scope of these analyses.

Correspondence concerning this paper should be addressed to Benjamin A Katz, Department of Psychology, The Hebrew University of Jerusalem. Email: Benjamin.katz@mail.huji.ac.il
}

serves as a biological basis of human personality. According to the original theory, the Behavioral Approach System (BAS) governs processes related to appetitive stimuli, whereas the separate, independent Behavioral Inhibition System (BIS) governs responses to aversive stimuli (Corr, 2008). Individuals' varied sensitivities in BAS and BIS functioning then lead to individual differences in reward processing, punishment processing, and personality. Those with a more sensitive BAS tend to show more cognitive styles and behaviors associated with reward promotion and the broad personality dimension of extraversion (Corr \& McNaughton, 2008; Depue \& Collins, 1999; J. A. Gray, 1987). A more sensitive BIS, on the other hand, impacts behaviors and psychological processes related to punishment and neuroticism (J. A. Gray, 1970; Smits \& Boeck, 2006).

In 2000, RST was revised (J. A. Gray \& McNaughton, 2000) to include three systems (Corr, 
2008). The BAS system remained governing all appetitive processing, while aversive processing was ascribed to the newly named Fight/Flight/Freeze System (FFFS) instead of the original BIS. The BIS in the revised version was theorized to be activated when the goals of the BAS and FFFS came into approach-avoidance conflicts. New measures (e.g., Corr \& Cooper, 2016; Jackson, 2009) have been developed with the purpose of differentiating the revised BIS from the FFFS (i.e., original BIS). In practice, they both correlate with measures of BIS developed under the original RST and much of the literature on RST, motivation and psychopathology continues to use the original terminology of BAS for appetitive sensitivity and BIS for aversive sensitivity (e.g., Bijttebier, Beck, Claes, \& Vandereycken, 2009; Trew, 2011). The current metaanalysis, in reviewing this literature, uses the terminology of the original RST when referring to basic appetitive and aversive processes as well.

When appetitive and aversive sensitivities are dysregulated, they are theorized to be diatheses for subsequent psychopathology. BAS hyposensitivity is indicated by deficits in anticipatory pleasure, consummatory pleasure, and appetitive motivation (Alloy, Olino, Freed, \& Nusslock, 2016; Olino, McMakin, \& Forbes, 2018; Zald \& Treadway, 2017). This anhedonic experience is a hallmark of dysthymia and major depressive disorder (American Psychiatric Association, 2013; Watson, Clark, et al., 1995). Accordingly, numerous studies have found reduced BAS sensitivity to be associated with depression among clinical (e.g., DelDonno et al., 2015; Greenwood et al., 2013; Zaninotto et al., 2015) and nonclinical samples (e.g., Hundt, NelsonGray, Kimbrel, Mitchell, \& Kwapil, 2007; Jarmolowicz et al., 2014; Peirson \& Heuchert, 2001) though not always (e.g., Carver \& Johnson, 2009). Among depressed patients, BAS hyposensitivity was found to predict greater concurrent symptom severity and a worse outcome following treatment (Kasch, Rottenberg, Arnow, \& Gotlib, 2002). Anxiety, on the other hand, is theorized to be weakly related to BAS sensitivity, if at all (J. A. Gray, 1987; J. A. Gray \& McNaughton, 2000; McNaughton \& Corr, 2004). Rather, anxiety is theorized to primarily occur as a function of aversive sensitivities, conceptualized as BIS hypersensitivity in the original RST (J. A. Gray, 1982, 1987). BIS hypersensitivity is associated with increased apprehension in the face of impending negative outcomes and more intense reactivity to punishment, which are experiences salient to anxiety disorders (Carver \& White, 1994;
Corr \& McNaughton, 2008; Hollon, 2019; Leen-Feldner, Zvolensky, Feldner, \& Lejuez, 2004). Later investigations, however, have found BIS levels to predict depression to a large degree as well (Eshel \& Roiser, 2010; Hundt et al., 2007; Johnson, Turner, \& Iwata, 2003; Pekka Jylhä \& Isometsä, 2006).

Thus, it appears that the BIS predicts both depression and anxiety while the BAS uniquely predicts depression (Bijttebier et al., 2009; Khan, Jacobson, Gardner, Prescott, \& Kendler, 2005). This pattern has been linked to similar hierarchical models of psychopathology such as the tripartite model, where general distress is present across depression and anxiety disorders, but deficits in positive affect are unique to depression (Clark \& Watson, 1991; Lahey, Krueger, Rathouz, Waldman, \& Zald, 2017; Zinbarg \& Yoon, 2008).

The multidisciplinary literature on the relationship between reinforcement sensitivity dysregulation and mood disorders has been summarized in a number of influential theoretical frameworks and models. The $B A S$ dysregulation model highlights the unique role that reward sensitivity plays in the development and maintenance of depression and bipolar disorder (Alloy et al., 2016; Stange et al., 2013). The joint system hypothesis suggests that internalizing pathology is most closely predicted by a confluence of hyposensitive BAS and hypersensitive BIS (Corr, 2001; Eddington, Majestic, \& Silvia, 2012; Hundt et al., 2007). Furthermore, RST has provided a theoretical basis for disorder classification models related to depression and anxiety in particular (Nusslock, Abramson, Harmon-Jones, Alloy, \& Hogan, 2007; Zinbarg \& Yoon, 2008), and mental illness in general (Bijttebier et al., 2009). RST has even served key roles in explaining how individual differences in general may impact the etiology (Kimbrel, 2008; Trew, 2011), severity (e.g., T. A. Brown, Chorpita, \& Barlow, 1998; Cloninger, Bayon, \& Svrakic, 1998) and classification (e.g., Caspi et al., 2014; Clark \& Watson, 1991; Eaton et al., 2013; Krueger \& Markon, 2006; Watson, 2009) of mental disorders. The National Institute of Mental Health has since included reward and punishment processing among its Research Domain Criteria (RDoC; Insel et al., 2010), further emphasizing the central role that RST plays in basic clinical science.

The current theoretical work, however, is limited by its reliance on narrative reviews, which often under-represent nonsignificant effects, unpublished effects, or effects that were secondary to the study at hand (Easterbrook, Gopalan, Berlin, \& Matthews, 1991; 
Rosenthal \& DiMatteo, 2001; Sterne, Gavaghan, \& Egger, 2000). This biased source selection may have theoretical implications. Constructs such as positive emotionality (Watson \& Naragon-Gainey, 2010) and extraversion (Krueger, Caspi, Moffitt, Silva, \& McGee, 1996) have been hypothesized to differentiate depression from anxiety. However, when subjected to the scrutiny of meta-analyses, neither construct conclusively discriminated between these disorders (Khazanov \& Ruscio, 2016; Kotov, Gamez, Schmidt, \& Watson, 2010). Similarly, the relationship between BAS hyposensitivity and anhedonic depression has been highlighted in narrative reviews of findings (e.g., Alloy et al., 2016; Zinbarg \& Yoon, 2008) derived from biological (e.g., DelDonno et al., 2015), behavioral (e.g., Treadway, Bossaller, Shelton, \& Zald, 2012), and selfreport data (e.g., Kircanski, Mazur, \& Gotlib, 2013), with some studies based upon quite sizeable samples (e.g., Johnson et al., 2003). However, it is also possible that the unique relationship between BAS sensitivity and anhedonia may not withstand the scrutiny of metaanalysis, as was the case of positive emotionality and extraversion.

Attempts to discriminate between depression and anxiety are further complicated by their high comorbidity (Watson, 2009). Depression and anxiety are noted risk factors for each other (Jacobson \& Newman, 2017), with overlapping symptom criteria (Borsboom \& Cramer, 2013), some shared basic mechanisms (Nolen-Hoeksema \& Watkins, 2011; Ruscio, Seitchik, Gentes, Jones, \& Hallion, 2011), and are especially comorbid among more severe clinical samples (Kessler, Chiu, Demler, \& Walters, 2005). To understand each disorder's unique relationship with reinforcement sensitivity, it is necessary to control for their shared variance. Only meta-analytic tools enable that, either by indirectly projecting shared covariance (e.g., Khazanov \& Ruscio, 2016) or by using structural equation modeling to directly control for it (M. W.-L. Cheung \& Chan, 2005; Jak, 2015). Thus, a systematic quantitative review is needed to adequately estimate the unique relationships between BAS, BIS, depression and anxiety, after controlling for the disorders' high rates of comorbidity.

Furthermore, a meta-analysis of the relationship between reinforcement sensitivity, depression and anxiety may answer the calls for identifying potential moderators to the relationship (see Bijttebier et al., 2009). One moderator of note is clinical state. Indeed, differences have been found between acute depressed patients and those in remission in measures of both reinforcement sensitivity (Pinto-Meza et al., 2006) and temperament (Nery et al., 2009; M. Takahashi et al., 2013). This was particularly true for punishment sensitivity (Hansenne \& Bianchi, 2009). To the best of our knowledge, however, the moderating role of clinical state on otherwise stable traits is largely neglected in the meta-analytic literature (Kotov et al., 2010; cf. Zaninotto et al., 2016), including the literature on reinforcement sensitivity.

In sum, numerous multimodal lines of research have found that dysregulated reinforcement sensitivity plays a critical role in the development and maintenance of depression and anxiety. Summaries of these findings, however, have been limited to narrative reviews. Without a quantitative summary of the literature, the range of observed effect sizes remains unknown, central hypotheses laid out in RST remain untested, and potential moderators remain unexamined. These questions impact the nature of reinforcement sensitivity's relationship with depression and anxiety, and warrant the performance of a meta-analysis.

\section{The Current Studies and Hypotheses}

The current meta-analyses aimed to quantify the relationships between reinforcement sensitivity, depression and anxiety, and to examine the factors that may moderate these relationships. First, we examined the broad relationships between reward and punishment sensitivity, and a single pathology factor consisting of both depression and anxiety (Aldao, Nolen-Hoeksema, \& Schweizer, 2010; Caspi et al., 2014). In doing so, we aimed to provide, for the first time, an estimation of the true effect size of the relationships between the components of reinforcement sensitivity, depression and anxiety.

We then examined potential moderators for these relationships. The moderator of primary interest was disorder cluster (i.e., anxiety vs depression). By including disorder cluster as a moderator, we could examine whether punishment sensitivity or reward sensitivity could reliably discriminate between anxiety and depression. We examined these relationships in two ways. First, using a large sample of studies, we used subgroup analysis to examine the bivariate relationships between the two components of reinforcement sensitivity and disorder cluster. A significant difference in BAS or BIS levels between disorder clusters would indicate that the

NOTE: This is a postprint of the study Katz, B. A., Matanky, K., Aviram, G., \& Yovel, I. (2020). Reinforcement sensitivity, depression and anxiety: A meta-analysis and meta-analytic structural equation model. Clinical Psychology Review, 101842, doi: 
reinforcement sensitivity system generally discriminates between depression and anxiety in the current literature. To more directly control comorbidity, we also performed a meta-analytic structural equation model (MASEM; Hunter \& Schmidt, 2004) analysis on a subgroup of eligible studies that estimated the unique covariance between all four elements (i.e., BIS, BAS, depression and anxiety). This allowed us, for example, to estimate the relationship between BAS and anxiety, independent of possible confounding relationships between BAS and depression. To maintain the independence of both forms of analysis, we partitioned the studies used in the MASEM away from the other studies. This ultimately led to the two separate meta-analytic studies presented below.

We also examined the role of diagnostic method plays moderating the observed effects. Indeed, as has been seen elsewhere (e.g., Aldao et al., 2010), effects that are taken from self-report measures of psychopathology (e.g., Beck Depression Inventory; Beck, Wartenberg, Mendelson, Mock, \& Erbaugh, 1961) may systematically differ from those taken from clinical diagnosis. Such differences are confounded by the fact that effects taken from self-report measures are usually derived from correlational data, while those taken from clinically diagnosed groups are usually derived from standardized mean comparisons with healthy control groups. This difference in analytic method may inflate the effect sizes of comparison groups due to the selection of statistically extreme participants (e.g., high in depression vs healthy; Kircanski et al., 2013). Thus, differences observed between self-report effects and diagnosed-healthy comparison effects could potentially be confounded by differences in clinical severity. To address this concern, we also examined whether clinical state (e.g., acute episode vs remission) would moderate effects among diagnosed-healthy comparisons. In doing so, we were able to quantify the moderating role of current clinical severity, within a diagnosed population. Significant moderators in this case would indicate meaningful differences in effect sizes, based on the clinical status of the participants (i.e., self-report vs diagnosed; acute vs remission). We examined the role of clinical status as a moderator for reinforcement sensitivity's relationships with psychopathology both across disorder clusters as well as within depression and anxiety.

\section{Operationalization of Reinforcement Sensitivity and Pathology}

NOTE: This is a postprint of the study Katz, B. A., Matanky, K., Aviram, G., \& Yovel, I. (2020). Reinforcement sensitivity, depression and anxiety: A meta-analysis and meta-analytic structural equation model. Clinical Psychology Review, 101842, doi:

10.1016/j.cpr.2020.101842. See online article for final text.
Reward and punishment sensitivities were operationalized in the form of self-report measures derived directly from RST (e.g., BIS/BAS; Carver \& White, 1994) or from measures with subscales generated to measure particular RST systems (e.g., Tridimensional Personality Questionnaire - Novelty Seeking and Harm Avoidance; Cloninger, 1987; Klein et al., 2011; for a fuller review, see Torrubia, Avila, \& Caseras, 2008). Psychopathology was operationalized either in the form of self-report measures of depression or anxiety (e.g., Beck Depression Inventory; Beck, et al. 1961), or in the form of a diagnosed anxiety, depressive, or mixed disorder.

\section{Hypotheses}

In Study 1, we first expected to find reinforcement sensitivity to predict psychopathology (Hypothesis 1). Specifically, based on the close relationship between BAS hyposensitivity and affective symptoms such as anhedonia (Zald \& Treadway, 2017), we expected a negative relationship between BAS sensitivity and psychopathology (Hypothesis 1a). On the other hand, due to the literature on punishment hypersensitivity (e.g., Smits \& Boeck, 2006), we expected to find a positive relationship between BIS sensitivity and psychopathology (Hypothesis 1b).

Second, we expected the role of reinforcement sensitivity to change as a function of disorder cluster (Hypothesis 2). BAS was predicted to play a discriminatory role (Alloy et al., 2016), in the form of a negative relationship with depressive disorders (Hypothesis 2a) which would be significantly larger than anxiety (Hypothesis $2 b$ ). We did not expect a significant relationship between BAS and anxiety. On the other hand, we expected the BIS would impact both depression and anxiety (Smits \& Boeck, 2006; Zinbarg \& Yoon, 2008). This would take the form of a positive relationship between the BIS and depression (Hypothesis 2c), as well as anxiety (Hypothesis 2d). We did not expect a difference between the two disorder clusters. Finally, we expected to see this pattern both when comparing between bivariate relationships using subgroup analysis (see Study 1), as well as when simultaneously estimating all relationships (e.g., between depression and anxiety) using MASEM (see Study 2).

Third, we expected clinical status to impact the observed relationships (Hypothesis 3). This would be reflected in the form of larger effect sizes for populations with more severe clinical statuses, both with regards to BAS (Hypothesis 3a) as well as BIS (Hypothesis 3b). Specifically, we expected that effects derived from 
self-report correlations would be smaller than those derived from clinical-healthy comparisons, which select for participants high and low in symptom severity. In keeping with this pattern, we also expected that clinical participants who currently suffer from more severe pathology would differ more from healthy controls in reinforcement sensitivity than those who are currently in remission. We examined this moderator across disorders, as well as within the depression and anxiety clusters.

\section{Method}

\section{Literature search}

Studies were identified through a set of 30 searches in PsycInfo and PubMed between 1991 and October 2017. Searches entailed permutations of (a) keywords related to reinforcement sensitivity theory and its scales - RST , "Reinforcement Sensitivity", "Reward Sensitivity", "Punishment Sensitivity", "Reward Dependence", BIS, BAS, "Behavioral Activation System", "Behavioral Approach", "Behavioral Inhibition", SPSRQ, "Sensitivity to Reward Questionnaire", "Brief Sensitivity to Punishment", "Appetitive Motivation Scale", RSQ, RST-PQ, "Gray-Wilson Personality Questionnaire", "General Reward and Punishment Expectancy Scale", "Tridimensional Personality Questionnaire", $T P Q$, "Temperament and Character Inventory", TCI and (b) depression, anxiety and their measures - depress*, MDD, dysth*, "mood disorder", "affective disorder", anxiety, GAD, fear, panic, STAI, "post*traumatic stress disorder", PTSD, "social phobia", "social anxiety", agoraphobia, phob*, "obsessive-compulsive disorder", $O C D$. The asterisk in search terms allowed for multiple word endings (e.g., phob* allowed for both phobia and phobic). An invitation for published and unpublished manuscripts was also publicized on ResearchGate. The reference sections of narrative literature reviews on the topic were reviewed for additional potential articles (Alloy \& Abramson, 2010; Bienvenu et al., 2001; Bijttebier et al., 2009; Khazanov \& Ruscio, 2016; Kimbrel, 2008; Klein et al., 2011; Kotov et al., 2010; Nusslock \& Alloy, 2017; Trew, 2011; Urosević, Abramson, Harmon-Jones, \& Alloy, 2008; Zald \& Treadway, 2017). All searches were performed between May and June, 2017. A search protocol may be found in the Supplemental Materials at https://osf.io/n6gv4/. This process yielded 10,572 references. We then uploaded the references to Endnote
X8.2 and scanned for duplicates. Following the elimination of duplicates, 5,995 references were approved for abstract screening (see Figure 1 for summary).

\section{Inclusion/Exclusion Criteria}

A study was evaluated according to its ability to furnish a unique effect size on the relationship between depressive/anxious symptomatology and sensitivity to reward and punishment. Specifically, a manuscript had to report one of three effects. The first possible effect was a correlation between a validated self-report symptom measure (e.g., the Beck Depression Inventory; Beck, et al., 1961) and a validated measure of reinforcement sensitivity (e.g., the BIS/BAS scale; Carver \& White, 1994). The second effect consisted of standard mean differences in reinforcement sensitivity between two groups derived from a symmetrical division (e.g., median split) of participants based on a self-report symptom measure (e.g., Aarts \& Pourtois, 2010). Third, effects were included if they compared reinforcement sensitivity levels between participants diagnosed with a depressive or anxiety disorder, and healthy controls. Only manuscripts written in English were included, though the research itself may have been performed in any language.

A number of exclusion criteria were applied as well. First, in order to aggregate comparable effect sizes, only trait self-report data was considered eligible for inclusion. Thus, clinical reinforcement sensitivity studies that did not include self-report data (e.g., only behavioral data; Kunisato et al., 2012) or only state data (e.g., State-Trait Anxiety Inventory-State; Spielberger, Gorsuch, Lushene, Vagg, \& Jacobs, 1983) were rejected. Second, standard mean differences among nonclinical participants were only included if they were symmetrical. Studies with non-symmetrical division of participants (e.g., high BAS vs moderate BAS; Stange et al., 2013) were not included. Third, in order to minimize the probability of confounding effects and oversampling of certain disorders, studies were rejected if the diagnosed group was selected on the basis of comorbidity with a disorder beyond the purview of the meta-analysis (e.g., eating disorders; Reba-Harrelson et al., 2008) or on the basis of any other clinically relevant criterion foreign to the meta-analysis (e.g., alcohol use; Sellman \& Joyce, 1996). Studies were included, however, if a correlation between RST and self-report symptom measures could be obtained from within the non-clinical controls (e.g., Senín-Calderón, PeronaGarcelán, Fuentes-Márquez, \& Rodríguez-Testal, 2017). Fourth, in the event that participants diagnosed

NOTE: This is a postprint of the study Katz, B. A., Matanky, K., Aviram, G., \& Yovel, I. (2020). Reinforcement sensitivity, depression and anxiety: A meta-analysis and meta-analytic structural equation model. Clinical Psychology Review, 101842, doi: 
with a depressive or anxiety disorder were included in the sample, a study would only be included if it included a healthy control group as well, in order to calculate a standard mean difference (cf. Kotov et al., 2010). Fifth, experiments and treatment studies were included only if data was collected before any intervention took place. The first author (BAK) sorted all studies in both the abstract review and full text review stages. The second author (KM) independently sorted a subset consisting of ten percent of the studies, randomly selected. Interrater reliability was high $(r \mathrm{~s}>.86)$ for all stages of the sorting process. Two hundred and fifty-five manuscripts indicated the collection of data appropriate for the meta-analysis, but did not report all of what was necessary for inclusion. Authors of these manuscripts were contacted for further information between February and April 2018, with 20 agreeing to send the unpublished data. Altogether, 244 manuscripts were included in the meta-analysis.

\section{Coding of Studies}

In the case of a single group, we recorded correlations between BAS/BIS and depression/anxiety measures. In the case of a dichotomous comparison between two groups (e.g., diagnosed depression and healthy control group), we recorded the data necessary for the calculation of standard mean differences (e.g., $M$ and $S D$ of BIS). A number of moderators were coded as well. We recorded demographic variables known to correlate with reinforcement sensitivity: average age and proportion of female participants (J. D. Gray, Hanna, Gillen, \& Rushe, 2016; Torrubia et al., 2008). We also recorded sample size and publication status as meta-data for each article (i.e., published $=1$, unpublished $=0$ ). We also recorded the measures used to assess reinforcement sensitivity, clinical severity and the diagnosis of participants in a clinical group.

The clinical status of the sample was recorded as well. This was done in two steps. First, the sample was coded based on whether effect sizes were derived from comparisons between clinical and healthy groups or from correlations with self-report measures (i.e., diagnostic $=1$, self-report $=0$ ). All correlational data was classified as self-report, along with two (i.e., Aarts \& Pourtois, 2010; Duley, Hillman, Coombes, \& Janelle, 2007) out of 118 standard mean differences. Studies with diagnosed participants were then coded based on their clinical status (Zaninotto et al., 2016). Participants who were currently experiencing a depressive episode or were diagnosed with a current, clinical-level, un- treated anxiety disorder were classified as Episode/Acute. Participants who reported a lifetime incidence of a depressive or anxiety disorder, but were below the threshold for a current depressive episode or anxiety diagnosis were classified as Euthymic/Remission. In addition to these two groups, there was a high incidence of studies where participants were recruited as outpatients in ambulatory clinics, but their current clinical state was not specified. Because such populations often represent participants at both clinical and sub-clinical levels of symptom severity, these participants were classified in a separate group, Outpatient.

The first author (BAK) coded all 244 studies. The second author (KM) independently coded a subset consisting of 102 studies $(41.8 \%)$ randomly selected from the pool of coded studies. Interrater reliability was high ( $r=.96$ or above) for all variables. Disagreements in ratings were discussed until a consensus was reached.

Coding decisions. A number of decisions needed to be made during the coding process when studies contained multiple measures. First, when multiple clinical or reinforcement sensitivity measures were included in the same sample, steps were taken to include all collected data while nevertheless maintaining the assumption of independence of all samples' effect sizes. Specifically, in studies with correlational data, the correlations were averaged together (Aldao et al., 2010). In studies consisting of group differences, the distributions of multiple measures were merged in order to generate two groups for comparison (i.e., an aggregated clinical group and an aggregated healthy control) using the standard analysis-of-variance approach to partitioning variance (Borenstein, Hedges, Higgins, \& Rothstein, 2009; Kirk, 1995). Multiple means were summed together and multiple standard deviations were merged by taking the square root of the pooled variances (Kotov et al., 2010). In the case of multiple clinical groups with a single healthy control group $(k=23)$, separate standard mean differences were calculated between each clinical group and the control group. The sample size of the control group was then evenly divided by the number of comparisons for which it was used (Borenstein et al., 2009; cf. Kotov et al., 2010). Finally, owing to the small portion of studies with longitudinal data $(k$ $=11$ ), only the initial cross-sectional effect was recorded.

\section{Division of Studies}

NOTE: This is a postprint of the study Katz, B. A., Matanky, K., Aviram, G., \& Yovel, I. (2020). Reinforcement sensitivity, depression and anxiety: A meta-analysis and meta-analytic structural equation model. Clinical Psychology Review, 101842, doi:

10.1016/j.cpr.2020.101842. See online article for final text. 
The two present meta-analytic studies utilized separate methodologies with different inclusion requirements. In Study 1, we aimed to quantify the bivariate relationships between reward/punishment sensitivity, depression and anxiety, and to identify moderators for these effects. To do so, we performed a series of metaanalyses and moderator analyses, which required studies that reported relationships between at least one clinical measure (i.e., depression and/or anxiety) and at least one reinforcement sensitivity measure (i.e., BAS and/or BIS). This intentionally broad criterion allowed for a comprehensive summary of the current literature and a well-powered moderator analysis. Study 2 examined the extent to which relationships observed in Study 1 may have been confounded by the high covariance between depression and anxiety. To address this question, we utilized the meta-analytic structural equation model (MASEM; Hunter \& Schmidt, 2004) method.

Estimating a MASEM requires a series of decisions that impact which studies are to be included. One approach to study selection is pairwise inclusion, wherein every correlation available is included in a meta-analysis (e.g., BAS-depression), even in the absence of other correlations (e.g., BAS-anxiety). This method includes a wider range of data but is also accompanied by complications related to questions of ideal sample size (e.g., average sample size vs sum of all samples, etc.; Cheung \& Chan, 2005) as well as by the risk of generating a non-positive definite matrix that is ineligible for the maximum likelihood estimator used in structural equation modeling (Kline, 2015; Naragon-Gainey, McMahon, \& Chacko, 2017; Wothke, 1993). For these reasons, we used a more conservative listwise inclusion of studies (M. W.-L. Cheung \& Chan, 2005; Hom, Caranikas-Walker, Prussia, \& Griffeth, 1992), wherein studies were only included in this MASEM if they reported correlations between all four elements in the model (i.e., BAS, BIS, depression and anxiety).

To ensure the independence of Study 1 and Study 2, effects included in Study 2 were not included in Study 1. Thus, following coding, 299 samples were partitioned into two groups. The majority of articles were included in Study $1(k=204)$. Those that reported correlations between all four elements were included in Study $2(k=39)$. Databases and analyses for Studies 1 and 2 may be found in the Supplemental Materials (https://osf.io/n6gv4/). No differences were found with regards to the meta-data of the self-report effects in Study 1 and the effects in Study 2. Furthermore, sensitivity analyses confirmed that no findings in Study 1 were impacted by the removal of studies for Study 2 (see Supplemental Materials; S1-S2).

\section{Study 1}

\section{Data Analytic Plan}

All effect sizes were transformed to standard mean differences using standard formulae $(\mathrm{H}$. Cooper, Hedges, \& Valentine, 2009). To correct for small sample sizes, Hedges' $g$ was used instead of Cohen's $d$ (Hedges \& Olkin, 1984), with non-clinical participants coded as 0 and clinical participants coded as 1 . Thus, positive effect sizes indicated elevated reinforcement sensitivity among those with higher clinical measures. We considered an absolute value of Hedges' $g$ under $|.10|$ to be trivial, between $|.10|$ and $|0.49|$ to be a small effect size, between $|0.50|$ and $|0.79|$ to be medium, and greater than |.80| to be large (Cohen, 1988). In keeping with other meta-analyses that assess unified constructs via self-report measures (e.g., Kotov et al., 2010; Naragon-Gainey et al., 2017), multiple measures of the same construct were included under the same analysis. Separate meta-analyses for each measure are reported in the supplemental materials (S3-S4).

First, to estimate the relationships between psychopathology and reinforcement sensitivity, we performed two separate meta-analyses - one for reward sensitivity (Hypothesis 1a) and one for punishment sensitivity (Hypothesis 1b). These meta-analyses followed procedures laid out by Borenstein et al (2009). Due to the assumption of true differences between studies and an interest in generalizing beyond the current dataset, we used a random-effects model (Schmidt, Oh, \& Hayes, 2009). The summary effect size was calculated as a weighted average, using the inverse of sample size as weights. Standard errors were calculated as a function of sampling error and between-study variance. Analyses were performed using $\mathrm{R}$ version 3.6.2 ( $\mathrm{R}$ Core Team, 2017). Effect sizes were calculated using the package 'compute.es' version 0.2-4 (Del Re, 2013); the meta analysis was performed using 'meta' version 4.10-0 (Schwarzer, 2007) and 'robumeta' version 2.0 (Fisher, Tipton, \& Zhipeng, 2017; for a full review of available packages, see Polanin, Hennessy, \& TannerSmith, 2017).

Next, to examine the role of disorder cluster (i.e., depression vs anxiety) as a moderator, we performed a mixed-effects subgroup analysis for the BAS (Hypotheses 2a-b) and BIS (Hypothesis 2c-d) meta-analyses using disorder as a grouping variable (Borenstein et al., 2009). Four studies involved data taken from patients

NOTE: This is a postprint of the study Katz, B. A., Matanky, K., Aviram, G., \& Yovel, I. (2020). Reinforcement sensitivity, depression and anxiety: A meta-analysis and meta-analytic structural equation model. Clinical Psychology Review, 101842, doi: 
with mixed depression/anxiety (Battaglia, Przybeck, Bellodi, \& Cloninger, 1996; S. L. Brown, Svrakic, Przybeck, \& Cloninger, 1992; Minaya \& Fresán, 2009; Minelli, Pedrini, Magni, \& Rotondo, 2009) and were ineligible for this stage of analysis. A series of mixedeffect subgroup analyses were then performed to examine the moderating roles of participant clinical status (Hypothesis 3) and publication status. Then, to examine the role of continuous variables as moderators, and to control for possible covariance between moderators, a two-step metaregression was undertaken (GonzalezMulé \& Aguinis, 2018; Piotrowska, Stride, Croft, \& Rowe, 2015). First, we performed a series of univariate regressions on all of the above categorical moderators, as well as on the continuous moderators of sample size, age and percent of women included in the sample. Categorical variables were dummy-coded into two levels. Then, all significant and non-trivial moderators from the univariate regressions (i.e., beta $>|.10|, p<.05$ ) were combined into a multivariate regression. Owing to the intercorrelation between moderators, a robust variance estimator was used (Hedges, Tipton, \& Johnson, 2010).

Two sets of analysis were not included in the main analysis due to complications arising from the dataset. First, we intended to examine whether individual disorders (e.g., social phobia vs generalized anxiety disorder) may have explained differences between depression and anxiety. However, the small sample sizes of each disorder (range $k=0-14$ ) other than major depressive disorder $(k=63)$ did not supply adequate statistical power to perform subgroup analysis (Borenstein et al., 2009). Second, we intended to analyze whether there would be significant differences based on reinforcement sensitivity measure. However, many studies (e.g., Gomez \& Gomez, 2005; Harnett, Loxton, \& Jackson, 2013) used more than one measure to assess reinforcement sensitivity. Owing to the dependency between measures' participant samples, subgroup analysis was inappropriate (Borenstein et al., 2009; H. Cooper et al., 2009). Thus, we report effect sizes grouped based on measure and disorder in the supplemental materials (S5), but do not test for differences.

Finally, small study effects (i.e., publication bias; Bakker, van Dijk, \& Wicherts, 2012) were considered. Most effect sizes were extracted from large tables with numerous findings, and were often tangential to the studies from which they came. Their statistical significance tended to be less required for publication, and we therefore expected bias to be minimal (e.g., Aldao et al., 2010). Nevertheless, bias was examined in two ways. First, the Egger's test was performed (Egger, Smith, Schneider, \& Minder, 1997; Sterne et al., 2000). The Egger's test is a regression of the effect size on the standard error, with weights provided by inverse variance, and provides a statistical test parallel to a "funnel plot" (i.e., a figure used to visualize bias based on sample size). To quantify the possible impact of effect size asymmetry, we then performed Duval and Tweedie's (2000) "trim-and-fill" procedure. First, studies that were missing because of publication bias were estimated and imputed into the database. Then a new metaanalysis was performed with an estimate of a possible alternative effect size. Both the Egger's test and the "trim-and-fill" procedure were performed on the main effects of BAS and BIS.

\section{Description of studies}

\section{Results}

Four hundred and eighty-three effect sizes were calculated, based on 260 distinct samples drawn from 204 articles that were published between 1991 and 2017 (see Table 1$)$. The majority of samples $(k=223)$ provided effect size data for both BAS as well as BIS. Five samples only provided effect size data for BAS while 32 samples provided for only BIS. The total sample size $(\mathrm{N})$ for this study was 79,657 , with samples ranging from 18 to 4,778 participants $(M=306.37, S D=$ 562.00). Participants comprised a wide mean age range $(M=30.45, S D=11.69$, range $=11.43-80.40)$. Two hundred and thirty-seven samples included in this study provided all the information necessary for calculating effect sizes while 23 samples required access to unpublished data.

\section{Strength of link between reinforcement sensitivity and pathology}

We predicted in Hypothesis 1 that BAS would have a negative relationship across disorders (Hypothesis 1a), and BIS would have a positive one (Hypothesis 1b). Analyses are summarized for BAS at the top of Table $2 \mathrm{a}$, and for BIS at the top of Table 2b. Indeed, a small, negative relationship was observed between BAS and psychopathology across disorders, $g=-.16,95 \%$ CI [$.21 ;-.11]$. A homogeneity of variance test found a large portion of real variance in the literature, $Q(227)=$ $1908.70, p<.0001 ; \operatorname{tau}^{2}=0.11 ; \mathrm{I}^{2}=88.1 \%$ [86.8\%; $89.3 \%$ ]. This large heterogeneity was also reflected in a wide prediction interval of observed effect sizes, $95 \%$ PI [-.82; .51]. BIS, on the other hand, had a large, positive relationship with pathology, $g=1.10,95 \% \mathrm{CI}$ $[1.02 ; 1.19]$. There was much heterogeneity in this sample as well, $Q(254)=6489.16, p<.0001 ; \operatorname{tau}^{2}=0.43$;

NOTE: This is a postprint of the study Katz, B. A., Matanky, K., Aviram, G., \& Yovel, I. (2020). Reinforcement sensitivity, depression and anxiety: A meta-analysis and meta-analytic structural equation model. Clinical Psychology Review, 101842, doi: 
$\mathrm{I}^{2}=96.1 \%$ [95.8\%; 96.3\%]. This large heterogeneity was reflected in a wide prediction interval for BIS as well, though the majority of effect sizes were in the same direction, 95\% PI [-.18; 2.40]. These findings were consistent with Hypothesis 1, indicating a small, negative effect for BAS across disorders, and a large, positive, effect for BIS.

Next, in order to test Hypothesis 2, we examined disorder cluster as a possible moderator for the above, relationships (see Tables $2 \mathrm{a}$ and $2 \mathrm{~b}$ ). BAS was found to have a small relationship with depressive disorders, $g=$ $-.21 ; 95 \%$ CI [-.28; -.15], and a trivial relationship with anxiety disorders, $g=-.11 ; 95 \%$ CI $[-.19 ;-.02]$. This was consistent with Hypothesis 2a. The difference between the two types of disorders was found to be significant, $Q(1)=3.83, p=.05$, which was consistent with Hypothesis 2b. BIS had a large, positive relationship with depression, $g=.99 ; 95 \%$ CI $[.87 ; 1.12]$, as well as anxiety $g=1.21 ; 95 \%$ CI $[1.10 ; 1.32]$, which was consistent with Hypotheses $2 \mathrm{c}$ and $2 \mathrm{~d}$. However, contrary to expectations, the effect sizes of the two groups significantly differed from each other, $Q(1)=$ $6.57, p=.01$. Taken together, BIS was found to have a large, positive effect size across disorders, which was significantly larger for anxiety. BAS, on the other hand, was found to have a small, negative effect size for depression, and a trivial one for anxiety. This was generally consistent with the patterns predicted in Hypothesis 2 .

\section{Moderator analysis}

The large portions of variance due to heterogeneity of effect sizes called for a further analysis of moderators. First, a series of subgroup analyses were performed to measure the impact of categorical moderators, in addition to disorder (Tables $2 \mathrm{a}$ and $2 \mathrm{~b}$ ). Consistent with our predictions in Hypothesis 3, greater effect sizes were observed when clinical assessment was derived from diagnostic means than from self-report measures with regards to BAS ( $g=-.28$ vs -.06 ) as well as BIS ( $g=1.29$ vs .96). These differences were significant ( $p$ s $<.0001)$. No other moderators were found to be significant for both the BAS and BIS ( $p s>.09$ ).

Next, to examine the role of continuous variables as moderators, a series of univariate regressions were performed (See Tables 3a and 3b). For BAS, the average age of participants was a significant moderator, but to a negligibly small degree $\left(b=-.01, \mathrm{R}^{2}<0.02\right)$. The percent of women in the sample was found to significantly impact BIS, $b=-.38, p=.02,95 \%$ CI [-.69; -.07], but not BAS $b=.16, p=.13,95 \%$ CI [-.05; .36]. Interpretation of the univariate analyses, however, was limited by the intercorrelation of moderator variables (see Table 4). Thus, a series of multivariate analyses were performed only for the significant moderators of BAS and BIS, including disorder. Clinical assessment method was found to be the only significant moderator in the multivariate analysis of BAS, with clinical diagnosis predicting a more negative effect size than self-report, $b=-.24, p=.001,95 \%$ CI [-.38; -.09]. BIS was significantly moderated by both clinical assessment method, $b=.40, p<.0001,95 \%$ CI $[.20 ; .60]$, disorder, $b=-.31$, $p=.005,95 \%$ CI [-.50; -.12], and percent women, $b=$ $-.32, p=.04,95 \%$ CI $[-.62 ;-.01]$. Thus, when controlling for disorder cluster and gender, clinical assessment method increased effect sizes for both BAS and BIS. When controlling for clinical assessment method and gender, larger effect sizes were found for anxiety (compared to depression) with regards to BIS, but not BAS.

\section{Interaction between disorder cluster and assess- ment method of sample}

In order to better understand the interaction between clinical assessment method and disorder, a series of subgroup analyses were performed to compare patterns of moderation in depression and anxiety samples. First, analyses were performed separately for studies that collected depression and anxiety data, with clinical assessment method as the grouping variable (see Figures $2 a-b$ and $3 a-b)$. Anxiety and depression followed two distinct patterns. For depression a small, significant relationship was found between BAS and depression when clinical diagnosis was used $(g=-.34,95 \%$ CI[$.43 ;-.24])$. No such relationship was found for self-report clinical assessment ( $g=-.07 ; 95 \%$ CI $[-.15 ; .02])$. This led to a significant difference between the subgroups, $Q(1)=17.88, p<.0001$. There was also a difference between the large positive effects found between depression and BIS among diagnosed $(g=1.23$, 95\% CI $[1.09 ; 1.36])$ and self-reporting ( $g=.72,95 \%$ CI $[.52 ; .92])$ samples that was statistically significant, $Q(1)=17.10, p<.0001$. Anxiety showed different patterns depending upon reinforcement system. Anxiety and BAS did not show a significant relationship among self-report correlations ( $g=-.05,95 \%$ CI $[-.13 ; .03])$ or comparisons between diagnosed and healthy participants $(g=-.22,95 \%$ CI $[-.46 ; .02])$, with no significant difference between these groups, $Q(1)=1.83, p=.18$. On the other hand, a large positive effect size was found between anxiety and BIS both among diagnosedhealthy comparisons $(g=1.44,95 \% \mathrm{CI}[1.18 ; 1.70]$ as

NOTE: This is a postprint of the study Katz, B. A., Matanky, K., Aviram, G., \& Yovel, I. (2020). Reinforcement sensitivity, depression and anxiety: A meta-analysis and meta-analytic structural equation model. Clinical Psychology Review, 101842, doi: 
well as self-report correlations $(g=1.12,95 \% \mathrm{CI}[1.00$; $1.24]$ ), with a significant difference between, $Q(1)=$ $4.83, p=.03$. However, the difference in BAS effect sizes between the two groups was quite smaller for anxiety $(Q(1)=4.83)$ than it was for depression $(Q(1)=$ 17.10).

Thus, an interaction was revealed between diagnostic method and disorder cluster. The relationship between BAS and depression was only significant for diagnosed-healthy comparisons, and not for self-report correlations. These groups significantly differed from each other. The relationship between BIS and depression also revealed a significant difference between groups, though both still maintained large effect sizes. For anxiety, neither group's BAS effect sizes were significantly different from zero, nor were the groups different from each other. Anxiety's groups did significantly differed from each other for BIS effect sizes, though to a much smaller degree than depression.

These between-group differences, however, may have been confounded by the fact that the majority of effect sizes drawn self-report assessment were based off of correlational data, whereas all the effect sizes drawn from clinical diagnosis were based off of standard mean differences. Thus, it remains unclear from these findings whether differences in effect sizes resulted from a meaningful differences between the groups, or from a statistical artifact (see Aldao, et al., 2010). Indeed, it is possible that the differences observed between self-report effects and clinical diagnosis effects were caused by greater levels of symptom severity observed in diagnosed samples. In order to better understand the role symptom severity in predicting reinforcement sensitivity, it would be necessary to compare participants recruited through similar diagnostic methods, but who differ in current symptom severity.

To circumvent the above statistical issue, a series of subgroup analyses were performed only on data derived from diagnosed-healthy comparison studies $(k$ $=112$ for BAS and 116 for BIS), comparing the effect sizes based on the clinical status of the participants (Tables 5a and 5b). Importantly, all effect sizes in this analysis were based on group differences between diagnosed and healthy participants. They only differed based on the severity of participants' current clinical state at the time of data collection. Depression's effect sizes did show significant differences both with regards to BAS, $Q(2)=13.02, p=.002$, as well as BIS, $Q(2)=$ $16.33, p=.0003$. An examination of overlapping confidence intervals revealed that depression's BAS effect sizes tended to cluster around two groups, with the weighted average effect size for Euthymic/Remission participants ( $g=-.14,95 \%$ CI $[-.26 ;-.01])$ distinct from those of the Episode/Acute group ( $g=-.51,95 \%$ CI [$.67 ;-.34])$. The Outpatient group overlapped with the other groups ( $g=-.35,95 \%$ CI [-.53; -.17]). A similar pattern emerged with regards to depression and BIS. There, the Episode/Acute group $(g=1.48,95 \% \mathrm{CI}$ $[1.29 ; 1.67])$ was distinct from the Euthymic/Remission group $(g=.87,95 \%$ CI $[.65 ; 1.10])$. Again, the Outpatient group $(g=1.32,95 \%$ CI $[.96 ; 1.68])$ overlapped with the two others. The effects of anxiety disorders were not moderated by clinical status with regards to BAS, $Q(2)=2.68, p=.26$, or BIS, $Q(2)=1.53$, $p=.47$.

Thus, two patterns emerged based on disorder. Depression's effect sizes were significantly larger when participants were selected for the sample based on clinical diagnosis. Furthermore, within diagnosedhealthy comparisons, effects were larger when clinical groups were in a current depressive episode than among those in remission. Anxiety, on the other hand, did not have these differences. No relationship was found between anxiety and BAS, regardless of diagnostic method or clinical state. Similarly, BIS and anxiety had a consistently large effect size. Differences were observed when comparing effect sizes derived from diagnosed-healthy comparisons versus self-report correlations. However, these differences were not maintained when comparing between clinical statuses within diagnosed-healthy comparisons.

\section{Publication bias analysis}

First, Egger's tests were conducted, to examine the possibility of a systematic bias. No such bias was found with regards to BAS, $t(226)=-1.06, p=.29$. BIS, on the other hand, was found to contain significant bias, $t(253)=3.11, p=.002$. Despite Egger's test only being significant with regards to BIS, a trim-and-fill procedure was applied to adjust for possible publication bias in both BAS and BIS (see Figures $4 \mathrm{a}$ and $4 \mathrm{~b}$ ). While the procedure reduced the average effect sizes, they nevertheless remained significant. Twenty-two studies were imputed into the BAS meta-analysis, reducing the average effect size from a small effect size, $g=-.16$, to a significant, albeit very small effect, $g=-.06,95 \% \mathrm{CI}$ $[-.12 ;-.01], p=.03$. Ninety-two studies were imputed into the BIS meta-analysis, reducing the effect size from a large effect, $g=1.11$, to a medium one, $g=.67$, $95 \%$ CI $[.58 ; .76]$. Thus, a robust significant effect remained with regards to BAS and BIS, though there is a

NOTE: This is a postprint of the study Katz, B. A., Matanky, K., Aviram, G., \& Yovel, I. (2020). Reinforcement sensitivity, depression and anxiety: A meta-analysis and meta-analytic structural equation model. Clinical Psychology Review, 101842, doi: 
possibility of some underreported findings, particularly with regard to BIS.

\section{Discussion}

The findings of the analyses performed in Study 1 tell a story that becomes richer at higher resolutions. First, BAS was found to have a small, negative relationship with pathology across depression and anxiety, whereas BIS has a large, positive one. Then, an interaction with disorder type was observed. On one hand, BAS was found to have a small, negative relationship with depression, whereas its relationship with anxiety was found to be trivial, albeit significant. On the other hand, BIS showed large, positive effects across disorder clusters, that were larger for anxiety than for depression. Finally, a series of moderator analyses found clinical status to interact with disorder type in predicting effect sizes. For depression, effect sizes grew larger as participants' clinical state became more severe. For anxiety, no such moderating effect was observed.

Taken together, these findings suggest a set of interrelated trends. In terms of reinforcement sensitivity, BAS was a small, negative predictor of pathology that was more closely related to depression. BIS, on the other hand, was found to be a large, shared predictor of depression and anxiety that was more strongly related with anxiety. Thus, BAS was confirmed to be a discriminating factor as theorized (Alloy et al., 2016; Stange et al., 2013). Similarly, BIS effects were consistent with both the current RST framework of affective pathology that frames BIS as a shared, neuroticism-like factor (Bijttebier et al., 2009; Caspi et al., 2014; Corr \& Cooper, 2016; Jackson, 2009; Knyazev, Slobodskaya, \& Wilson, 2004; Slobodskaya, 2007; Smillie, Jackson, \& Dalgleish, 2006; Smits \& Boeck, 2006) and the older framework that more closely related it to anxiety (Bijttebier et al., 2009). Furthermore, depression was consistent with the joint system hypothesis wherein severest pathology entailed a combination of low BAS functioning and high BIS functioning (Corr, 2001; Eddington, et al., 2012).

Finally, differences were found between depression and anxiety regarding their interactions with clinical state. Depression showed significantly larger relationships with both BAS and BIS when participants in the clinical group were undergoing an episode than when participants were euthymic. Anxiety, on the other hand, was found to have similar effect sizes across clinical states. Thus, when compared to healthy controls, participants with current depression showed larger differences in reinforcement sensitivity than did their peers in remission. Participants with anxiety, on the other hand, showed levels of reinforcement sensitivity that had similar sizes of difference from healthy controls, regardless of symptom severity.

Study 1 was limited by only quantifying bivariate relationships between reinforcement sensitivity, depression and anxiety. Importantly, despite the high comorbidity rates between them (Watson, 2009), depression and anxiety were estimated separately. Thus, their shared variance was only indirectly estimated via robust variance estimation. A more exact estimate of the reinforcement sensitivity's relationship with depression and anxiety would directly control for covariance between the disorder clusters as well.

\section{Study 2}

In order to account for high levels of covariance between depression and anxiety, Study 2 aimed to simultaneously estimate each relationship between appetitive sensitivity (i.e., BAS), aversive sensitivity (i.e., BIS), depression and anxiety. This was done using a meta-analytic structural equation modeling approach (MASEM; Hunter \& Schmidt, 2004).

\section{Method}

\section{Data analysis plan}

The MASEM was performed in three steps (M. W.L. Cheung \& Chan, 2005; Hagger, Chan, Protogerou, \& Chatzisarantis, 2016; Riketta, 2008; Viswesvaran \& Ones, 1995). First, we assembled a matrix consisting of the weighted average of every bivariate correlation. Because all articles included in this study reported correlational data, no effect transformation was necessary. As in Study 1, each weighted average was calculated using a random effects meta-analysis, weighted as a function of sample size (Borenstein et al., 2009). Second, we performed a path analysis using the assembled average correlation matrix as input using a maximum likelihood estimator. The sum of all studies' sample sizes was used as the sample size in the model. This practice is preferred over alternatives (e.g., average sample size) in order to increase the sensitivity of significance tests (M. W.-L. Cheung \& Chan, 2005). Because all objects in the matrix were derived from standardized correlations, variances in the path model were constrained to one. In so doing, all possible loadings were able to be included in the initial model, while having it remain eligible for goodness of fit statistics (see Nohe, Meier, Sonntag, \& Michel, 2014). Finally, we considered alternate models in order to distill the most

NOTE: This is a postprint of the study Katz, B. A., Matanky, K., Aviram, G., \& Yovel, I. (2020). Reinforcement sensitivity, depression and anxiety: A meta-analysis and meta-analytic structural equation model. Clinical Psychology Review, 101842, doi: 
parsimonious one. This was done by systematically removing relationships between elements and comparing the new model's fit statistics to those of the original. In the event of model equivalence, the new model with more degrees of freedom was retained as the more parsimonious of the two. In the event of model non-equivalence, the one with the better fit was retained.

The $\chi^{2}$ test was calculated as an initial measure of goodness of fit, and was used as the measure of relative fit when comparing alternate models. However, due to the $\chi^{2}$ statistic's overestimation of lack of model fit, particularly among studies with a large sample size (Bollen, 1989; Browne \& Cudeck, 1993), we reviewed additional indices of fit as well. Recommended cutoff scores (Hu \& Bentler, 1999; Kline, 2015) were: comparative fit index (CFI) above .95, root mean square error of approximation index (RMSEA) below .06 and standardized root means residual (SRMR) below .08. Analyses were performed using $\mathrm{R}$ version 3.4.0 ( $\mathrm{R}$ Core Team, 2017). The meta-analysis was performed using 'meta' version 4.9-1 (Schwarzer, 2007) and path analysis using 'lavaan' version 0.5-23.1097 (Rosseel, 2012).

\section{Results \\ Description of studies}

One hundred and fifty-six effect sizes were calculated, based on 39 distinct samples $(k)$ drawn from 39 articles that were published between 1997 and 2018 (see Table 6). The total sample size $(\mathrm{N})$ for this study was 13,572 , with samples ranging from 20 to 2,725 participants $(M=348, S D=455.38)$. The mean age centered around young adults $(M=25.90, S D=9.10$, range $=16.0-47.6)$. Twenty-eight samples offered data already available in the published article, whereas 11 samples entailed unpublished data.

Importantly, constraints placed on study selection required correlations to be reported between depression and anxiety symptom severity, as well as punishment and reward sensitivity. No clinical-healthy comparison studies offered every correlation between these four elements. Thus, this analysis includes only studies with healthy participants.

\section{Path analysis}

First, we performed a series of meta-analyses on the correlations between each element in the path analysis (Table 7). The sizes and directions of the correlations between reinforcement sensitivity, depression and anxiety were consistent with those found among healthy participants in Study 1. The large correlation between depression and anxiety $(r=.65, p<.001)$ was consistent with other findings (Jacobson \& Newman, 2017), and the trivial, nonsignificant correlation between BAS and BIS $(r=.01, p=.90)$ was consistent with their theorized orthogonal relationship (Corr, 2008).

We then performed a path analysis using the above correlations as an input matrix. The initial model estimated covariance between BAS and BIS, and each loaded on both depression and anxiety. Covariance for depression and anxiety was estimated as well (see Figure 5a). Results showed that reward and punishment sensitivity did not covary $(\boldsymbol{\beta}=.01, p=.54,95 \%$ CI [$.01 ; .02])$, whereas depression and anxiety shared a large covariance $(\boldsymbol{\beta}=.64, p<.001,95 \%$ CI $[.63 ; .65])$. Reward sensitivity only loaded significantly on depression $(\boldsymbol{\beta}=-.07, p<.001,95 \%$ CI [-.08; -.05]) but not on anxiety $(\boldsymbol{\beta}=.01, p=.21,95 \%$ CI $[-.01 ; .03])$. Punishment sensitivity, on the other hand, loaded similarly on both anxiety $(\boldsymbol{\beta}=.35, p<.001,95 \% \mathrm{CI}[.33 ; .37])$ and depression $(\boldsymbol{\beta}=.37, p<.001,95 \%$ CI $[.35 ; .38])$.

Next, we considered alternative models (see Table 8). First, we removed the covariance between BAS and BIS from the model (path $a$ in Figure 5a), as per their theorized orthogonality (Corr, 2008; J. A. Gray \& McNaughton, 2000) . A comparison of goodness of fit found the two models to be equivalent, $\Delta \chi^{2}(1)=.37, p=.54$. Thus, the second model was retained as the more parsimonious of the two. Next, we considered removing paths between BAS and the psychopathology elements, due to their small effect sizes. In a third model, BAS did not load on depression (path $b$ in Figure 5a). That model proved to be a significantly worse fit than the second, $\Delta \chi^{2}(1)=60.27, p<.001$, and was therefore rejected. Thus, the loading of BAS on depression was maintained. Finally, we considered a fourth model with the loading of BAS on anxiety removed (path $c$ in Figure 5a). When compared to the second model, the fourth model was an equally good fit and thus maintained as the most parsimonious, $\Delta \chi^{2}(1)$ $=1.55, p=.21$. All other paths led to significantly worse-fitting models when removed ( $p$ s $<.001$ ).

In the final model (see Fig. 5b), BAS loaded on depression with a very small effect size $(\boldsymbol{\beta}=-.07, p<.001$, $95 \%$ CI $[-.09 ;-.06])$. BIS loaded with a small effect on both anxiety $(\boldsymbol{\beta}=.35, p<.001,95 \% \mathrm{CI}[.33 ; .36])$ and depression $(\boldsymbol{\beta}=.37, p<.001,95 \%$ CI $[.35 ; .38])$. Depression and anxiety shared a moderate portion of their variance $(\boldsymbol{\beta}=.64, p<.001,95 \%$ CI $[.63 ; .65])$. Altogether, this model was consistent with the predictions 
laid out in Hypothesis 2 that predicted a negative relationship between BAS and depression (Hypothesis 2a) which would be larger than that of BAS and anxiety (Hypothesis 2b). Furthermore, we expected a positive relationship between BIS and depression (Hypothesis 2c) as well as BIS and anxiety (Hypothesis $2 \mathrm{~d}$ ).

Results of the $\chi^{2}$ test indicated a bad fit for the final model, $\chi^{2}(6)=182.84, \mathrm{p}<.0001$. Other indices, however, indicated a good fit: $\mathrm{CFI}=.982, \mathrm{RMSEA}=.047$, $95 \%$ CI $[.041, .053]$, SRMR $=.070$. In light of the large sample of participants in this analysis, we concluded that the fit indices indicate a good fit to the final model.

\section{Discussion}

Study 2 aimed to simultaneously estimate the effects of BAS and BIS on both depression and anxiety while controlling for covariance between depression and anxiety. Doing so affirmed the general relationships between reinforcement sensitivity, depression and anxiety that were observed in Study 1. As in Study 1 , punishment sensitivity was a shared predictor of both depression and anxiety (Bijttebier et al., 2009; Smillie et al., 2006). Similarly, reward sensitivity impacted only depression and not anxiety (Alloy \& Abramson, 2010; Bijttebier et al., 2009; Trew, 2011), with the joint effects of hyposensitive BAS and hypersensitive BIS predicting depression together (Corr, 2001; Eddington et al., 2012). As opposed to Study 1, BIS did not have a stronger relationship with anxiety than it did with depression. Rather, the relationships of the BIS with anxiety and depression were virtually the same. Similarly, the theorized independence of the BAS and BIS (J. A. Gray \& McNaughton, 2000) and the high covariance between depression and anxiety (Jacobson \& Newman, 2017) were confirmed in the final model.

Importantly, Studies 1 and 2 differ in that Study 1 includes clinical-healthy comparisons, whereas Study 2 includes only non-clinical participants. Thus, the role of clinical state in this model remains unclear. Furthermore, as seen in Study 1, effects derived from correlations taken among non-clinical samples are smaller than standardized mean differences taken from clinical samples (see Figures 2a-b, and 3a-b). This may explain why the effect sizes in Study 2 were smaller overall. On one hand, these smaller effect sizes may impact the robustness of the final structural equation model among smaller samples. On the other hand, it is notable that the relationships between reinforcement sensitivity depression and anxiety were confirmed despite smaller effect sizes.

\section{General Discussion}

The relationships between reinforcement sensitivity (Corr \& McNaughton, 2008; J. A. Gray, 1970, 1987; J. A. Gray \& McNaughton, 2000) depression and anxiety have been widely studied and brought together through influential theoretical narratives (e.g., Alloy et al., 2016; Kimbrel, 2008; McNaughton \& Corr, 2008; Trew, 2011; Zinbarg \& Yoon, 2008). However, until now, there has been no attempt to summarize the literature quantitatively or to systematically consider factors that may moderate these relationships across studies. To address this need, two complementary sets of meta-analyses were performed to summarize the crosssectional relationships between reinforcement sensitivity, depression and anxiety, and to trace the extent to which these relationships differ between depression and anxiety, or between different levels of clinical severity. In the first study, a broad range of bivariate relationships between reward sensitivity, punishment sensitivity, depression, and anxiety were summarized and examined for moderators. In the second study, stricter inclusion criteria were set to allow for a metaanalytic structural equation model (MASEM) that directly controlled for the comorbidity between depression and anxiety.

Across studies and meta-analytic methodologies, certain findings consistently emerged. Sensitivity to aversive stimuli, or BIS sensitivity, was found to play a common role in the form of large, positive relationships with both depression and anxiety. Sensitivity to appetitive stimuli, or BAS sensitivity, discriminated between depression and anxiety. A small, negative relationship was observed between BAS and depression, and a significantly smaller, trivial-to-nonsignificant relationship was observed with anxiety. Clinical characteristics of the sample interacted with disorder cluster to moderate effect sizes as well. Clinical diagnosis and greater clinical severity (i.e., Acute/Episode vs Euthymic/Remission) predicted larger effect sizes, but only for depression. However, they did not moderate effect sizes for anxiety.

When brought together, these findings are generally consistent with clinical models of RST, particularly with the joint subsystems hypothesis (Carver, Johnson, \& Joormann, 2008; Corr, 2002; Eddington et al., 2012; Kimbrel, Mitchell, Hundt, Robertson, \& Nelson-Gray, 2012). According to this theoretical approach, under certain conditions, the two subsystems may antagonize or facilitate each other. Thus, clinically relevant phe-

NOTE: This is a postprint of the study Katz, B. A., Matanky, K., Aviram, G., \& Yovel, I. (2020). Reinforcement sensitivity, depression and anxiety: A meta-analysis and meta-analytic structural equation model. Clinical Psychology Review, 101842, doi: 
nomena are best understood in the context of both reinforcement sensitivities' effects on affect and behavior. In depression, for example, BAS hyposensitivity and BIS hypersensitivity may coalesce to inhibit goal pursuit (Trew, 2011). In the current meta-analysis, the results are consistent with models wherein a hypersensitive BIS predicts pathology in general, but a hyposensitive BAS makes the general pathology depressogenic (Knyazev \& Wilson, 2004; Watson, 2009; Watson, Clark, et al., 1995). Indeed, hyposensitive BAS may only be pathological insofar as it is in the presence of a hypersensitive BIS (Hundt et al., 2007). Anxiety, on the other hand, would be most likely in a case of hypersensitive BIS, with a trivial relationship with BAS sensitivity, if at all (Bijttebier et al., 2009; Hollon, 2019; cf. Corr, 2002). However, it is worth noting that most studies of the joint subsystem hypothesis were performed within normative levels of reinforcement sensitivity (Bijttebier et al., 2009). For example, in externalizing symptoms such as substance use and ADHD, the joint subsystem hypothesis only has partial support (Coplan, Wilson, Frohlick, \& Zelenski, 2006; Hundt, Kimbrel, Mitchell, \& Nelson-Gray, 2008; Knyazev \& Wilson, 2004). Further research is required to directly assess whether of one form of reinforcement sensitivity will impact the extent to which the other one predicts psychopathology (e.g., Harnett et al., 2013).

The distinctive roles of a common factor BIS and discriminatory BAS parallel other nosological models of pathology, most closely the tripartite model of depression and anxiety (Anderson \& Hope, 2008; Watson, Clark, et al., 1995; Watson, Weber, et al., 1995). The tripartite model first posits a general distress dimension shared among these disorders. Then, it suggests that there are disorder-specific factors as well, with anhedonia uniquely predicting depression and somatic arousal uniquely predicting anxiety. It has been suggested elsewhere that punishment sensitivity may parallel the shared general distress dimension and that reward hyposensitivity may parallel anhedonia (Shankman \& Klein, 2003; Zinbarg \& Yoon, 2008). The current findings are consistent with such a claim and highlight the role of the BIS as a possible common factor behind the substantial comorbidity between depression and anxiety (e.g., Kessler et al., 2005). Furthermore, the current findings are consistent with other hierarchical models such as the Hierarchical Taxonomy of Psychopathology (HiTOP; Conway et al., 2019; Kotov et al., 2017; Widiger et al., 2018). In the HiTOP, disorders of distress (e.g., major depressive disorder, general anxi- ety disorder) and disorders of fear (e.g., specific phobia, obsessive compulsive disorder) are predicted by factors common to all internalizing disorders, as well as disorder-specific factors. The high rates of BIS across disorder clusters make it a candidate for being a higher-ordered, common factor, and the discriminatory role of low BAS may identify it as a depression-specific factor.

In summary, the current findings represent a call for greater theoretical work on the interplay between reward sensitivity and punishment sensitivity. Clinical theories that focus on positively valenced constructs such as positive emotionality, reward sensitivity, reward motivation, and extraversion may be complemented with closer study of their negatively valenced counterparts (e.g., Carl, Soskin, Kerns, \& Barlow, 2013; Khazanov \& Ruscio, 2016; Millgram, Joormann, Huppert, Lampert, \& Tamir, 2019; Naragon-Gainey \& Watson, 2014; Naragon-Gainey, Watson, \& Markon, 2009; Watson, Stasik, Ellickson-Larew, \& Stanton, 2015). The BAS dysregulation model, for example, has accurately identified the central role that the BAS plays in longitudinally predicting fluctuations in mania and depression (Alloy, Bender, Wagner, Abramson, \& Urosevic, 2009; Urosević et al., 2008). However, it has been found that some aspects of bipolar disorder's course, such as progression to bipolar I disorder, are only predicted by the BAS in the presence of a high BIS (Alloy et al., 2012). Based on the present findings, similar interactions are likely to be present for depression as well, and accounting for them has been found to improve the fit of predictive models based on reinforcement sensitivity (Gershuny \& Sher, 1998). Indeed, cross-sectional and temporal models of depression, general anxiety disorder and social phobia account for the majority of variance when they include reinforcement sensitivity, positive affect and negative affect ( $T$. A. Brown, 2007; T. A. Brown et al., 1998). However, that is not always the case (Jorm et al., 2000).

The current findings also indicate ways through which reinforcement sensitivity and symptom severity may interrelate. Ample evidence supports the emergence of dysregulated levels of reinforcement sensitivity prior to the development of psychopathology (Alloy et al., 2008; Carver \& White, 1994; B. Meyer, Johnson, \& Carver, 1999; T. D. Meyer \& Hofmann, 2005; Urosević et al., 2008). However, different models predict different levels of reciprocity to this relationship. Some models interpret reinforcement sensitivity as a stable trait temperament that serves as a diathesis to the future de- 
velopment and maintenance of affective psychopathology (Klein et al., 2011; Kotov et al., 2010; NaragonGainey, Gallagher, \& Brown, 2013). Others posit more dynamic, reciprocal models wherein temperaments such as reinforcement sensitivity function as a combination of diathetic personality traits alongside pathology-induced "personality states" incurred during acute episodes (T. A. Brown, 2007; Clark, Vittengl, Kraft, \& Jarrett, 2003; Cole, Martin, \& Steiger, 2005; Kendall et al., 2015).

In Study 1, effect sizes were compared between diagnosed-healthy comparison studies, based on current clinical severity. For depression, participants in a current depressive episode (i.e., Acute/Episode) showed larger differences from healthy controls than did participants with lifetime depression who were currently euthymic (i.e., Euthymic/Remission). For anxiety, no such differences were observed based on whether participants currently suffered from a clinical anxiety disorder (i.e., Acute/Episode) or from a previous one that is now at subclinical levels (i.e., Euthymic/Remission). This interaction between disorder cluster and clinical state may indicate that reinforcement sensitivity has varied relationships with symptom severity, depending on the disorder. For depression, it seems that reinforcement sensitivity is best construed according to the dynamic models (T. A. Brown, 2007; Clark et al., 2003). This may reflect the episodic nature of depression, which is designated by discrete periods of clinical severity (American Psychiatric Association, 2013). The relationship between reinforcement sensitivity and anxiety, on the other hand, was not moderated by clinical state. As opposed to depression, anxiety was most consistent with models that emphasize the stability of trait reinforcement sensitivity across clinical states (Klein et al., 2011). The observed pattern of relationships between RST and anxiety was also consistent with current conceptualizations of anxiety that approach it as a continuum ranging from calmness to high arousal, as opposed to a set of discrete states (Clark, Cuthbert, Lewis-Fernández, Narrow, \& Reed, 2017; Siddaway, Taylor, \& Wood, 2018; Vautier \& Pohl, 2009). As opposed to depression, where different clinical states led to categorically different effect sizes, levels of reinforcement sensitivity for anxiety were revealed to have a much larger overlap across clinical states. Thus, the present findings strongly indicate that the models used to understand the nature of reinforcement sensitivity's relationship with psychopathology may best be developed in a disorderspecific fashion.
Finally, the current findings also support contemporary therapeutic trends in developing interventions for both negatively and positively valenced basic processes that underlie affective disorders. The Unified Protocol for Treatment (Barlow et al., 2010; Carl, Gallagher, SauerZavala, Bentley, \& Barlow, 2014; Griffith et al., 2010), for example, was originally developed to reduce the deleterious effects of neuroticism across disorders (Barlow, Sauer-Zavala, Carl, Bullis, \& Ellard, 2014; Griffith et al., 2010). Recent augmentations to the Unified Protocol have aimed to impact positive emotionality as well (Carl, Gallagher, \& Barlow, 2018). Indeed, recent calls have been made for a new wave of cognitive behavioral interventions that target transdiagnostic basic processes in addition to those specific to particular disorders (Hofmann \& Hayes, 2019). The current meta-analyses emphasize the need for transdiagnostic interventions for punishment sensitivity, such as distress tolerance and acceptance-based exercises (Katz, Breznitz, \& Yovel, 2019; M. J. Zvolensky, Vujanovic, Bernstein, \& Leyro, 2010), alongside disorder-specific modules that promote rewarding experiences, such as behavioral activation (Cuijpers, van Straten, \& Warmerdam, 2007; Hofmann \& Hayes, 2019).

Despite the overall similarity in the conclusions derived from both studies, certain inconsistencies are worth noting. First, the effects in Study 2 were smaller in size than those observed in Study 1. This was perhaps a result of the fact that Study 2 only drew effects from healthy populations. Indeed, the ranges of effect sizes observed in Study 2 were similar to those observed among healthy participants in Study 1. It is also worth noting that the role of BIS differed somewhat between the two studies. In Study 1, BIS was found to have a larger relationship with anxiety than with depression. This difference was not observed in Study 2. It is unlikely that this is due to a difference in statistical power, as the weighted average correlations between BIS-anxiety and BIS-depression in this study were nearly equal $(r=.35$ vs .34 , respectively; see Figure 7$)$. It is also unlikely that this incongruity is a result of differences in the studies' populations. As seen in Study 1, depression and anxiety actually had weighted means that were further apart among healthy groups ( $g=.72$ vs 1.12 , respectively) than among clinical groups ( $g=1.23$ vs 1.39 , respectively). Thus, the large positive role of BIS across anxiety and depression may be considered robust across meta-analytic studies, but it remains a question for future study whether it has a larger relationship with anxiety, and if so, under what conditions.

NOTE: This is a postprint of the study Katz, B. A., Matanky, K., Aviram, G., \& Yovel, I. (2020). Reinforcement sensitivity, depression and anxiety: A meta-analysis and meta-analytic structural equation model. Clinical Psychology Review, 101842, doi: 


\section{Limitations and future directions}

The present findings should be evaluated in light of certain qualifications. First, the effects included in the present studies were cross-sectional. This limits our ability to extract etiological conclusions, which are inherently longitudinal (T. A. Brown, 2007). Clinical state's role as a moderator, for example, provides an indirect, between-subject indication that reinforcement sensitivity functions at different levels depending on depression severity. Longitudinal studies (e.g., Alloy et al., 2012), however, may more directly estimate these questions by accounting for within-subject variance as well. Currently, such studies (e.g., Goekoop, De Winter, \& Goekoop, 2011) are too limited in number to provide the statistical power necessary for a meaningful meta-analysis. Future studies may utilize repeated measures of reinforcement sensitivity and symptom severity to better understand the role of reinforcement sensitivity as a predictor of etiology and course of depressive and anxiety disorders (Alloy et al., 2016).

Second, it is worth noting that reinforcement sensitivity was assessed in all studies included in the present meta-analyses using self-report measures, as was symptom severity among non-diagnosed populations. This raises both theoretical and methodological issues. On a theoretical level, RST was originally based in the link between biology and behavior (Corr, 2008; J. A. Gray, 1987), and self-report is thus an indirect proxy of the intended constructs. Methodologically, this also raises a concern for shared method effects (Eid, Lischetzke, Nussbeck, \& Trierweiler, 2003). Indeed, some RST measures themselves even contain items that reference clinically relevant phenomena. The BIS subscale of the BIS/BAS (Carver \& White, 1994), for example, references worry (e.g., I worry about making mistakes), a basic process closely linked with anxiety (Watkins, 2008). It is worth noting that group comparisons between clinical and non-clinical populations used different methods - psychiatric diagnosis and selfreported reinforcement sensitivity. Nevertheless, they showed larger effect sizes than correlations in non-diagnosed populations that perhaps benefited from this type of shared method variance. Furthermore, the use of self-report reinforcement sensitivity ensured that only measures with prior validation would be included in the systematic review. However, assessment of reinforcement sensitivity was only done through self-report methods. As such, some findings may have been partially impacted by other factors associated with clinical severity, such as limited insight, current mood and response style (Chmielewski \& Watson, 2009; Klein et al., 2011; Watson, 2004). Future meta-analyses may account for these concerns by including behavioral (e.g., Millgram et al., 2019; Treadway et al., 2012) and biological measures (e.g., DelDonno et al., 2015) in their assessments of reinforcement sensitivity. These measures are more theoretically aligned with the biological-behavioral foundation of RST (J. A. Gray, 1970, 1987) and are also less susceptible to spurious shared-method covariance and biased responses.

Third, the majority of reinforcement sensitivity measures included in the present meta-analyses (Ball \& Zuckerman, 1990; Carver \& White, 1994; Cloninger, 1991, 1994; MacAndrew \& Steele, 1991; Torrubia, Ávila, Moltó, \& Caseras, 2001) were developed under the original version of RST (J. A. Gray, 1970, 1987). In 2000, a major revision was undertaken that significantly realigned the theoretical structure of punishment processing (Bijttebier et al., 2009; Corr, 2008; J. A. Gray \& McNaughton, 2000). The novel Fight/Flight/Freeze system (FFFS) became responsible for the processing of aversive stimuli, while the revised BIS (r-BIS) became responsible for detection of threat and reduction of goal conflicts (Bijttebier et al., 2009; Corr, 2008). While self-report measures have been developed directly for the revised RST (Corr \& Cooper, 2016; Jackson, 2009), they were released too recently to have supplanted more traditional measures of RST such as the BIS/BAS (Carver \& White, 1994). Comparison studies have found that BAS measures from the original RST are closely related to measures of BAS in the revised RST, and measures of the original BIS correlate with measures of both the revised BIS and the revised FFFS - particularly the Flight and Freeze subscales of FFFS measures (Jackson, 2009; Krupić, Corr, Ručević, Križanić, \& Gračanin, 2016; Torrubia et al., 2008). Thus, the current meta-analyses are best understood as summaries of the relationship between reward sensitivity, punishment sensitivity, depression and anxiety. These basic processes are already the subjects of numerous lines of clinical research (Insel et al., 2010). However, future studies that utilize measures based on revised RST (e.g., J-5; Jackson, 2009) will be better able to explore which of the revised subsystems are more closely linked with which disorder.

Similarly, because the current meta-analyses consider the broad constructs of reward sensitivity and punishment sensitivity, they do not consider potential differences among each sensitivity's subtypes (Corr, 2013; Zald \& Treadway, 2017). Indeed, reward sensitivity and punishment sensitivity are multifaceted, evolving constructs with multiple subtypes (Insel et al.,

NOTE: This is a postprint of the study Katz, B. A., Matanky, K., Aviram, G., \& Yovel, I. (2020). Reinforcement sensitivity, depression and anxiety: A meta-analysis and meta-analytic structural equation model. Clinical Psychology Review, 101842, doi: 
2010; Krupić, Gračanin, \& Corr, 2016). These subtypes may have unique clinical ramifications both within reward sensitivity (e.g., reward responsiveness vs. fun seeking; Taubitz, Pedersen, \& Larson, 2015) and punishment sensitivity (e.g., loss aversion vs. punishment responsiveness; Sokol-Hessner \& Rutledge, 2019). Future reviews may examine the extent to which the varied subtypes of reward sensitivity and punishment sensitivity carry meaningful difference, whether assessed through the subscales of self-report measures, or through varied physiological and behavioral paradigms (e.g., physiological response to anticipatory vs consummatory pleasure; Corr, 2013; Insel et al., 2010; Nusslock \& Alloy, 2017).

Additionally, future studies may benefit from a closer resolution of clinical phenomena on the level of disorder or even symptom. Indeed, it is possible that the relatively larger variances observed in the anxiety cluster reflect a real heterogeneity between the different anxiety disorders. Low positive affect, for example, has been found to be uniquely associated with social phobia (Naragon-Gainey et al., 2009; Watson, Clark, \& Tellegen, 1988) and post-traumatic stress disorder (Nawijn et al., 2015), as compared to other anxiety disorders. This may reflect disorder-specific deficiencies of reward processing (Anderson \& Hope, 2008). The current meta-analysis, however, did not have an adequate number of studies that represented each disorder to assess such a possibility. Similarly, low-arousal anxiety disorders and high-arousal fear disorders are theorized to have different relationships with the subsystems of revised RST (Perkins, Kemp, \& Corr, 2007) and have been found to load on separate factors within internalizing disorders (Eaton et al., 2013). Additionally, different symptoms within the same disorder may carry different relationships with reinforcement sensitivity as well (Watson, 2009). For example, it is possible that BAS hyposensitivity relates specifically to symptoms unique to depression, such as anhedonia, whereas BIS hypersensitivity is more closely connected to symptoms that appear in multiple disorders, such as disturbed sleep (Borsboom \& Cramer, 2013; Hundt et al., 2007). Future studies may quantify such differences by examining whether reinforcement sensitivity's relationships vary among different disorders within a single cluster, or among different symptoms within a single disorder.

Finally, the effects included in the meta-analysis are also impacted by decisions made within their component studies. For example, participants' data were only included in the meta-analysis if the relevant effect sizes were made available. While 244 manuscripts were identified as potentially having data which could have been included, data for only 20 were furnished upon request. While the impact of publication bias was estimated to be small, the current meta-analyses should be evaluated in light of the significant number of effect sizes which were not included. Similarly, participants were only included in the meta-analysis if they were approved by their component study's inclusion and exclusion criteria. Thus, exclusion criteria common to clinical studies (e.g., psychosis) were likely de facto applied to the current meta-analyses as well.

\section{Conclusion}

The present meta-analyses summarize the current state of RST, depression and anxiety, and signal new avenues of future inquiry. Ultimately, we found robust support for a hierarchical approach to reinforcement sensitivity (e.g., Zinbarg \& Yoon, 2008) that may be consistent with the joint subsystem hypothesis (e.g., Corr, 2002). Punishment hypersensitivity was found to be a higher-order, shared factor for both depression and anxiety, whereas reward hyposensitivity was specific to depression. Furthermore, we found that clinical diagnosis and more severe levels of depression predicted larger effect sizes for both reward sensitivity and punishment sensitivity, which was not found with anxiety. Attention to the ways such differences interact, covary and change may improve how the nature of affective pathology is understood, and ultimately, how more effective, personalized treatments may be developed.

\section{References}

\footnotetext{
* - articles included in Study 1

$\dagger$ - articles included in Study 2

* - Aarts, K., \& Pourtois, G. (2010). Anxiety not only increases, but also alters early error-monitoring functions. Cognitive, Affective \& Behavioral Neuroscience, 10(4), 479-492. https://doi.org/10.3758/CABN.10.4.479

* - Abbate-Daga, G., Buzzichelli, S., Marzola, E., Amianto, F., \& Fassino, S. (2014). Clinical investigation of set-shifting subtypes in anorexia nervosa. Psychiatry Research, 219(3 PG592-597), 592-597. https://doi.org/10.1016/j.psychres.2014.06.024

† - Ak, M., Haciomeroglu, B., Turan, Y., Lapsekili, N., Doruk, A., Bozkurt, A., \& Akar, A. (2012). Temperament and character properties of male psoriasis patients. Journal of Health Psychology, 17(5), 774-781. https://doi.org/10.1177/1359105311423863

† - Albrecht, B., Staiger, P. K., Hall, K., Kambouropoulos, N., \& Best, D. (2016). Motivational drive and alprazolam misuse: A
}

NOTE: This is a postprint of the study Katz, B. A., Matanky, K., Aviram, G., \& Yovel, I. (2020). Reinforcement sensitivity, depression and anxiety: A meta-analysis and meta-analytic structural equation model. Clinical Psychology Review, 101842, doi: 
recipe for aggression? Psychiatry Research, 240, 381-389. https://doi.org/10.1016/j.psychres.2016.04.040

Aldao, A., Nolen-Hoeksema, S., \& Schweizer, S. (2010). Emotion-regulation strategies across psychopathology: A meta-analytic review. Clinical Psychology Review, 30(2), 217-237. https://doi.org/10.1016/j.cpr.2009.11.004

* - Alfimova, M., Korovaitseva, G., Lezheiko, T., \& Golimbet, V. (2014). Interaction effects of the COMT and DRD4 genes with anxiety-related traits on selective attention. The Spanish Journal of Psychology, 17. https://doi.org/10.1017/sjp.2014.46

Alloy, L. B., \& Abramson, L. Y. (2010). The role of the behavioral approach system (BAS) in bipolar spectrum disorders. Current Directions in Psychological Science, 19(3), 189-194. https://doi.org/10.1177/0963721410370292

Alloy, L. B., Abramson, L. Y., Walshaw, P. D., Cogswell, A., Grandin, L. D., Hughes, M. E., ... Hogan, M. E. (2008). Behavioral approach system and behavioral inhibition system sensitivities and bipolar spectrum disorders: Prospective prediction of bipolar mood episodes. Bipolar Disorders, 10(2), 310-322. https://doi.org/10.1111/j.1399-5618.2007.00547.x

Alloy, L. B., Bender, R. E., Wagner, C. A., Abramson, L. Y., \& Urosevic, S. (2009). Longitudinal predictors of bipolar spectrum disorders: A behavioral approach system perspective. Clinical Psychology: Science and Practice, 16(2), 206-226. https://doi.org/10.1111/j.1468-2850.2009.01160.x

Alloy, L. B., Olino, T., Freed, R. D., \& Nusslock, R. (2016). Role of reward sensitivity and processing in major depressive and bipolar spectrum disorders. Behavior Therapy, 47(5), 600621. https://doi.org/10.1016/j.beth.2016.02.014

Alloy, L. B., Urošević, S., Abramson, L. Y., Jager-Hyman, S., Nusslock, R., Whitehouse, W. G., \& Hogan, M. (2012). Progression along the bipolar spectrum: A longitudinal study of predictors of conversion from bipolar spectrum conditions to bipolar I and II disorders. Journal of Abnormal Psychology, 121(1), 16-27. https://doi.org/10.1037/a0023973

* - Alonso, P., Menchon, J. M., Jimenez, S., Segalas, J., MataixCols, D., Jaurrieta, N., ... Pujol, J. (2008). Personality dimensions in obsessive-compulsive disorder: relation to clinical variables, 157(1-3), 159-168. https://doi.org/10.1016/j.psychres.2006.06.003

American Psychiatric Association. (2013). Diagnostic and Statistical Manual of Mental Disorders (5th ed.) (5th ed.). Washington, D.C.: American Psychiatric Publishing.

* - Ammerman, B. A., Kleiman, E. M., Jenkins, A. L., Berman, M. E., \& McCloskey, M. S. (2017). Using Propensity Scores to Examine the Association Between Behavioral Inhibition/Activation and Nonsuicidal and Suicidal Self-Injury. Crisis, 38(4), 227-236. https://doi.org/10.1027/02275910/a000436

Anderson, E. R., \& Hope, D. A. (2008). A review of the tripartite model for understanding the link between anxiety and depression in youth. Clinical Psychology Review, 28(2), 275-287. https://doi.org/10.1016/j.cpr.2007.05.004

* - Applegate, E., El-Deredy, W., \& Bentall, R. P. (2009). Reward responsiveness in psychosis-prone groups: Hypomania and negative schizotypy. Personality and Individual Differences, 47(5), 452-456. https://doi.org/10.1016/j.paid.2009.04.017

$\dagger$ - Atkinson, J., Sharp, C., Schmitz, J., \& Yaroslavsky, I. (2012). Behavioral activation and inhibition, negative affect, and gambling severity in a sample of young adult college students.
Journal of Gambling Studies, 28(3), 437-449. https://doi.org/10.1007/s10899-011-9273-x

* - Avila, C., \& Parcet, M. A. (2001). Personality and inhibitory deficits in the stop-signal task: The mediating role of Gray's anxiety and impulsivity. Personality and Individual Differences, 31(6 PG-975-986), 975-986. https://doi.org/10.1016/S0191-8869(00)00199-9

* - Baggio, S., Iglesias, K., Deline, S., Studer, J., Henchoz, Y., Mohler-Kuo, M., \& Gmel, G. (2015). Not in education, employment, or training status among young Swiss men: Longitudinal associations with mental health and substance use. Journal of Adolescent Health, 56(2), 238-243. https://doi.org/10.1016/j.jadohealth.2014.09.006

* - Bajraktarov, S., Gudeva-Nikovska, D., Manuseva, N., \& Arsova, S. (2017). Personality vharacteristics as predictive factors for the occurrence of depressive disorder. Open Access Maced J Med Sci, 5(1), 48-53. https://doi.org/10.3889/oamjms.2017.022

Bakker, M., van Dijk, A., \& Wicherts, J. M. (2012). The rules of the game called psychological science. Perspectives on Psychological Science, 7(6), 543-554. https://doi.org/10.1177/1745691612459060

Ball, S. A., \& Zuckerman, M. (1990). Sensation seeking, Eysenck's personality dimensions and reinforcement sensitivity in concept formation. Personality and Individual Differences, 11(4), 343-353. https://doi.org/10.1016/0191-8869(90)90216$\mathrm{E}$

* - Balsamo, M. (2013). Personality and depression: Evidence of a possible mediating role for anger trait in the relationship between cooperativeness and depression. Comprehensive Psychiatry, 54(1), 46-52. https://doi.org/10.1016/j.comppsych.2012.05.007

Barlow, D. H., Farchione, T. J., Fairholme, C. P., Ellard, K. K., Boisseau, C. L., Allen, L. B., \& May, J. T. E. (2010). Unified Protocol for Transdiagnostic Treatment of Emotional Disorders: Therapist Guide (Vol. 12). Oxford University Press, USA.

Barlow, D. H., Sauer-Zavala, S., Carl, J. R., Bullis, J. R., \& Ellard, K. K. (2014). The nature, diagnosis, and treatment of neuroticism: Back to the future. Clinical Psychological Science, 2(3), 344-365. https://doi.org/10.1177/2167702613505532

* - Battaglia, M., Bertella, S., Bajo, S., Politi, E., \& Bellodi, L. (1998). An investigation of the co-occurrence of panic and somatization disorders through temperamental variables. $P$ sychosomatic Medicine, 60(6), 726-729. https://doi.org/10.1097/00006842-199811000-00013

* - Battaglia, M., Przybeck, T. R., Bellodi, L., \& Cloninger, C. R. (1996). Temperament dimensions explain the comorbidity of psychiatric disorders. Comprehensive Psychiatry, 37(4), 292298. https://doi.org/10.1016/S0010-440X(96)90008-5

Beck, A. T., Wartenberg, H. C., Mendelson, M., Mock, J., \& Erbaugh, J. (1961). An inventory for measuring depression. Archives of General Psychiatry, 4, 561-571.

$\uparrow$ - Beevers, C. G., \& Meyer, B. (2002). Lack of positive experiences and positive expectancies mediate the relationship between BAS responsiveness and depression. Cognition \& Emotion, 16(4), 549-564. https://doi.org/10.1080/02699930143000365

* - Bensaeed, S., Ghanbari Jolfaei, A., Jomehri, F., \& Moradi, A. (2014). The relationship between major depressive disorder

NOTE: This is a postprint of the study Katz, B. A., Matanky, K., Aviram, G., \& Yovel, I. (2020). Reinforcement sensitivity, depression and anxiety: A meta-analysis and meta-analytic structural equation model. Clinical Psychology Review, 101842, doi: 
and personality traits. Iranian Journal of Psychiatry, 9(1), 3741.

* - Bergdahl, M., \& Bergdahl, J. (2003). Temperament and character personality dimensions in patients with dental anxiety. European Journal of Oral Sciences, 111(2), 93-98. https://doi.org/10.1034/j.1600-0722.2003.00028.x

* - Berger, U., \& Anaki, D. (2014). The behavioral inhibition system (BIS) mediates major aspects of the relationship between disgust and OCD symptomology. Journal of Obsessive-Compulsive and Related Disorders, 3(3), 249-256. https://doi.org/10.1016/j.jocrd.2014.06.004

* - Bey, K., Lennertz, L., Riesel, A., Klawohn, J., Kaufmann, C., Heinzel, S., ... Wagner, M. (2017). Harm avoidance and childhood adversities in patients with obsessive-compulsive disorder and their unaffected first-degree relatives. Acta Psychiatrica Scandinavica, 135(4), 328-338. https://doi.org/10.1111/acps.12707

Bienvenu, O. J., Brown, C., Samuels, J. F., Liang, K.-Y., Costa, P. T., Eaton, W. W., \& Nestadt, G. (2001). Normal personality traits and comorbidity among phobic, panic and major depressive disorders. Psychiatry Research, 102(1), 73-85. https://doi.org/10.1016/S0165-1781(01)00228-1

Bijttebier, P., Beck, I., Claes, L., \& Vandereycken, W. (2009). Gray's Reinforcement Sensitivity Theory as a framework for research on personality-psychopathology associations. Clinical Psychology Review, 29(5), 421-430. https://doi.org/10.1016/j.cpr.2009.04.002

* - Bodas, M., Siman-Tov, M., Kreitler, S., \& Peleg, K. (2017). Psychological correlates of civilian preparedness for conflicts. Disaster Medicine and Public Health Preparedness, 11(04), 451-459. https://doi.org/10.1017/dmp.2016.163

Bollen, K. A. (1989). Structural equations with latent variables. New York, NY, NY: Wiley.

* - Booth, C., \& Hasking, P. (2009). Social anxiety and alcohol consumption: The role of alcohol expectancies and reward sensitivity. Addictive Behaviors, 34(9), 730-736. https://doi.org/10.1016/j.addbeh.2009.04.010

Borenstein, M., Hedges, L. V., Higgins, J. P. T., \& Rothstein, H. R. (2009). Introduction to Meta-Analysis. https://doi.org/10.1002/9780470743386.fmatter

* - Borgomaneri, S., Vitale, F., \& Avenanti, A. (2017). Behavioral inhibition system sensitivity enhances motor cortex suppression when watching fearful body expressions. Brain Structure and Function, 222(7), 3267-3282. https://doi.org/10.1007/s00429-017-1403-5

Borsboom, D., \& Cramer, A. O. J. (2013). Network analysis: An integrative approach to the structure of psychopathology. Annual Review of Clinical Psychology, 9(1), 91-121. https://doi.org/10.1146/annurev-clinpsy-050212-185608

* - Brailean, A. M., Koster, E. H. W., Hoorelbeke, K., \& De Raedt, R. (2014). Attentional modulation by reward and punishment cues in relation to depressive symptoms. Journal of Behavior Therapy and Experimental Psychiatry, 45(3), 351359. https://doi.org/10.1016/j.jbtep.2014.03.003

$\dagger$ - Brook, C. A., \& Willoughby, T. (2016). Social anxiety and alcohol use across the university years: Adaptive and maladaptive groups. Developmental Psychology, 52(5), 835-845. https://doi.org/10.1037/dev0000110

* - Brown, S. L., Svrakic, D. M., Przybeck, T. R., \& Cloninger, R. C. (1992). The relationship of personality to mood and anxiety states: A dimensional approach. Journal of Psychiatric Research, 26(3), 197-211. https://doi.org/10.1016/00223956(92)90023-H

Brown, T. A. (2007). Temporal course and structural relationships among dimensions of temperament and DSM-IV anxiety and mood disorder constructs. Journal of Abnormal Psychology, 116(2), 313-328. https://doi.org/10.1037/0021843X.116.2.313

Brown, T. A., Chorpita, B. F., \& Barlow, D. H. (1998). Structural relationships among dimensions of the DSM-IV anxiety and mood disorders and dimensions of negative affect, positive affect, and autonomic arousal. Journal of Abnormal Psychology, 107(2), 179-192. https://doi.org/10.1037/0021843X.107.2.179

Browne, M. W., \& Cudeck, R. (1993). Alternative ways of assessing model fit. In K. Bollen \& K. Long (Eds.), Testing structural equation models (pp. 163-162). Beverly Hills, CA, CA: Sage.

$\dagger$ - Brunborg, G. S., Johnsen, B. H., Pallesen, S., Molde, H., Mentzoni, R. A., \& Myrseth, H. (2010). The relationship between aversive conditioning and risk-avoidance in gambling. Journal of Gambling Studies, 26(4), 545-559. https://doi.org/10.1007/s10899-010-9178-0

* - Buchman, A. S., Yu, L., Wilson, R. S., Shulman, J. M., Boyle, P. A., \& Bennett, D. A. (2014). Harm avoidance is associated with progression of parkinsonism in community-dwelling older adults: a prospective cohort study. BMC geriatrics, 14(1), 54. https://doi.org/ 10.1186/1471-2318-14-54

Campbell-Sills, L., Liverant, G. I., \& Brown, T. A. (2004). Psychometric Evaluation of the Behavioral Inhibition/Behavioral Activation Scales in a Large Sample of Outpatients With Anxiety and Mood Disorders. Psychological Assessment, 16(3 PG244-254), 244-254. https://doi.org/10.1037/10403590.16.3.244

Carl, J. R., Gallagher, M. W., \& Barlow, D. H. (2018). Development and preliminary evaluation of a positive emotion regulation augmentation module for anxiety and depression. Behavior Therapy, 49(6), 939-950. https://doi.org/10.1016/j.beth.2017.11.008

Carl, J. R., Gallagher, M. W., Sauer-Zavala, S. E., Bentley, K. H., \& Barlow, D. H. (2014). A preliminary investigation of the effects of the unified protocol on temperament. Comprehensive Psychiatry, 55(6), 1426-1434. https://doi.org/10.1016/j.comppsych.2014.04.015

Carl, J. R., Soskin, D. P., Kerns, C., \& Barlow, D. H. (2013). Positive emotion regulation in emotional disorders: A theoretical review. Clinical Psychology Review, 33(3), 343-360. https://doi.org/10.1016/j.cpr.2013.01.003

* - Carver, C. S., \& Johnson, S. L. (2009). Tendencies toward mania and tendencies toward depression have distinct motivational, affective, and cognitive correlates. Cognitive Therapy and Research, 33(6), 552-569. https://doi.org/10.1007/s10608-008-9213-y

Carver, C. S., Johnson, S. L., \& Joormann, J. (2008). Serotonergic function, two-mode models of self-regulation, and vulnerability to depression: What depression has in common with impulsive aggression. Psychological Bulletin, 134(6), 912-943. https://doi.org/10.1037/a0013740

Carver, C. S., \& White, T. L. (1994). Behavioral inhibition, behavioral activation, and affective responses to impending reward and punishment: The BIS/BAS Scales. Journal of Personality

NOTE: This is a postprint of the study Katz, B. A., Matanky, K., Aviram, G., \& Yovel, I. (2020). Reinforcement sensitivity, depression and anxiety: A meta-analysis and meta-analytic structural equation model. Clinical Psychology Review, 101842, doi: 
and Social Psychology, 67(2), 319-333. https://doi.org/10.1037/0022-3514.67.2.319

* - Caseras, X., Ávila, C., \& Torrubia, R. (2003). The measurement of individual differences in behavioural inhibition and behavioural activation systems: A comparison of personality scales. Personality and Individual Differences, 34(6), 9991013. https://doi.org/10.1016/S0191-8869(02)00084-3

Caspi, A., Houts, R. M., Belsky, D. W., Goldman-Mellor, S. J., Harrington, H., Israel, S., ... Moffitt, T. E. (2014). The p Factor. Clinical Psychological Science, 2(2), 119-137. https://doi.org/10.1177/2167702613497473

* - Celikel, F. C., Kose, S., Cumurcu, B. E., Erkorkmaz, U., Sayar, K., Borckardt, J. J., \& Cloninger, C. R. (2009). Cloninger's temperament and character dimensions of personality in patients with major depressive disorder. Comprehensive Psychiatry, 50(6), 556-561. https://doi.org/10.1016/j.comppsych.2008.11.012

$\dagger$ - Ceschi, G., Hearn, M., Billieux, J., \& Linden, M. Van der. (2011). Lifetime exposure to adverse events and reinforcement sensitivity in obsessive-compulsive prone individuals. Behaviour Change, 28(02), 75-86. https://doi.org/10.1375/bech.28.2.75

* - Chang, H.A., Chang, C.C., Chen, C.L., Kuo, T. B. J., Lu, R.B., \& Huang, S.-Y. (2013). Heart rate variability in patients with fully remitted major depressive disorder. Acta Neuropsychiatrica, 25(01), 33-42. https://doi.org/10.1111/j.16015215.2012.00658.x

* - Chang, H. A., Chang, C. C., Tzeng, N. S., Kuo, T. B., Lu, R. B., \& Huang, S. Y. (2013a). Decreased cardiac vagal control in drug-naive patients with panic disorder: A case-control study in Taiwan. Asia Pacific Psychiatry, 5(2 PG-80-9), 8089. https://doi.org/10.1111/appy.12032

* - Chang, H. A., Chang, C. C., Tzeng, N. S., Kuo, T. B., Lu, R. B., \& Huang, S. Y. (2013b). Decreased cardiac vagal control in drug-naive patients with posttraumatic stress disorder. Psychiatry Investig, 10(2 PG-121-30), 121-130. https://doi.org/10.4306/pi.2013.10.2.121

* - Chatterjee, S., Sunitha, T. A., Velayudhan, A., \& Khanna, S. (1997). An investigation into the psychobiology of social phobia: Personality domains and serotonergic function. Acta Psychiatrica Scandinavica, 95(6), 544-550. https://doi.org/10.1111/j.1600-0447.1997.tb10144.x

*† - Chen, Z., Lu, X., \& Kitamura, T. (2011). The effects of temperament and character on symptoms of depression in a Chinese nonclinical population. Depression Research and Treatment, 2011, 1-8. https://doi.org/10.1155/2011/198591

* - Cheung, G., \& Todd-Oldehaver, C. (2006). Personality trait of harm avoidance in late-life depression. International Journal of Geriatric Psychiatry, 21(2), 192-193. https://doi.org/10.1002/gps.1431

Cheung, M. W.-L., \& Chan, W. (2005). Meta-analytic structural equation modeling: A two-stage approach. Psychological Methods, 10(1), 40-64. https://doi.org/10.1037/1082989X.10.1.40

$\dagger$ - Choi, J.-S., Park, S. M., Roh, M.-S., Lee, J.-Y., Park, C.-B., Hwang, J. Y., ... Jung, H. Y. (2014). Dysfunctional inhibitory control and impulsivity in Internet addiction. Psychiatry Research, 215(2), 424-428. https://doi.org/10.1016/j.psychres.2013.12.001

Chmielewski, M., \& Watson, D. (2009). What is being assessed and why it matters: the impact of transient error on trait research. Journal of personality and social psychology, 97(1), 186. https://doi.org/10.1037/a0015618.

* - Claes, L., Bijttebier, P., Mitchell, J. E., de Zwaan, M., \& Mueller, A. (2011). The relationship between compulsive buying, eating disorder symptoms, and temperament in a sample of female students. Comprehensive Psychiatry, 52(1), 50-55. https://doi.org/10.1016/j.comppsych.2010.05.003

Clark, L. A., Cuthbert, B., Lewis-Fernández, R., Narrow, W. E., \& Reed, G. M. (2017). Three approaches to understanding and classifying mental disorder: ICD-11, DSM-5, and the National Institute of Mental Health's Research Domain Criteria (RDoC). Psychological Science in the Public Interest, 18(2), 72-145. https://doi.org/10.1177/1529100617727266

Clark, L. A., Vittengl, J., Kraft, D., \& Jarrett, R. B. (2003). Separate personality traits from states to predict depression. Journal of Personality Disorders, 17(2), 152-172. https://doi.org/10.1521/pedi.17.2.152.23990

Clark, L. A., \& Watson, D. (1991). Tripartite model of anxiety and depression: Psychometric evidence and taxonomic implications. Journal of Abnormal Psychology, 100(3), 316-336. https://doi.org/10.1037/0021-843X.100.3.316

Cloninger, C. R. (1987). A systematic method for clinical description and classification of personality variants. A proposal. Archives of General Psychiatry, 44(6), 573-588. https://doi.org/10.1001/archpsyc.1987.01800180093014

Cloninger, C. R. (1991). The Tridimensional Personality Questionnaire: U.S. normative data. Psychological Reports, 69(7), 1047-1057. https://doi.org/10.2466/PR0.69.7.1047-1057

Cloninger, C. R. (1994). The Temperament and Character Inventory (TCI): A guide to its development and use. St. Louis, MO, MO: Washington University, Center for the Psychobiology of Personality.

* - Cloninger, C. R., Bayon, C., \& Svrakic, D. M. (1998). Measurement of temperament and character in mood disorders: a model of fundamental states as personality types. Journal of Affective Disorders, 51(1), 21-32. https://doi.org/10.1016/S0165-0327(98)00153-0

Cohen, J. (1988). Statistical power analysis for the behavioral sciences (2nd ed.). New Jersey: Lawrence Erlbaum.

Cole, D. A., Martin, N. C., \& Steiger, J. H. (2005). Empirical and conceptual problems with longitudinal trait-state models: Introducing a trait-state-occasion model. Psychological Methods, 10(1), 3-20. https://doi.org/10.1037/1082-989X.10.1.3

* - Contractor, A. A., Elhai, J. D., Ractliffe, K. C., \& Forbes, D. (2013). PTSD's underlying symptom dimensions and relations with behavioral inhibition and activation. Journal of Anxiety Disorders, 27(7), 645-651. https://doi.org/10.1016/j.janxdis.2013.07.007

* - Cooper, A., \& Gomez, R. (2008). The development of a short form of the Sensitivity to Punishment and Sensitivity to Reward Questionnaire. Journal of Individual Differences, 29(2), 90-104. https://doi.org/10.1027/1614-0001.29.2.90

* - Cooper, A. J., Duke, Ã., Pickering, A. D., \& Smillie, L. D. (2014). Individual differences in reward prediction error: Contrasting relations between feedback-related negativity and trait measures of reward sensitivity, impulsivity and extraversion.

NOTE: This is a postprint of the study Katz, B. A., Matanky, K., Aviram, G., \& Yovel, I. (2020). Reinforcement sensitivity, depression and anxiety: A meta-analysis and meta-analytic structural equation model. Clinical Psychology Review, 101842, doi: 
Frontiers in Human Neuroscience, 8. https://doi.org/10.3389/fnhum.2014.00248

Cooper, H., Hedges, L. V., \& Valentine, J. C. (Eds.). (2009). The Handbook of Research Synthesis and Meta-Analysis. Russell Sage Foundation.

Cooper, H. M., \& Rosenthal, R. (1980). Statistical versus traditional procedures for summarizing research findings. Psychological Bulletin, 87(3), 442-449. https://doi.org/10.1037/00332909.87.3.442

Conway, C. C., Forbes, M. K., Forbush, K. T., Fried, E. I., Hallquist, M. N., Kotov, R., ... \& Sunderland, M. (2019). A hierarchical taxonomy of psychopathology can transform mental health research. Perspectives on Psychological Science, 1745691618810696.

Corr, P. J. (2001). Testing problems in J. A. Gray's personality theory. Personality and Individual Differences, 30(2), 333352. https://doi.org/10.1016/S0191-8869(00)00028-3

Corr, P. J. (2002). J. A. Gray's reinforcement sensitivity theory: Tests of the joint subsystems hypothesis of anxiety and impulsivity. Personality and Individual Differences, 33(4), 511-532. https://doi.org/10.1016/S0191-8869(01)00170-2

Corr, P. J. (2008). Reinforcement Sensitivity Theory (RST): Introduction. In P. J. Corr (Ed.), The Reinforcement Sensitivity Theory of Personality (pp. 1-43). Cambridge: Cambridge University Press. https://doi.org/10.1017/CBO9780511819384.002

Corr, P. J. (2013). Approach and avoidance behaviour: Multiple systems and their interactions. Emotion Review, 5(3), 285290. https://doi.org/10.1177/1754073913477507

* - Corr, P. J., \& Cooper, A. J. (2016). The Reinforcement Sensitivity Theory of Personality Questionnaire (RST-PQ): Development and validation. Psychological Assessment., 28(11), 418-427. https://doi.org/http://dx.doi.org/10.1037/pas0000273

Corr, P. J., \& McNaughton, N. (2008). Reinforcement sensitivity theory and personality. In P. J. Corr (Ed.), The Reinforcement Sensitivity Theory of Personality (Vol. 28, pp. 155-187). Cambridge: Cambridge University Press. https://doi.org/10.1016/j.neubiorev.2004.01.005

* - Cowley, D. S., Roy-Byrne, P. P., Greenblatt, D. J., \& Hommer, D. W. (1993). Personality and benzodiazepine sensitivity in anxious patients and control subjects. Psychiatry Research, 47(2), 151-162. https://doi.org/10.1016/0165-1781(93)90045I

* - Cremers, H. R., Veer, I. M., Spinhoven, P., Rombouts, S. A. R. B., Yarkoni, T., Wager, T. D., \& Roelofs, K. (2015). Altered cortical-amygdala coupling in social anxiety disorder during the anticipation of giving a public speech. Psychological Medicine, 45(7), 1521-1529. https://doi.org/10.1017/S0033291714002657

* - Cruz-Fuentes, C., Blas, C., Gonzalez, L., Camarena, B., \& Nicolini, H. (2004). Severity of obsessive-compulsive symptoms is related to self-directedness character trait in obsessive-compulsive disorder. CNS Spectrums, 9(08), 607-612. https://doi.org/10.1017/S1092852900002789

Cuijpers, P., van Straten, A., \& Warmerdam, L. (2007). Behavioral activation treatments of depression: A meta-analysis. Clinical Psychology Review, 27(3), 318-326. https://doi.org/10.1016/j.cpr.2006.11.001

* - Dalbudak, E., Evren, C., Aldemir, S., Coskun, K. S., Yıldırım, F. G., \& Ugurlu, H. (2013). Alexithymia and personality in relation to social anxiety among university students. Psychiatry
Research, 209(2), 167-172. https://doi.org/10.1016/j.psychres.2012.11.027

* - Davenport, K., Houston, J. E., \& Griffiths, M. D. (2012). Excessive eating and compulsive buying behaviours in women: An empirical pilot study examining reward sensitivity, anxiety, impulsivity, self-esteem and social desirability. International Journal of Mental Health and Addiction, 10(4), 474489. https://doi.org/10.1007/s11469-011-9332-7

* - de la Torre-Luque, A., Fiol-Veny, A., Balle, M., \& Bornas, X. (2016). Heartbeat scaling in early adolescents: Its association with anxiety symptoms and sensitivity to punishment. International Journal of Clinical and Health Psychology, 16(3), 287294. https://doi.org/10.1016/j.ijchp.2016.04.002

* - De Pascalis, V., Cozzuto, G., \& Russo, E. (2013). Effects of personality trait emotionality on acoustic startle response and prepulse inhibition including N100 and P200 event-related potential. Clinical Neurophysiology, 124(2), 292-305. https://doi.org/10.1016/j.clinph.2012.07.018

Del Re, A. (2013). compute.es: Compute Effect Sizes. R package version $0.2-2$. Retrieved from http://cran.r-project.org/web/packages/compute.es

* - DelDonno, S. R., Weldon, A. L., Crane, N. A., Passarotti, A. M., Pruitt, P. J., Gabriel, L. B., ... Langenecker, S. A. (2015). Affective personality predictors of disrupted reward learning and pursuit in major depressive disorder. Psychiatry Research, 230(1), 56-64. https://doi.org/10.1016/j.psychres.2015.08.011

$* \dagger$ - Dennis, T. A. (2007). Interactions between emotion regulation strategies and affective style: Implications for trait anxiety versus depressed mood. Motivation and Emotion, 31(3), 200207. https://doi.org/10.1007/s11031-007-9069-6

Dennis, T. A., \& Chen, C.-C. (2007). Neurophysiological mechanisms in the emotional modulation of attention: The interplay between threat sensitivity and attentional control. Biological Psychology, 76(1-2), 1-10. https://doi.org/10.1016/j.biopsycho.2007.05.001

Depue, R. A., \& Collins, P. F. (1999). Neurobiology of the structure of personality: Dopamine, facilitation of incentive motivation, and extraversion. Behavioral and Brain Sciences, 22(3), 491-569. https://doi.org/10.1017/S0140525X99002046

* - Derntl, B., Seidel, E.-M., Eickhoff, S. B., Kellermann, T., Gur, R. C., Schneider, F., \& Habel, U. (2011). Neural correlates of social approach and withdrawal in patients with major depression. Social Neuroscience, 6(5-6), 482-501. https://doi.org/10.1080/17470919.2011.579800

* - Díaz, A., \& Pickering, A. D. (1993). The relationship between Gray's and Eysenck's personality spaces. Personality and Individual Differences, 15(3), 297-305. https://doi.org/10.1016/0191-8869(93)90220-W

* - Dinovo, S. A., \& Vasey, M. W. (2011). Reactive and self-regulatory dimensions of temperament: Interactive relations with symptoms of general distress and anhedonia. Journal of Research in Personality, 45(5), 430-440. https://doi.org/10.1016/j.jrp.2011.05.002

* - Dodd, A. L., Mansell, W., Bentall, R. P., \& Tai, S. (2011). Do extreme beliefs about internal states predict mood swings in an analogue sample? Cognitive Therapy and Research, 35(6), 497-504. https://doi.org/10.1007/s10608-010-9342-y

* - Dufey, M., Fernández, A. M., \& Mourgues, C. (2011). Assessment of the behavioral inhibition system and the behavioral approach system: Adaptation and validation of the Sensitivity to Punishment and Sensitivity to Reward Questionnaire

NOTE: This is a postprint of the study Katz, B. A., Matanky, K., Aviram, G., \& Yovel, I. (2020). Reinforcement sensitivity, depression and anxiety: A meta-analysis and meta-analytic structural equation model. Clinical Psychology Review, 101842, doi: 
(SPSRQ) in a Chilean sample. The Spanish Journal of Psychology, 14(1), 432-440.

https://doi.org/10.5209/rev_SJOP.2011.v14.n1.39

* - Duley, A. R., Hillman, C. H., Coombes, S., \& Janelle, C. M. (2007). Sensorimotor gating and anxiety: Prepulse inhibition following acute exercise. International Journal of Psychophysiology, 64, 157-164. https://doi.org/10.1016/j.ijpsycho.2007.01.006

Duval, S., \& Tweedie, R. (2000). Trim and fill: A simple funnelplot-based method of testing and adjusting for publication bias in meta-analysis. Biometrics, 56(2), 455-463. https://doi.org/10.1111/j.0006-341X.2000.00455.x

Easterbrook, P. J., Gopalan, R., Berlin, J. A., \& Matthews, D. R. (1991). Publication bias in clinical research. The Lancet, 337(8746), 867-872. https://doi.org/10.1016/01406736(91)90201-Y

Eaton, N. R., Krueger, R. F., Markon, K. E., Keyes, K. M., Skodol, A. E., Wall, M., ... Grant, B. F. (2013). The structure and predictive validity of the internalizing disorders. Journal of Abnormal Psychology, 122(1), 86-92. https://doi.org/10.1037/a0029598

Eddington, K. M., Majestic, C., \& Silvia, P. J. (2012). Contrasting regulatory focus and reinforcement sensitivity: A daily diary study of goal pursuit and emotion. Personality and Individual Differences, 53(3), 335-340.

https://doi.org/10.1016/j.paid.2012.04.001

Egger, M., Smith, G. D., Schneider, M., \& Minder, C. (1997). Bias in meta-analysis detected by a simple, graphical test. BMJ, 315(7109), 629-634. https://doi.org/10.1136/bmj.315.7109.629

Eid, M., Lischetzke, T., Nussbeck, F. W., \& Trierweiler, L. I. (2003). Separating trait effects from trait-specific method effects in multitrait-multimethod models: A multiple-indicator CT-C(M-1) model. Psychological Methods, 8(1), 38-60. https://doi.org/10.1037/1082-989X.8.1.38

* - Ekinci, O., Albayrak, Y., \& Ekinci, A. E. (2012). Temperament and character in euthymic major depressive disorder patients: The effect of previous suicide attempts and psychotic mood Episodee. Psychiatry Investigation, 9(2), 119. https://doi.org/10.4306/pi.2012.9.2.119

* - Elovainio, M., Kivimäki, M., Puttonen, S., Heponiemi, T., Pulkki, L., \& Keltikangas-Järvinen, L. (2004). Temperament and depressive symptoms: A population-based longitudinal study on Cloninger's psychobiological temperament model. Journal of Affective Disorders, 83, 227-232. https://doi.org/10.1016/j.jad.2004.06.005

Eshel, N., \& Roiser, J. P. (2010). Reward and punishment processing in depression. Biological Psychiatry, 68(2), 118-124. https://doi.org/10.1016/j.biopsych.2010.01.027

* - Ettelt, S., Grabe, H. J., Ruhrmann, S., Buhtz, F., Hochrein, A., Kraft, S., ... Wagner, M. (2008). Harm avoidance in subjects with obsessive-compulsive disorder and their families. Journal of Affective Disorders, 107(1-3), 265-269. https://doi.org/10.1016/j.jad.2007.08.017

* - Farmer, R. F., \& Seeley, J. R. (2009). Temperament and character predictors of depressed mood over a 4-year interval. Depression and Anxiety, 26(4), 371-381. https://doi.org/10.1002/da.20459

$\dagger$ - Fayazi, M., \& Hasani, J. (2017). Structural relations between brain-behavioral systems, social anxiety, depression and inter- net addiction: With regard to revised Reinforcement Sensitivity Theory (r-RST). Computers in Human Behavior, 72, 441448. https://doi.org/10.1016/j.chb.2017.02.068

$\dagger$ - Feil, J., \& Hasking, P. (2008). The relationship between personality, coping strategies and alcohol use. Addiction Research \& Theory, 16(5), 526-537. https://doi.org/10.1080/16066350802025714

Fisher, Z., Tipton, E., \& Zhipeng, H. (2017). robumeta: Robust variance meta-regression. R package version 2.0. Retrieved from https://cran.r-project.org/package=robumeta

Garland, E. L., Fredrickson, B., Kring, A. M., Johnson, D. P., Meyer, P. S., \& Penn, D. L. (2010). Upward spirals of positive emotions counter downward spirals of negativity: Insights from the broaden-and-build theory and affective neuroscience on the treatment of emotion dysfunctions and deficits in psychopathology. Clinical Psychology Review, 30(7), 849-864. https://doi.org/10.1016/j.cpr.2010.03.002

$\uparrow$ - Gawęda, Ł., \& Kokoszka, A. (2014). Meta-cognitive beliefs as a mediator for the relationship between Cloninger's temperament and character dimensions and depressive and anxiety symptoms among healthy subjects. Comprehensive Psychiatry, 55(4), 1029-1037. https://doi.org/10.1016/j.comppsych.2013.10.013

* - Gazioglu, S., Cakmak, V. A., Ozkorumak, E., Usta, N. C., Ates, C., \& Boz, C. (2014). Personality traits of patients with multiple sclerosis and their relationship with clinical characteristics. Journal of Nervous and Mental Disease, 202(5), 408-411. https://doi.org/10.1097/NMD.0000000000000114

Gershuny, B. S., \& Sher, K. J. (1998). The relation between personality and anxiety: Findings from a 3-year prospective study. Journal of Abnormal Psychology, 107(2), 252-262. https://doi.org/10.1037/0021-843X.107.2.252

* - Gil, S. (2005). Pre-traumatic personality as a predictor of posttraumatic stress disorder among undergraduate students exposed to a terrorist attack: A prospective study in Israel. Personality and Individual Differences, 39(4), 819-827. https://doi.org/10.1016/j.paid.2005.03.007

* - Gillath, O., Giesbrecht, B., \& Shaver, P. R. (2009). Attachment, attention, and cognitive control: Attachment style and performance on general attention tasks. Journal of Experimental Social Psychology, 45(4), 647-654. https://doi.org/10.1016/j.jesp.2009.02.011

* - Goekoop, J. G., \& De Winter, R. F. P. (2011). Temperament and character in psychotic depression compared with other subcategories of depression and normal controls. Depression Research and Treatment, 2011, 1-7. https://doi.org/10.1155/2011/730295

Goekoop, J. G., De Winter, R. F., \& Goekoop, R. (2011). An increase of the character function of self-directedness is centrally involved in symptom reduction during remission from major depression. Depression Research and Treatment, 2011.

* - Gökdağ, C., \& Arkar, H. (2016). [An examination of the relationships between psychobiological model of personality and cognitive theory in patients diagnosed with major depression and healthy individuals]. Turk Psikiyatri Dergisi, 27(4), 257265.

* - Gomez, R., \& Gomez, A. (2005). Convergent, discriminant and concurrent validities of measures of the behavioural approach

NOTE: This is a postprint of the study Katz, B. A., Matanky, K., Aviram, G., \& Yovel, I. (2020). Reinforcement sensitivity, depression and anxiety: A meta-analysis and meta-analytic structural equation model. Clinical Psychology Review, 101842, doi: 
and behavioural inhibition systems: Confirmatory factor analytic approach. Personality and Individual Differences, 38(1), 87-102. https://doi.org/10.1016/j.paid.2004.03.011

$\uparrow$ - Goncalves, D. M., \& Cloninger, C. R. (2010). Validation and normative studies of the Brazilian Portuguese and American versions of the Temperament and Character Inventory - Revised (TCI-R). Journal of Affective Disorders, 124(1-2), 126133. https://doi.org/10.1016/j.jad.2009.11.007

Gonzalez-Mulé, E., \& Aguinis, H. (2018). Advancing theory by assessing boundary conditions with metaregression: A critical review and best-practice recommendations. Journal of Management, 44(6), 2246-2273. https://doi.org/10.1177/0149206317710723

Gray, J. A. (1970). The psychophysiological basis of introversionextraversion. Behaviour Research and Therapy, 8(3), 249266. https://doi.org/10.1016/0005-7967(70)90069-0

Gray, J. A. (1982). The Neuropsychology of Anxiety: An Enquiry into the Functions of the Septo-Hippocampal System. Oxford, England: Oxford University Press.

Gray, J. A. (1987). The Neuropsychology of Anxiety. Oxford: Oxford University Press.

Gray, J. A., \& McNaughton, N. (2000). The Neuropsychology of Anxiety: An Enquiry into the Functions of the Septo-Hippocampal System (2nd edition). Oxford, England, England: Oxford University Press.

Gray, J. D., Hanna, D., Gillen, A., \& Rushe, T. (2016). A closer look at Carver and White's BIS/BAS scales: Factor analysis and age group differences. Personality and Individual Differences, 95, 20-24. https://doi.org/10.1016/j.paid.2016.02.022

* - Greenwood, T. A., Badner, J. A., Byerley, W., Keck, P. E., McElroy, S. L., Remick, R. A., ... Kelsoe, J. R. (2013). Heritability and linkage analysis of personality in bipolar disorder. Journal of Affective Disorders, 151(2), 748-755. https://doi.org/10.1016/j.jad.2013.06.015

Griffith, J. W., Zinbarg, R. E., Craske, M. G., Mineka, S., Rose, R. D., Waters, A. M., \& Sutton, J. M. (2010). Neuroticism as a common dimension in the internalizing disorders. Psychological Medicine, 40(7), 1125-1136. https://doi.org/10.1017/S0033291709991449

* - Gudiño, O. G. (2013). Behavioral inhibition and risk for posttraumatic stress symptoms in Latino children exposed to violence. Journal of Abnormal Child Psychology, 41(6), 983992. https://doi.org/10.1007/s10802-013-9731-2

* - Hagenaars, M. A. (2016). Tonic immobility and PTSD in a large community sample. Journal of Experimental Psychopathology, 7(2), 246-260. https://doi.org/10.5127/jep.051915

Hagger, M. S., Chan, D. K. C., Protogerou, C., \& Chatzisarantis, N. L. D. (2016). Using meta-analytic path analysis to test theoretical predictions in health behavior: An illustration based on meta-analyses of the theory of planned behavior. Preventive Medicine, 89, 154-161. https://doi.org/10.1016/j.ypmed.2016.05.020

Hagger, M. S., Wood, C., Stiff, C., \& Chatzisarantis, N. L. D. (2010). Ego depletion and the strength model of self-control: A meta-analysis. Psychological Bulletin, 136(4), 495-525. https://doi.org/10.1037/a0019486

Halvorsen, M., Wang, C. E., Richter, J., Myrland, I., Pedersen, S. K., Eisemann, M., \& Waterloo, K. (2009). Early maladaptive schemas, temperament and character traits in clinically de- pressed and previously depressed subjects. Clinical Psychology \& Psychotherapy, 16(5), 394-407.

https://doi.org/10.1002/cpp.618

$\dagger$ - Hamill, T. S., Pickett, S. M., Amsbaugh, H. M., \& Aho, K. M. (2015). Mindfulness and acceptance in relation to Behavioral Inhibition System sensitivity and psychological distress. Personality and Individual Differences, 72, 24-29. https://doi.org/10.1016/j.paid.2014.08.007

* - Han, D. H., Kim, J. H., Lee, Y. S., Bae, S. J., Bae, S. J., Kim, H. J., ... Lyoo, I. K. (2006). Influence of temperament and anxiety on athletic performance. Journal of Sports Science and Medicine, 5(3), 381-389. Retrieved from NS -

* - Hannan, S. M., \& Orcutt, H. K. (2013). Emotion dysregulation as a partial mediator between reinforcement sensitivity and posttraumatic stress symptoms. Personality and Individual Differences, 55(5), 574-578. https://doi.org/10.1016/j.paid.2013.04.028

* - Hansenne, M., \& Ansseau, M. (2001). Contingent negative variation and personality in depression. Neuropsychobiology, 44(1), 7-12. https://doi.org/10.1159/000054907

* - Hansenne, M., \& Bianchi, J. (2009). Emotional intelligence and personality in major depression: Trait versus state effects. Psychiatry Research, 166(1), 63-68. https://doi.org/10.1016/j.psychres.2008.03.015

* - Harmon-Jones, E., \& Allen, J. J. B. (1997). Behavioral activation sensitivity and resting frontal EEG asymmetry: Covariation of putative indicators related to risk for mood disorders. Journal of Abnormal Psychology, 106(1), 159-163. https://doi.org/10.1037/0021-843X.106.1.159

$\dagger$ - Harnett, P. H., Reid, N., Loxton, N. J., \& Lee, N. (2016). The relationship between trait mindfulness, personality and psychological distress: A revised reinforcement sensitivity theory perspective. Personality and Individual Differences, 99, 100105. https://doi.org/10.1016/j.paid.2016.04.085

* - Hasler, B. P., Allen, J. J. B. B., Sbarra, D. A., Bootzin, R. R., \& Bernert, R. A. (2010). Morningness-eveningness and depression: Preliminary evidence for the role of the behavioral activation system and positive affect. Psychiatry Research, 176(2-3), 166-173. https://doi.org/10.1016/j.psychres.2009.06.006

Hedges, L. V., \& Olkin, I. (1984). Nonparametric estimators of effect size in meta-analysis. Psychological Bulletin, 96(3), 573580. https://doi.org/10.1037/0033-2909.96.3.573

Hedges, L. V., Tipton, E., \& Johnson, M. C. (2010). Robust variance estimation in meta-regression with dependent effect size estimates. Research Synthesis Methods, 1(1), 39-65. https://doi.org/10.1002/jrsm.5

* - Hellerstein, D. J., Kocsis, J. H., Chapman, D., Stewart, J. W., \& Harrison, W. (2000). Double-blind comparison of sertraline, imipramine, and placebo in the treatment of dysthymia: Effects on personality. American Journal of Psychiatry, 157(9), 1436-1444. https://doi.org/10.1176/appi.ajp.157.9.1436

* - Highsmith, J. M., Wuensch, K. L., Tran, T., Stephenson, A. J., \& Everhart, D. E. (2017). It's not what you expect: Feedback negativity is independent of reward expectation and affective responsivity in a non-probabilistic task. Brain Informatics, 4(1), 51-63. https://doi.org/10.1007/s40708-016-0050-6

* - Hirano, S., Sato, T., Narita, T., Kusunoki, K., Ozaki, N., Kimura, S., ... Uehara, T. (2002). Evaluating the state dependency of the Temperament and Character Inventory dimensions

NOTE: This is a postprint of the study Katz, B. A., Matanky, K., Aviram, G., \& Yovel, I. (2020). Reinforcement sensitivity, depression and anxiety: A meta-analysis and meta-analytic structural equation model. Clinical Psychology Review, 101842, doi: 
in patients with major depression: A methodological contribution. Journal of Affective Disorders, 69(1-3), 31-38. https://doi.org/10.1016/S0165-0327(00)00329-3

Hofmann, S. G., \& Hayes, S. C. (2019). The future of intervention science: Process-based therapy. Clinical Psychological Science, 7(1), 37-50. https://doi.org/10.1177/2167702618772296

Hollon, S. D. (2019). Process trumps protocol: What I liked about Hofmann and Hayes. Clinical Psychological Science, 7(1), 54-56. https://doi.org/10.1177/2167702618797111

* - Holmes, A. J., Lee, P. H., Hollinshead, M. O., Bakst, L., Roffman, J. L., Smoller, J. W., \& Buckner, R. L. (2012). Individual differences in amygdala-medial prefrontal anatomy link negative affect, impaired social functioning, and polygenic depression risk. The Journal of Neuroscience, 32(50), 18087-18100. https://doi.org/10.1523/JNEUROSCI.2531-12.2012

Hom, P. W., Caranikas-Walker, F., Prussia, G. E., \& Griffeth, R. W. (1992). A meta-analytical structural equations analysis of a model of employee turnover. Journal of Applied Psychology, 77(6), 890-909. https://doi.org/10.1037/0021-9010.77.6.890

* - Hoyer, J., Braeuer, D., Crawcour, S., Klumbies, E., \& Kirschbaum, C. (2013). Depersonalization/derealization during acute social stress in social phobia. Journal of Anxiety Disorders, 27(2), 178-187. https://doi.org/10.1016/j.janxdis.2013.01.002

$\mathrm{Hu}, \mathrm{L} .$, \& Bentler, P. M. (1999). Cutoff criteria for fit indexes in covariance structure analysis: Conventional criteria versus new alternatives. Structural Equation Modeling: A Multidisciplinary Journal, 6(1), 1-55. https://doi.org/10.1080/10705519909540118

$\dagger$ - Hundt, N. E., Brown, L. H., Kimbrel, N. A., Walsh, M. A., Nelson-Gray, R., \& Kwapil, T. R. (2013). Reinforcement sensitivity theory predicts positive and negative affect in daily life. Personality and Individual Differences, 54(3), 350-354. https://doi.org/10.1016/j.paid.2012.09.021

$\uparrow$ - Hundt, N. E., Nelson-Gray, R. O., Kimbrel, N. A., Mitchell, J. T., \& Kwapil, T. R. (2007). The interaction of reinforcement sensitivity and life events in the prediction of anhedonic depression and mixed anxiety-depression symptoms. Personality and Individual Differences, 43(5), 1001-1012. https://doi.org/10.1016/j.paid.2007.02.021

Hunter, J. A., \& Schmidt, F. L. (2004). Methods of meta-analysis: Correcting error and bias in research findings (2nd ed.). Thousand Oaks, CA, CA: Sage.

* - Hur, J.-W., \& Kim, Y.-K. (2009). Comparison of clinical features and personality dimensions between patients with major depressive disorder and nonrmal control. Psychiatry Investigation, 6(3), 150. https://doi.org/10.4306/pi.2009.6.3.150

* - Iidaka, T., Matsumoto, A., Ozaki, N., Suzuki, T., Iwata, N., Yamamoto, Y., ... Sadato, N. (2006). Volume of left amygdala subregion predicted temperamental trait of harm avoidance in female young subjects. A voxel-based morphometry study. Brain Research, 1125(1), 85-93. https://doi.org/10.1016/j.brainres.2006.09.015

Insel, T., Cuthbert, B., Garvey, M., Heinssen, R., Pine, D. S., Quinn, K., ... Wang, P. (2010). Research Domain Criteria (RDoC): Toward a new classification framework for research on mental disorders. American Journal of Psychiatry, 167(7), 748-751. https://doi.org/10.1176/appi.ajp.2010.09091379

$\dagger$ - Izadpanah, S., Schumacher, M., \& Barnow, S. (2017). Anger rumination mediates the relationship between reinforcement sensitivity and psychopathology: Results of a 5-year longitudinal study. Personality and Individual Differences, 110, 49-54. https://doi.org/10.1016/j.paid.2017.01.023

* - Izci, F., Gültekin, B. K., Saglam, S., Koc, M. I., Zincir, S. B., \& Atmaca, M. (2014). Temperament, character traits, and alexithymia In patients with panic disorder. Neuropsychiatric disease and treatment, 10, 879-885. https://doi.org/ 10.2147/NDT.S62647

* - Jackson, C. J. (2009). Jackson-5 scales of revised Reinforcement Sensitivity Theory (r-RST) and their application to dysfunctional real world outcomes. Journal of Research in Personality, 43(4), 556-569. https://doi.org/10.1016/j.jrp.2009.02.007

Jacobson, N. C., \& Newman, M. G. (2017). Anxiety and depression as bidirectional risk factors for one another: A meta-analysis of longitudinal studies. Psychological Bulletin, 143(11), 1155-1200. https://doi.org/10.1037/bul0000111

Jak, S. (2015). Meta-Analytic Structural Equation Modelling. Cham: Springer International Publishing. https://doi.org/10.1007/978-3-319-27174-3

* - Jarmolowicz, D. P., Cherry, J. B. C., Reed, D. D., Bruce, J. M., Crespi, J. M., Lusk, J. L., \& Bruce, A. S. (2014). Robust relation between temporal discounting rates and body mass. Appetite, 78(PG-63-67), 63-67. https://doi.org/10.1016/j.appet.2014.02.013

* - Jiang, N., Sato, T., Hara, T., Takedomi, Y., Ozaki, I., \& Yamada, S. (2003). Correlations between trait anxiety, personality and fatigue study based on the temperament and character inventory. Journal of Psychosomatic Research, 55(6), 493500. https://doi.org/10.1016/S0022-3999(03)00021-7

* - Jiang, Y., \& Tiliopoulos, N. (2014). Individual differences in adult attachment and reinforcement sensitivity. Personality and Individual Differences, 68, 205-210. https://doi.org/10.1016/j.paid.2014.04.022

† - Jiménez-Murcia, S., Granero, R., Moragas, L., Steiger, H., Israel, M., Aymamí, N., ... Fernández-Aranda, F. (2015). Differences and similarities between bulimia nervosa, compulsive buying and gambling disorder. European Eating Disorders Review, 23(2), 111-118. https://doi.org/10.1002/erv.2340

* - Johnson, S. L., \& Carver, C. S. (2006). Extreme goal setting and vulnerability to mania among undiagnosed young adults. Cognitive Therapy and Research, 30(3), 377-395. https://doi.org/10.1007/s10608-006-9044-7

* - Johnson, S. L., Turner, R. J., \& Iwata, N. (2003). BIS/BAS levels and psychiatric disorder: An epidemiological study. Journal of Psychopathology and Behavioral Assessment, 25(1), 25-36. https://doi.org/10.1023/A:1022247919288

* - Jokela, M., \& Keltikangas-Järvinen, L. (2011). The association between low socioeconomic status and depressive symptoms depends on temperament and personality traits. Personality and Individual Differences, 51(3), 302-308. https://doi.org/10.1016/j.paid.2010.05.004

* - Jones, S., \& Day, C. (2008). Self appraisal and behavioural activation in the prediction of hypomanic personality and depressive symptoms. Personality and Individual Differences, 45(7), 643-648. https://doi.org/10.1016/j.paid.2008.07.008

$\uparrow$ - Jorm, A. F., Christensen, H., Henderson, A. S., Jacomb, P. A., Korten, A. E., \& Rodgers, B. (1998). Using the BIS/BAS scales to measure behavioural inhibition and behavioural acti-

NOTE: This is a postprint of the study Katz, B. A., Matanky, K., Aviram, G., \& Yovel, I. (2020). Reinforcement sensitivity, depression and anxiety: A meta-analysis and meta-analytic structural equation model. Clinical Psychology Review, 101842, doi: 
vation: Factor structure, validity and norms in a large community sample. Personality and Individual Differences, 26(1), 49-58. https://doi.org/10.1016/S0191-8869(98)00143-3

Jorm, A. F., Christensen, H., Henderson, A. S., Jacomb, P. A., Korten, A. E., \& Rodgers, B. (2000). Predicting anxiety and depression from personality: Is there a synergistic effect of neuroticism and extraversion? Journal of Abnormal Psychology, 109(1), 145-149. https://doi.org/10.1037/0021843X.109.1.145

* - Josefsson, A., Larsson, C., Sydsjö, G., \& Nylander, P.-O. (2007). Temperament and character in women with postpartum depression. Archives of Women's Mental Health, 10(1), 3-7. https://doi.org/10.1007/s00737-006-0159-3

* - Joyce, P. R., Light, K. J., Rowe, S. L., Cloninger, C. R., \& Kennedy, M. A. (2010). Self-mutilation and suicide attempts: Relationships to bipolar disorder, borderline personality disorder, temperament and character. Australian and New Zealand Journal of Psychiatry, 44(3), 250-257. https://doi.org/10.3109/00048670903487159

* - Jung, W. H., Kang, D. -H, Han, J. Y., Jang, J. H., Gu, B. -M, Choi, J. -S, ... Kwon, J. S. (2011). Aberrant ventral striatal responses during incentive processing in unmedicated patients with obsessive-compulsive disorder. Acta Psychiatrica Scandinavica, 123(5), 376-386. https://doi.org/10.1111/j.16000447.2010.01659.x

$\dagger$ - Jylhä, P., \& Isometsä, E. (2006). Temperament, character and symptoms of anxiety and depression in the general population. European Psychiatry, 21(6), 389-395. https://doi.org/10.1016/j.eurpsy.2005.09.003

* - Jylhä, P., Mantere, O., Melartin, T., Suominen, K., Vuorilehto, M., Arvilommi, P., ... Isometsä, E. (2011). Differences in temperament and character dimensions in patients with bipolar I or II or major depressive disorder and general population subjects. Psychological Medicine, 41(8), 1579-1591. https://doi.org/10.1017/S0033291710002606

* - Kambouropoulos, N., Egan, S., O’Connor, E. J., \& Staiger, P. K. (2014). Escaping threat: Understanding the importance of threat sensitivity in social anxiety. Journal of Individual Differences, 35(1), 47-53. https://doi.org/10.1027/1614$0001 / \mathrm{a} 000126$

* - Kaneda, A., Yasui-Furukori, N., Nakagami, T., Sato, Y., \& Kaneko, S. (2011). The influence of personality factors on paroxetine response time in patients with major depression. Journal of Affective Disorders, 135(1-3), 321-325. https://doi.org/10.1016/j.jad.2011.06.050

* - Kang, K. D., Han, D. H., Hannon, J. C., Hall, M. S., \& Choi, J. W. (2015). Temperamental predictive factors for success in korean professional baseball players. Psychiatry Investigation, 12(4), 459. https://doi.org/10.4306/pi.2015.12.4.459

* - Kasch, K. L., Rottenberg, J., Arnow, B. A., \& Gotlib, I. H. (2002). Behavioral activation and inhibition systems and the severity and course of depression. Journal of Abnormal Psychology, 111(4), 589-597. https://doi.org/10.1037/0021843X.111.4.589

* - Kashdan, T. B., \& Roberts, J. E. (2006). Affective outcomes in superficial and intimate interactions: Roles of social anxiety and curiosity. Journal of Research in Personality, 40(2), 140 167. https://doi.org/10.1016/j.jrp.2004.10.005

Katz, B. A., Breznitz, H., \& Yovel, I. (2019). Gain through pain: Augmenting in vivo exposure with enhanced attention to inter- nal experience leads to increased resilience to distress. Behaviour Research and Therapy, 113, 9-17. https://doi.org/10.1016/j.brat.2018.12.001

$\dagger$ - Katz, B. A., \& Yovel, I. (2018). A psychological mediation framework of reinforcement sensitivity. In Association For Behavioral and Cognitive Therapies 52nd Annual Convention. Washington, D.C.

Kazdin, A. E. (2007). Mediators and mechanisms of change in psychotherapy research. Annual Review of Clinical Psychology, 3(1), 1-27. https://doi.org/10.1146/annurev.clinpsy.3.022806.091432

Kendall, A. D., Zinbarg, R. E., Mineka, S., Bobova, L., Prenoveau, J. M., Revelle, W., \& Craske, M. G. (2015). Prospective associations of low positive emotionality with first onsets of depressive and anxiety disorders: Results from a 10-wave latent trait-state modeling study. Journal of Abnormal Psychology, 124(4), 933-943. https://doi.org/10.1037/abn0000105

* - Kerremans, A., Claes, L., \& Bijttebier, P. (2010). Disordered eating in adolescent males and females: Associations with temperament, emotional and behavioral problems and perceived self-competence. Personality and Individual Differences, 49(8), 955-960. https://doi.org/10.1016/j.paid.2010.08.003

Kessler, R. C., Chiu, W. T., Demler, O., \& Walters, E. E. (2005). Prevalence, severity, and comorbidity of 12-month DSM-IV disorders in the national comorbidity survey replication. Archives of General Psychiatry, 62(6), 617-627. https://doi.org/10.1001/archpsyc.62.6.617

* - Keune, P. M., Bostanov, V., Kotchoubey, B., \& Hautzinger, M. (2012). Mindfulness versus rumination and behavioral inhibition: A perspective from research on frontal brain asymmetry. Personality and Individual Differences, 53(3), 323328. https://doi.org/10.1016/j.paid.2012.03.034

Khan, A. A., Jacobson, K. C., Gardner, C. O., Prescott, C. A., \& Kendler, K. S. (2005). Personality and comorbidity of common psychiatric disorders. The British Journal of Psychiatry, 186(3), 190-196. https://doi.org/10.1192/bjp.186.3.190

Khazanov, G. K., \& Ruscio, A. M. (2016). Is low positive emotionality a specific risk factor for depression? A meta-analysis of longitudinal studies. Psychological Bulletin, 142(9), 9911015. https://doi.org/10.1037/bul0000059

* - Kim, S. J., Kang, J. I., \& Kim, C.-H. (2009). Temperament and character in subjects with obsessive-compulsive disorder. Comprehensive Psychiatry, 50(6), 567-572. https://doi.org/10.1016/j.comppsych.2008.11.009

* - Kim, S. W., \& Grant, J. E. (2001). Personality dimensions in pathological gambling disorder and obsessive-compulsive disorder. Psychiatry Research, 104(3), 205-212. https://doi.org/10.1016/S0165-1781(01)00327-4

Kimbrel, N. A. (2008). A model of the development and maintenance of generalized social phobia. Clinical Psychology Review, 28(4), 592-612. https://doi.org/10.1016/j.cpr.2007.08.003

* - Kimbrel, N. A., Cobb, A. R., Mitchell, J. T., Hundt, N. E., \& Nelson-Gray, R. O. (2008). Sensitivity to punishment and low maternal care account for the link between bulimic and social anxiety symptomology. Eating Behaviors, 9(2), 210-217. https://doi.org/10.1016/j.eatbeh.2007.09.005

Kimbrel, N. A., Mitchell, J. T., Hundt, N. E., Robertson, C. D., \& Nelson-Gray, R. O. (2012). BIS and BAS interact with per-

NOTE: This is a postprint of the study Katz, B. A., Matanky, K., Aviram, G., \& Yovel, I. (2020). Reinforcement sensitivity, depression and anxiety: A meta-analysis and meta-analytic structural equation model. Clinical Psychology Review, 101842, doi: 
ceived parental affectionless control to predict personality disorder symptomatology. Journal of Personality Disorders, 26(2), 203-212. https://doi.org/10.1521/pedi.2012.26.2.203

* - Kimbrel, N. A., Nelson-Gray, R. O., \& Mitchell, J. T. (2012). BIS, BAS, and bias: The role of personality and cognitive bias in social anxiety. Personality and Individual Differences, 52(3), 395-400. https://doi.org/10.1016/j.paid.2011.10.041

* - Kimura, S., Sato, T., Takahashi, T., Narita, T., Hirano, S., \& Goto, M. (2000). Typus melancholicus and the Temperament and Character Inventory personality dimensions in patients with major depression. Psychiatry and Clinical Neurosciences, 54(2), 181-189. https://doi.org/10.1046/j.14401819.2000.00656.x

* - Kircanski, K., Mazur, H., \& Gotlib, I. H. (2013). Behavioral activation system moderates self-referent processing following recovery from depression. Psychological Medicine, 43(9), 1909-1919. https://doi.org/10.1017/S0033291712002851

Kirk, R. E. (1995). Experimental design: Procedures for behavioral sciences (3rd ed.). Belmont, CA: Brooks/Cole.

Klein, D. N., Kotov, R., \& Bufferd, S. J. (2011). Personality and depression: Explanatory models and review of the evidence. Annual Review of Clinical Psychology, 7(1), 269-295. https://doi.org/10.1146/annurev-clinpsy-032210-104540

Kline, R. B. (2015). Principles and practices of structural equation modelling (4th ed.). New York, NY: The Guilford Press.

* - Knyazev, G. G., Bocharov, A. V, Slobodskaya, H. R., \& Ryabichenko, T. I. (2008). Personality-linked biases in perception of emotional facial expressions. Personality and Individual Differences, 44(5), 1093-1104.

https://doi.org/10.1016/j.paid.2007.11.001

* - Knyazev, G. G., Levin, E. A., \& Savostyanov, A. N. (2008). Impulsivity, anxiety, and individual differences in evoked and induced brain oscillations. International Journal of Psychophysiology, 68(3), 242-254. https://doi.org/10.1016/j.ijpsycho.2008.02.010

* - Knyazev, G. G., \& Slobodskaya, H. R. (2003). Personality trait of behavioral inhibition is associated with oscillatory systems reciprocal relationships. International Journal of Psychophysiology, 48(3), 247-261. https://doi.org/10.1016/S01678760(03)00072-2

Knyazev, G. G., Slobodskaya, H. R., \& Wilson, G. D. (2004). Comparison of the construct validity of the Gray-Wilson Personality Questionnaire and the BIS/BAS scales. Personality and Individual Differences, 37(8), 1565-1582. https://doi.org/10.1016/j.paid.2004.02.013

Knyazev, G. G., \& Wilson, G. D. (2004). The role of personality in the co-occurrence of emotional and conduct problems in adolescents: A confirmation of Corr's "joint subsystems" hypothesis. Personality and Individual Differences, 37(1), 4363. https://doi.org/10.1016/j.paid.2003.08.026

Kotov, R., Gamez, W., Schmidt, F., \& Watson, D. (2010). Linking "big" personality traits to anxiety, depressive, and substance use disorders: A meta-analysis. Psychological Bulletin, 136(5), 768-821. https://doi.org/10.1037/a0020327

Kotov, R., Krueger, R. F., Watson, D., Achenbach, T. M., Althoff, R. R., Bagby, R. M., ... Zimmerman, M. (2017). The Hierarchical Taxonomy of Psychopathology (HiTOP): A dimen- sional alternative to traditional nosologies. Journal of Abnormal Psychology, 126(4), 454-477.

https://doi.org/10.1037/abn0000258

* - Kramer, S., Rodriguez, B. F., \& Kertz, S. J. (2015). Predicting socially anxious group membership using reinforcement sensitivity theory. Personality and Individual Differences, 86, 474476. https://doi.org/10.1016/j.paid.2015.06.053

Krueger, R. F., Caspi, A., Moffitt, T. E., Silva, P. A., \& McGee, R. (1996). Personality traits are differentially linked to mental disorders: A multitrait-multidiagnosis study of an adolescent birth cohort. Journal of Abnormal Psychology, 105(3), 299312. https://doi.org/10.1037/0021-843X.105.3.299

Krueger, R. F., \& Markon, K. E. (2006). Reinterpreting comorbidity: A model-based approach to understanding and classifying psychopathology. Annual Review of Clinical Psychology, 2(1), 111-133. https://doi.org/10.1146/annurev.clinpsy.2.022305.095213

Krupić, D., Corr, P. J., Ručević, S., Križanić, V., \& Gračanin, A. (2016). Five reinforcement sensitivity theory (RST) of personality questionnaires: Comparison, validity and generalization. Personality and Individual Differences, 97, 19-24. https://doi.org/10.1016/j.paid.2016.03.012

Krupić, D., Gračanin, A., \& Corr, P. J. (2016). The evolution of the Behavioural Approach System (BAS): Cooperative and competitive resource acquisition strategies. Personality and Individual Differences, 94, 223-227. https://doi.org/10.1016/j.paid.2016.01.044

Kunisato, Y., Okamoto, Y., Ueda, K., Onoda, K., Okada, G., Yoshimura, S., ... Yamawaki, S. (2012). Effects of depression on reward-based decision making and variability of action in probabilistic learning. Journal of Behavior Therapy and Experimental Psychiatry, 43(4), 1088-1094. https://doi.org/10.1016/j.jbtep.2012.05.007

* - Kushner, M. G., Abrams, K., Thuras, P., \& Hanson, K. L. (2000). Individual differences predictive of drinking to manage anxiety among non-problem drinkers with panic disorder. Alcoholism: Clinical and Experimental Research, 24(4), 448458. https://doi.org/10.1111/j.1530-0277.2000.tb02011.x

* - Kusunoki, K., Sato, T., Taga, C., Yoshida, T., Komori, K., Narita, T., ... Ozaki, N. (2000). Low novelty-seeking differentiates obsessive-compulsive disorder from major depression. Acta Psychiatrica Scandinavica, 101(5), 403-405. https://doi.org/10.1034/j.1600-0447.2000.101005403.x

Lahey, B. B., Krueger, R. F., Rathouz, P. J., Waldman, I. D., \& Zald, D. H. (2017). A hierarchical causal taxonomy of psychopathology across the life span. Psychological Bulletin, 143(2), 142-186. https://doi.org/10.1037/bul0000069

* - Landman, A., Nieuwenhuys, A., \& Oudejans, R. R. D. (2016). The impact of personality traits and professional experience on police officers' shooting performance under pressure. Ergonomics, 59(7), 950-961.

* - Lee, S., Kim, S. J., Park, J. E., Cho, S.-J., Cho, I. H., \& Lee, Y. J. (2012). Biogenetic temperament and character in insomnia and depression. Journal of Psychosomatic Research, 72(5), 383-387. https://doi.org/10.1016/j.jpsychores.2012.01.016

Leen-Feldner, E. W., Zvolensky, M. J., Feldner, M. T., \& Lejuez, C. W. (2004). Behavioral inhibition: Relation to negative emo-

NOTE: This is a postprint of the study Katz, B. A., Matanky, K., Aviram, G., \& Yovel, I. (2020). Reinforcement sensitivity, depression and anxiety: A meta-analysis and meta-analytic structural equation model. Clinical Psychology Review, 101842, doi: 
tion regulation and reactivity. Personality and Individual Differences, 36, 1235-1247. https://doi.org/10.1016/S01918869(02)00113-7

* - Leikas, S., Lindeman, M., Roininen, K., \& Lähteenmäki, L. (2007). Food risk perceptions, gender, and individual differences in avoidance and approach motivation, intuitive and analytic thinking styles, and anxiety. Appetite, 48(2), 232-240. https://doi.org/10.1016/j.appet.2006.09.009

* - Lemaire, M., El-Hage, W., \& Frangou, S. (2014). Reappraising suppression: subjective and physiological correlates of experiential suppression in healthy adults. Frontiers in Psychology, 5. https://doi.org/10.3389/fpsyg.2014.00571

* - Lemogne, C., Bergouignan, L., Boni, C., Gorwood, P., Pélissolo, A., \& Fossati, P. (2009). Genetics and personality affect visual perspective in autobiographical memory. Consciousness and Cognition: An International Journal, 18(3), 823-830. https://doi.org/10.1016/j.concog.2009.04.002

* - Levinson, C. A., Rodebaugh, T. L., \& Frye, T. (2011). An examination of the factor, convergent, and discriminant validity of the Behavioral Inhibition System and Behavioral Activation System Scales. Journal of Psychopathology and Behavioral Assessment, 33(1), 87-100. https://doi.org/10.1007/s10862010-9202-9

* - Li, Y., Xu, Y., \& Chen, Z. (2015). Effects of the behavioral inhibition system (BIS), behavioral activation system (BAS), and emotion regulation on depression: A one-year follow-up study in Chinese adolescents. Psychiatry Research, 230(2), 287-293. https://doi.org/10.1016/j.psychres.2015.09.007

$\dagger$ - Liao, S.-C., Chen, I.-M., Tu, C.-Y., Hsu, C.-K., Ma, H.-M., Lee, M.-T., \& Huang, W.-L. (2017). Subsyndromal psychosomatic concepts and personality traits in community adults. Comprehensive Psychiatry, 75, 110-116. https://doi.org/10.1016/j.comppsych.2017.03.002

* - Lochner, C., Hemmings, S., Seedat, S., Kinnear, C. J., Schoeman, R., Annerbrink, K., ... Allgulander, C. (2007). Genetics and personality traits in patients with social anxiety disorder: A case-control study in South Africa. European Neuropsychopharmacology, 17(5), 321-327. https://doi.org/10.1016/j.euroneuro.2006.06.010

* - Lorian, C. N., \& Grisham, J. R. (2010). The safety bias: Riskavoidance and social anxiety pathology. Behaviour Change, 27(1), 29-41. https://doi.org/10.1375/bech.27.1.29

* - Lovallo, W. R., Enoch, M.-A., Yechiam, E., Glahn, D. C., Acheson, A., Sorocco, K. H., ... Goldman, D. (2014). Differential impact of serotonin transporter activity on temperament and behavior in persons with a family history of alcoholism in the Oklahoma family health patterns project. Alcoholism: Clinical and Experimental Research, 38(6), 1575-1581. https://doi.org/10.1111/acer.12412

* - Lövdahl, H., Bøen, E., Falkum, E., Hynnekleiv, T., \& Malt, U. F. (2010). Temperament and character in patients with bipolar II disorder and recurrent brief depression. Comprehensive Psychiatry, 51(6), 607-617. https://doi.org/10.1016/j.comppsych.2010.03.003

$\dagger$ - Lu, X., Chen, Z., Cui, X., Uji, M., Miyazaki, W., Oda, M., ... Katoh, T. (2012). Effects of temperament and character profiles on state and trait depression and anxiety: A prospective study of a Japanese youth population. Depression Research and Treatment, 2012, 1-8. https://doi.org/10.1155/2012/604684

* - Lyoo, I. K., Yoon, T., Kang, D. H., \& Kwon, J. S. (2003). Patterns of changes in temperament and character inventory scales in subjects with obsessive-compulsive disorder following a 4-month treatment. Acta Psychiatrica Scandinavica, 107(4), 298-304. https://doi.org/10.1034/j.16000447.2003.00054.x

* - Lyvers, M., Duric, N., \& Thorberg, F. A. (2014a). Caffeine use and alexithymia in university students. Journal of Psychoactive Drugs, 46(4), 340-346. https://doi.org/10.1080/02791072.2014.942043

$\dagger$ - Lyvers, M., Karantonis, J., Edwards, M. S., \& Thorberg, F. A. (2016). Traits associated with internet addiction in young adults: Potential risk factors. Addictive Behaviors Reports, 3, 56-60. https://doi.org/10.1016/j.abrep.2016.04.001

* - Lyvers, M., Lysychka, O., \& Thorberg, F. A. (2014b). Alexithymia and drinking in young adults: The role of alcohol-related intrusive thoughts. Personality and Individual Differences, 57, 70-73. https://doi.org/10.1016/j.paid.2013.09.021

* - Maack, D. J., Buchanan, E., \& Young, J. (2015). Development and psychometric investigation of an inventory to assess fight, flight, and freeze tendencies: The fight, flight, freeze questionnaire. Cognitive Behaviour Therapy, 44(2), 117-127. https://doi.org/10.1080/16506073.2014.972443

* - Maack, D. J., Tull, M. T., \& Gratz, K. L. (2012). Examining the incremental contribution of behavioral inhibition to generalized anxiety disorder relative to other Axis I disorders and cognitive-emotional vulnerabilities. Journal of Anxiety Disorders, 26(6), 689-695. https://doi.org/10.1016/j.janxdis.2012.05.005

MacAndrew, C., \& Steele, T. (1991). Gray's behavioral inhibition system: A psychometric examination. Personality and Individual Differences, 12(2), 157-171. https://doi.org/10.1016/01918869(91)90099-W

$\uparrow$ - Manfredi, C., Caselli, G., Rovetto, F., Rebecchi, D., Ruggiero, G. M., Sassaroli, S., \& Spada, M. M. (2011). Temperament and parental styles as predictors of ruminative brooding and worry. Personality and Individual Differences, 50(2), 186191. https://doi.org/10.1016/j.paid.2010.09.023

* - Mansell, W., Rigby, Z., Tai, S., \& Lowe, C. (2008). Do current beliefs predict hypomanic symptoms beyond personality style? Factor analysis of the Hypomanic Attitudes and Positive Predictions Inventory (HAPPI) and its association with hypomanic symptoms in a student population. Journal of Clinical Psychology, 64(4), 450-465. https://doi.org/10.1002/jclp.20455

* - Marchesi, C., Cantoni, A., Fontò, S., Giannelli, M. R., \& Maggini, C. (2006). The effect of temperament and character on response to selective serotonin reuptake inhibitors in panic disorder. Acta Psychiatrica Scandinavica, 114(3), 203-210. https://doi.org/10.1111/j.1600-0447.2006.00772.x

* - Mardaga, S., \& Hansenne, M. (2009). Autonomic aspect of emotional response in depressed patients: Relationships with personality. Neurophysiologie Clinique/Clinical Neurophysiology, 39(4-5), 209-216. https://doi.org/10.1016/j.neucli.2009.06.002

* - Mardaga, S., \& Iakimova, G. (2014). Neurocognitive processing of emotion facial expressions in individuals with selfreported depressive symptoms: The role of personality and anxiety. Neurophysiologie Clinique/Clinical Neurophysiology, 44(5), 447-455. https://doi.org/10.1016/j.neucli.2014.08.007

$\dagger$ - Markarian, S. A., Pickett, S. M., Deveson, D. F., \& Kanona, B. B. (2013). A model of BIS/BAS sensitivity, emotion regulation difficulties, and depression, anxiety, and stress symptoms

NOTE: This is a postprint of the study Katz, B. A., Matanky, K., Aviram, G., \& Yovel, I. (2020). Reinforcement sensitivity, depression and anxiety: A meta-analysis and meta-analytic structural equation model. Clinical Psychology Review, 101842, doi: 
in relation to sleep quality. Psychiatry Research, 210(1), 281286. https://doi.org/10.1016/j.psychres.2013.06.004

* - Marteinsdottir, I., Tillfors, M., Furmark, T., Anderberg, U. M., \& Ekselius, L. (2003). Personality dimensions measured by the Temperament and Character Inventory (TCI) in subjects with social phobia. Nordic Journal of Psychiatry, 57(1), 2935. https://doi.org/10.1080/08039480310000239

$\dagger$ - Matsudaira, T., \& Kitamura, T. (2006). Personality traits as risk factors of depression and anxiety among Japanese students. Journal of Clinical Psychology, 62(1), 97-109. https://doi.org/10.1002/jclp.20215

McNaughton, N., \& Corr, P. J. (2004). A two-dimensional neuropsychology of defense: Fear/anxiety and defensive distance. Neuroscience and Biobehavioral Reviews, 28(3), 285-305. https://doi.org/10.1016/j.neubiorev.2004.03.005

McNaughton, N., \& Corr, P. J. (2008). The neuropsychology of fear and anxiety: A foundation for Reinforcement Sensitivity Theory. In P. J. Corr (Ed.), The Reinforcement Sensitivity Theory of Personality (pp. 44-94). Cambridge: Cambridge University Press.

* - Meerkerk, G. J., van den Eijnden, R. J. J. M., Franken, I. H. A., \& Garretsen, H. F. L. (2010). Is compulsive internet use related to sensitivity to reward and punishment, and impulsivity? Computers in Human Behavior, 26(4), 729-735. https://doi.org/10.1016/j.chb.2010.01.009

* - Mertol, S., \& Alkın, T. (2012). Temperament and character dimensions of patients with adult separation anxiety disorder. Journal of Affective Disorders, 139(2), 199-203. https://doi.org/10.1016/j.jad.2012.02.034

Meyer, B., Johnson, S. L., \& Carver, C. S. (1999). Exploring behavioral activation and inhibition sensitivities among college students at risk for bipolar spectrum symptomatology. Journal of Psychopathology and Behavioral Assessment, 21(4), 275292. https://doi.org/10.1023/A:1022119414440

Meyer, T. D., \& Hofmann, B. U. (2005). Assessing the dysregulation of the behavioral activation system: The hypomanic personality scale and the BIS-BAS scales. Journal of Personality Assessment, 85(3), 318-324. https://doi.org/10.1207/s15327752jpa8503_08

Millgram, Y., Joormann, J., Huppert, J. D., Lampert, A., \& Tamir, M. (2019). Motivations to experience happiness or sadness in depression: Temporal stability and implications for coping with stress. Clinical Psychological Science, 7(1), 216770261879793. https://doi.org/10.1177/2167702618797937

* - Minaya, O., \& Fresán, A. (2009). Anxiety disorders comorbidity in first-episode depressed patients: Personality differences based on the Temperament and Character Inventory. Personality and Individual Differences, 47(5), 522-526. https://doi.org/10.1016/j.paid.2009.05.006

* - Minelli, A., Pedrini, L., Magni, L. R., \& Rotondo, A. (2009). Personality traits in an Italian sample: Relationship with anxiety and depression. Clinical Practice \& Epidemiology in Mental Health, 5(1), 26-30. https://doi.org/10.2174/1745017900905010026

* - Mitchell, J. T., \& Nelson-Gray, R. O. (2006). Attention-Deficit/Hyperactivity Disorder symptoms in adults: Relationship to Gray's Behavioral Approach System. Personality and Individual Differences, 40(4), 749-760. https://doi.org/10.1016/j.paid.2005.08.011

* - Mitsui, N., Asakura, S., Shimizu, Y., Fujii, Y., Kako, Y., Tanaka, T., ... Kusumi, I. (2013). Temperament and character profiles of Japanese university students with depressive episodes and ideas of suicide or self-harm: A PHQ-9 screening study. Comprehensive Psychiatry, 54(8), 1215-1221. https://doi.org/10.1016/j.comppsych.2013.05.014

* - Miyoshi, R., Matsuo, H., Takeda, R., Komatsu, H., Abe, H., \& Ishida, Y. (2016). Burnout in Japanese residents and its associations with temperament and character. Asian Journal of Psychiatry, 24, 5-9. https://doi.org/10.1016/j.ajp.2016.08.009

* - Mommersteeg, P. M. C., Denollet, J., Kavelaars, A., Geuze, E., Vermetten, E., \& Heijnen, C. J. (2011). Type D personality, temperament, and mental health in military personnel awaiting deployment. International Journal of Behavioral Medicine, 18(2), 131-138. https://doi.org/10.1007/s12529-010-9096-7

* - Mörtberg, E., Bejerot, S., \& Wistedt, A. Ä. (2007). Temperament and character dimensions in patients with social phobia: Patterns of change following treatments? Psychiatry Research, 152(1), 81-90. https://doi.org/10.1016/j.psychres.2006.10.003

* - Movius, H. L., \& Allen, J. J. B. (2005). Cardiac Vagal Tone, defensiveness, and motivational style. Biological Psychology, 68(2), 147-162. https://doi.org/10.1016/j.biopsycho.2004.03.019

* - Mueller, A., Claes, L., Mitchell, J. E., Faber, R. J., Fischer, J., $\&$ de Zwaan, M. (2011). Does compulsive buying differ between male and female students? Personality and Individual Differences, 50(8), 1309-1312. https://doi.org/10.1016/j.paid.2011.02.026

* - Mulder, R. T., Joyce, P. R., \& Cloninger, C. R. (1994). Temperament and early environment influence comorbidity and personality disorders in major depression. Comprehensive Psychiatry, 35(3), 225-233. https://doi.org/10.1016/0010440X(94)90195-3

* - Müller, J. M., \& Wytykowska, A. M. (2005). Psychometric properties and validation of a Polish adaptation of Carver and White's BIS/BAS scales. Personality and Individual Differences, 39(4), 795-805. https://doi.org/10.1016/j.paid.2005.03.006

* - Naito, M., Kijima, N., \& Kitamura, T. (2000). Temperament and Character Inventory (TCI) as predictors of depression among Japanese college students. Journal of Clinical Psychology, 56(12), 1579-1585. https://doi.org/10.1002/10974679(200012)56:12<1579::AID-8>3.0.CO;2-K

Naragon-Gainey, K., Gallagher, M. W., \& Brown, T. A. (2013). Stable "trait" variance of temperament as a predictor of the temporal course of depression and social phobia. Journal of Abnormal Psychology, 122(3), 611-623. https://doi.org/10.1037/a0032997

Naragon-Gainey, K., McMahon, T. P., \& Chacko, T. P. (2017). The structure of common emotion regulation strategies: A meta-analytic examination. Psychological Bulletin, 143(4), 384-427. https://doi.org/10.1037/bul0000093

Naragon-Gainey, K., \& Watson, D. (2014). Consensually defined facets of personality as prospective predictors of change in depression symptoms. Assessment, 21(4), 387-403. https://doi.org/10.1177/1073191114528030

Naragon-Gainey, K., Watson, D., \& Markon, K. E. (2009). Differential relations of depression and social anxiety symptoms to the facets of extraversion/positive emotionality. Journal of $A b$ normal Psychology, 118(2), 299-310. https://doi.org/10.1037/a0015637

Nawijn, L., van Zuiden, M., Frijling, J. L., Koch, S. B. J., Veltman, D. J., \& Olff, M. (2015). Reward functioning in PTSD:

NOTE: This is a postprint of the study Katz, B. A., Matanky, K., Aviram, G., \& Yovel, I. (2020). Reinforcement sensitivity, depression and anxiety: A meta-analysis and meta-analytic structural equation model. Clinical Psychology Review, 101842, doi: 
A systematic review exploring the mechanisms underlying anhedonia. Neuroscience \& Biobehavioral Reviews, 51, 189204. https://doi.org/10.1016/j.neubiorev.2015.01.019

* - Nery, F. G., Hatch, J. P., Nicoletti, M. A., Monkul, E. S., Najt, P., Matsuo, K., ... Soares, J. C. (2009). Temperament and character traits in major depressive disorder: Influence of mood state and recurrence of episodes. Depression and Anxiety, 26(4), 382-388. https://doi.org/10.1002/da.20478

* - Nicholls, J., Staiger, P. K., Williams, J. S., Richardson, B., \& Kambouropoulos, N. (2014). When social anxiety co-occurs with substance use: Does an impulsive social anxiety subtype explain this unexpected relationship? Psychiatry Research, 220(3), 909-914. https://doi.org/10.1016/j.psychres.2014.08.040

Nohe, C., Meier, L. L., Sonntag, K., \& Michel, A. (2014). The chicken or the egg ? A meta-analysis of panel studies of the relationship between work - family conflict. Journal of Applied Psychology, 100(2), 1-15. https://doi.org/10.1037/a0038012

Nolen-Hoeksema, S., \& Watkins, E. R. (2011). A heuristic for developing transdiagnostic models of psychopathology: Explaining multifinality and divergent trajectories. Perspectives on Psychological Science, 6(6), 589-609. https://doi.org/10.1177/1745691611419672

* - Norris, C. J., Larsen, J. T., Crawford, L. E., \& Cacioppo, J. T. (2011). Better (or worse) for some than others: Individual differences in the positivity offset and negativity bias. Journal of Research in Personality, 45(1), 100-111. https://doi.org/10.1016/j.jrp.2010.12.001

* - North, C. S., \& Cloninger, C. R. (2012). Personality and major depression among directly exposed survivors of the Oklahoma City bombing. Depression Research and Treatment, 2012, 16. https://doi.org/10.1155/2012/204741

* - Nowakowska, C., Strong, C. M., Santosa, C. M., Wang, P. W., \& Ketter, T. A. (2005). Temperamental commonalities and differences in euthymic mood disorder patients, creative controls, and healthy controls. Journal of Affective Disorders, 85(1-2), 207-215. https://doi.org/10.1016/j.jad.2003.11.012

Nusslock, R., Abramson, L. Y., Harmon-Jones, E., Alloy, L. B., \& Hogan, M. E. (2007). A goal-striving life event and the onset of hypomanic and depressive episodes and symptoms: Perspective from the Behavioral Approach System (BAS) dysregulation theory. Journal of Abnormal Psychology, 116(1 PG105-115), 105-115. https://doi.org/10.1037/0021843X.116.1.105

Nusslock, R., \& Alloy, L. B. (2017). Reward processing and mood-related symptoms: An RDoC and translational neuroscience perspective. Journal of Affective Disorders, 216, 3-16. https://doi.org/10.1016/j.jad.2017.02.001

* - Nyman, E., Miettunen, J., Freimer, N., Joukamaa, M., Mäki, P., Ekelund, J., ... Paunio, T. (2011). Impact of temperament on depression and anxiety symptoms and depressive disorder in a population-based birth cohort. Journal of Affective Disorders, 131(1-3), 393-397. https://doi.org/10.1016/j.jad.2010.12.008

* - O’Connor, E. J., Staiger, P. K., Kambouropoulos, N., \& Smillie, L. D. (2014). Pathways to social anxiety: The role of reinforcement sensitivities and emotion regulation. Psychiatry Research, 220(3), 915-920. https://doi.org/10.1016/j.psychres.2014.09.007

Olino, T. M., McMakin, D. L., \& Forbes, E. E. (2018). Toward an empirical multidimensional structure of anhedonia, reward sensitivity, and positive emotionality: An exploratory factor analytic study. Assessment, 25(6), 679-690. https://doi.org/10.1177/1073191116680291

* - Panayiotou, G., Karekla, M., \& Panayiotou, M. (2014). Direct and indirect predictors of social anxiety: The role of anxiety sensitivity, behavioral inhibition, experiential avoidance and self-consciousness. Comprehensive Psychiatry, 55(8), 18751882. https://doi.org/10.1016/j.comppsych.2014.08.045

$\dagger$ - Park, S. M., Park, Y. A., Lee, H. W., Jung, H. Y., Lee, J.-Y., \& Choi, J.-S. (2013). The effects of behavioral inhibition/approach system as predictors of Internet addiction in adolescents. Personality and Individual Differences, 54(1), 7-11. https://doi.org/10.1016/j.paid.2012.07.033

* - Peirson, A. R., \& Heuchert, J. W. (2001). The relationship between personality and mood: Comparison of the BDI and the TCI. Personality and Individual Differences, 30(3), 391-399. https://doi.org/10.1016/S0191-8869(00)00031-3

* - Perich, T., Manicavasagar, V., Mitchell, P. B., \& Ball, J. R. (2011). Mindfulness, response styles and dysfunctional attitudes in bipolar disorder. Journal of Affective Disorders, 134(1-3), 126-132. https://doi.org/10.1016/j.jad.2011.06.004

* - Perkins, A. M., Cooper, A., Abdelall, M., Smillie, L. D., \& Corr, P. J. (2010). Personality and defensive reactions: Fear, trait anxiety, and threat magnification. Journal of Personality, 78(3), 1071-1090. https://doi.org/10.1111/j.14676494.2010.00643.x

* - Perkins, A. M., \& Corr, P. J. (2006). Reactions to threat and personality: Psychometric differentiation of intensity and direction dimensions of human defensive behaviour. Behavioural Brain Research, 169(1), 21-28. https://doi.org/10.1016/j.bbr.2005.11.027

* - Perkins, A. M., Kemp, S. E., \& Corr, P. J. (2007). Fear and anxiety as separable emotions: An investigation of the revised reinforcement sensitivity theory of personality. Emotion, 7(2), 252-261. https://doi.org/10.1037/1528-3542.7.2.252

* - Pfohl, B., Black, D. W., Noyes, R., Kelley, M., \& Blum, N. (1990). A test of the tridimensional personality theory: Association with diagnosis and platelet imipramine binding in obsessive-compulsive disorder. Biological Psychiatry, 28(1), 41-46. https://doi.org/10.1016/0006-3223(90)90430-A

* - Pickett, S. M., Bardeen, J. R., \& Orcutt, H. K. (2011). Experiential avoidance as a moderator of the relationship between behavioral inhibition system sensitivity and posttraumatic stress symptoms. Journal of Anxiety Disorders, 25(8), 10381045. https://doi.org/10.1016/j.janxdis.2011.06.013

* - Pinciotti, C. M., Seligowski, A. V, \& Orcutt, H. K. (2017). Psychometric properties of the PACT Scale and relations with symptoms of PTSD. Psychological Trauma: Theory, Research, Practice, and Policy, 9(3), 362-369. https://doi.org/10.1037/tra0000206

* - Pinto-Meza, A., Caseras, X., Soler, J., Puigdemont, D., Pérez, V., \& Torrubia, R. (2006). Behavioural inhibition and behavioural activation systems in current and recovered major depression participants. Personality and Individual Differences, 40(2), 215-226. https://doi.org/10.1016/j.paid.2005.06.021

Piotrowska, P., Stride, C., Croft, S., \& Rowe, R. (2015). Socioeconomic status and antisocial behaviour among children and adolescents: A systematic review and meta-analysis. Clinical Psychology Review, 35, 47-55. https://doi.org/10.1016/j.cpr.2014.11.003

Polanin, J. R., Hennessy, E. A., \& Tanner-Smith, E. E. (2017). A review of meta-analysis packages in R. Journal of Educational

NOTE: This is a postprint of the study Katz, B. A., Matanky, K., Aviram, G., \& Yovel, I. (2020). Reinforcement sensitivity, depression and anxiety: A meta-analysis and meta-analytic structural equation model. Clinical Psychology Review, 101842, doi: 
and Behavioral Statistics, 42(2), 206-242. https://doi.org/10.3102/1076998616674315

Prochwicz, K., \& Gawęda, Ł. (2016). Depression and anxiety mediate the relationship between temperament and character and psychotic-like experiences in healthy subjects. Psychiatry Research, 246, 195-202. https://doi.org/10.1016/j.psychres.2016.09.037

* - Putman, P., van Peer, J., Maimari, I., \& van der Werff, S. (2010). EEG theta/beta ratio in relation to fear-modulated response-inhibition, attentional control, and affective traits. Biological Psychology, 83(2), 73-78. https://doi.org/10.1016/j.biopsycho.2009.10.008

R Core Team. (2017). R: A language and environment for statistical computing. Vienna, Australia: R Foundation for Statistical Computing. Retrieved from https://www.r-project.org/

Reba-Harrelson, L., Von Holle, A., Thornton, L. M., Klump, K. L., Berrettini, W. H., Brandt, H., ... Bulik, C. M. (2008). Features associated with diet pill use in individuals with eating disorders. Eating Behaviors, 9(1), 73-81. https://doi.org/10.1016/j.eatbeh.2007.04.001

* - Reimold, M., Batra, A., Knobel, A., Smolka, M. N., Zimmer, A., Mann, K., ... Heinz, A. (2008). Anxiety is associated with reduced central serotonin transporter availability in unmedicated patients with unipolar major depression: a [11C]DASB PET study, 13(6), 557,606-613. https://doi.org/10.1038/sj.mp.4002149

* - Richman, H., \& Frueh, B. C. (1997). Personality and PTSD II: Personality assessment of PTSD-diagnosed Vietnam veterans using the Cloninger Tridimensional Personality Questionnaire (TPQ). Depression and Anxiety, 6(2), 70-77. https://doi.org/10.1002/(SICI)1520-6394

* - Richter, J., Eisemann, M., \& Richter, G. (2000). Temperament and character during the course of uniploar depression among inpatients. European Archives of Psychiatry and Clinical Neuroscience, 250(1), 40-47. https://doi.org/10.1007/PL00007538

* - Richter, J., Polak, T., \& Eisenmann, M. (2003). Depressive mood and personality in terms of temperament and character among the normal population and depressive inpatients. Personality and Individual Differences, 35(4), 917-927. https://doi.org/10.1016/S0191-8869(02)00308-2

* - Richter, M. A., Summerfeldt, L. J., Joffe, R. T., \& Swinson, R. P. (1996). The Tridimensional Personality Questionnaire in obsessive-compulsive disorder. Psychiatry Research, 65(3), 185-188. https://doi.org/10.1016/S0165-1781(96)02944-7

Riketta, M. (2008). The causal relation between job attitudes and performance: A meta-analysis of panel studies. Journal of Applied Psychology, 93(2), 472-481. https://doi.org/10.1037/0021-9010.93.2.472

† - Rodríguez-Testal, J. F., Perona-Garcelán, S., Senín-Calderón, C., García-Jiménez, M. M., Álvarez-García, P., \& NúñezGaitán, M. C. (2016). Kretschmer revisited: Mental fatigue and ideas of reference: Contributions from reinforcement sensitivity theory. Revista de Psicopatología y Psicología Clínica, 2l(1), 35-43. https://doi.org/10.5944/rppc.vol.21.num.1.2016.16372

* - Rönnlund, M., Vestergren, P., Mäntylä, T., \& Nilsson, L.-G. (2011). Predictors of self-reported prospective and retrospective memory in a population-based sample of older adults. The
Journal of Genetic Psychology: Research and Theory on Human Development, 172(3), 266-284.

https://doi.org/10.1080/00221325.2010.538450

Rosenthal, R., \& DiMatteo, M. R. (2001). Meta-analysis: Recent developments in quantitative methods for literature reviews. Annual Review of Psychology, 52(1), 59-82. https://doi.org/10.1146/annurev.psych.52.1.59

Rosseel, Y. (2012). lavaan: An R package for structural equation modeling. Journal of Statistical Software, 48(2), 1-36. https://doi.org/10.18637/jss.v048.i02

$\dagger$ - Rubinart, M., Fornieles, A., \& Deus, J. (2017). The psychological impact of the Jesus prayer among non-conventional Catholics. Pastoral Psychology, 66(4), 487-504. https://doi.org/10.1007/s11089-017-0762-4

Ruscio, A. M., Seitchik, A. E., Gentes, E. L., Jones, J. D., \& Hallion, L. S. (2011). Perseverative thought: A robust predictor of response to emotional challenge in generalized anxiety disorder and major depressive disorder. Behaviour Research and Therapy, 49(12), 867-874. https://doi.org/10.1016/j.brat.2011.10.001

* - Rybakowski, F., Slopien, A., Zakrzewska, M., Hornowska, E., \& Rajewski, A. (2004). Temperament and Character Inventory (TCI) in adolescents with anorexia nervosa. Acta Neuropsychiatrica, 16(3), 169-174. https://doi.org/10.1111/j.09242708.2004.00073.x

$\dagger$ - Sanders, W., \& Abaied, J. (2015). Motivational systems and autonomic functioning: Overlapping and differential contributions to anhedonic depression and anxious arousal. Motivation and Emotion, 39(4), 602-612. https://doi.org/10.1007/s11031015-9470-5

* - Sasayama, D., Hori, H., Teraishi, T., Hattori, K., Ota, M., Matsuo, J., ... Kunugi, H. (2011). Difference in Temperament and Character Inventory scores between depressed patients with bipolar II and unipolar major depressive disorders. Journal of Affective Disorders, 132(3), 319-324. https://doi.org/10.1016/j.jad.2011.03.009

* - Sato, T., Hirano, S., Narita, T., Kusunoki, K., Kato, J., Goto, M., ... Uehara, T. (1999). Temperament and character inventory dimensions as a predictor of response to antidepressant treatment in major depression. Journal of Affective Disorders, 56(2-3), 153-161. https://doi.org/10.1016/S01650327(99)00047-6

* - Saviotti, F. M., Grandi, S., Savron, G., Ermentini, R., Bartolucci, G., Conti, S., \& Fava, G. A. (1991). Characterological traits of recovered patients with panic disorder and agoraphobia. Journal of Affective Disorders, 23(3), 113-117. https://doi.org/10.1016/0165-0327(91)90023-L

Schmidt, F. L., Oh, I.-S., \& Hayes, T. L. (2009). Fixed- versus random-effects models in meta-analysis: Model properties and an empirical comparison of differences in results. British Journal of Mathematical and Statistical Psychology, 62(1), 97128. https://doi.org/10.1348/000711007X255327

Schwarzer, G. (2007). Meta: An R package for meta-analysis. $R$ News, 7(no.3), 40-45.

$\uparrow$ - Scott-Parker, B., Watson, B., King, M. J., \& Hyde, M. K. (2012). The influence of sensitivity to reward and punishment, propensity for sensation seeking, depression, and anxiety on the risky behaviour of novice drivers: A path model. British Journal of Psychology, 103(2), 248-267. https://doi.org/10.1111/j.2044-8295.2011.02069.x

* - Segarra, P., Poy, R., López, R., \& Moltó, J. (2014). Characterizing Carver and White's BIS/BAS subscales using the Five

NOTE: This is a postprint of the study Katz, B. A., Matanky, K., Aviram, G., \& Yovel, I. (2020). Reinforcement sensitivity, depression and anxiety: A meta-analysis and meta-analytic structural equation model. Clinical Psychology Review, 101842, doi: 
Factor Model of personality. Personality and Individual Differences, 61-62, 18-23. https://doi.org/10.1016/j.paid.2013.12.027

Sellman, J. D., \& Joyce, P. R. (1996). Phobic disorders are associated with temperament in alcoholic men. Australian \& New Zealand Journal of Psychiatry, 30(1), 110-113. https://doi.org/10.3109/00048679609076078

Senín-Calderón, C., Perona-Garcelán, S., Fuentes-Márquez, S., \& Rodríguez-Testal, J. F. (2017). A mediation model for ideas of reference: The role of the gray model, self-consciousness, and emotional symptoms. Psychological Reports, 120(3), 443459. https://doi.org/10.1177/0033294117693593

* - Shachar, I., Aderka, I. M., \& Gilboa-Schechtman, E. (2014). The factor structure of the Liebowitz social anxiety scale for children and adolescents: Development of a brief version. Child Psychiatry \& Human Development, 45(3), 285-293. https://doi.org/10.1007/s10578-013-0398-2

Shankman, S. A., \& Klein, D. N. (2003). The relation between depression and anxiety: An evaluation of the tripartite, approachwithdrawal and valence-arousal models. Clinical Psychology Review, 23(4), 605-637. https://doi.org/10.1016/S02727358(03)00038-2

* - Sharma, A., Wolf, D. H., Ciric, R., Kable, J. W., Moore, T. M., Vandekar, S. N., ... Satterthwaite, T. D. (2017). Common dimensional reward deficits across mood and psychotic disorders: A connectome-wide association study. American Journal of Psychiatry, 174(7), 657-666. https://doi.org/10.1176/appi.ajp.2016.16070774

Siddaway, A. P., Taylor, P. J., \& Wood, A. M. (2018). Reconceptualizing anxiety as a continuum that ranges from high calmness to high anxiety: The joint importance of reducing distress and increasing well-being. Journal of Personality and Social Psychology, 114(2), 1-11. https://doi.org/10.1037/pspp0000128

* - Slessareva, E., \& Muraven, M. (2004). Sensitivity to punishment and self-control: the mediating role of emotion. Personality and Individual Differences, 36(2), 307-319. https://doi.org/10.1016/S0191-8869(03)00087-4

Slobodskaya, H. R. (2007). The associations among the Big Five, Behavioural Inhibition and Behavioural Approach systems and child and adolescent adjustment in Russia. Personality and Individual Differences, 43(4), 913-924. https://doi.org/10.1016/j.paid.2007.02.012

* - Smillie, L. D., Dalgleish, L. I., \& Jackson, C. J. (2007). Distinguishing between learning and motivation in behavioral tests of the Reinforcement Sensitivity Theory of Personality. Personality and Social Psychology Bulletin, 33(4), 476-489. https://doi.org/10.1177/0146167206296951

Smillie, L. D., Jackson, C. J., \& Dalgleish, L. I. (2006). Conceptual distinctions among Carver and White's (1994) BAS scales: A reward-reactivity versus trait impulsivity perspective. Personality and Individual Differences, 40(5), 10391050. https://doi.org/10.1016/j.paid.2005.10.012

* - Smith, D. J., Duffy, L., Stewart, M. E., Muir, W. J., \& Blackwood, D. H. R. (2005). High harm avoidance and low self-di- rectedness in euthymic young adults with recurrent, early-onset depression. Journal of Affective Disorders, 87(1), 83-89. https://doi.org/10.1016/j.jad.2005.03.014

Smits, D. J. M., \& Boeck, P. D. (2006). From BIS / BAS to the Big Five. European Journal of Personnality, 270(October 2004), 255-270. https://doi.org/10.1002/per.583

Sokol-Hessner, P., \& Rutledge, R. B. (2019). The psychological and neural basis of loss aversion. Current Directions in Psychological Science, 28(1), 20-27. https://doi.org/10.1177/0963721418806510

* - Soler, J., Vega, D., Elices, M., Feliu-Soler, A., Soto, À., Martín-Blanco, A., ... Pascual, J. C. (2014). Testing the reinforcement sensitivity theory in borderline personality disorder compared with major depression and healthy controls. Personality and Individual Differences, 61-62, 43-46. https://doi.org/10.1016/j.paid.2014.01.005

Spielberger, C. D., Gorsuch, R. L., Lushene, R., Vagg, P. R., \& Jacobs, G. A. (1983). Manual for the State-Trait Anxiety Inventory, STAI (Form Y). Palo Alto, CA: Mind Garden.

Stange, J. P., Shapero, B. G., Jager-Hyman, S., Grant, D. A., Abramson, L. Y., \& Alloy, L. B. (2013). Behavioral Approach System (BAS)-relevant cognitive styles in individuals with high versus moderate BAS sensitivity: A behavioral high-risk design. Cognitive Therapy and Research, 37(1), 139-149. https://doi.org/10.1007/s10608-012-9443-x

* - Stein, M. B., Chartier, M. J., Lizak, M. V, \& Jang, K. L. (2001). Familial aggregation of anxiety-related quantitative traits in generalized social phobia: Clues to understanding disorder heritability. American Journal of Medical Genetics, 105(1), 79-83. https://doi.org/10.1002/1096-8628

Sterne, J. A. ., Gavaghan, D., \& Egger, M. (2000). Publication and related bias in meta-analysis. Journal of Clinical Epidemiology, 53(11), 1119-1129. https://doi.org/10.1016/S08954356(00)00242-0

* - Stewart, M. E., Donaghey, C., Deary, I. J., \& Ebmeier, K. P. (2008). Suicidal thoughts in young people: Their frequency and relationships with personality factors. Personality and Individual Differences, 44(4), 809-820. https://doi.org/10.1016/j.paid.2007.10.018

* - Takahashi, M., Shirayama, Y., Muneoka, K., Suzuki, M., Sato, K., \& Hashimoto, K. (2013). Personality traits as risk factors for treatment-resistant depression. PLoS ONE, 8(5). https://doi.org/10.1371/journal.pone.0063756

* - Takahashi, Y., Ozaki, K., Roberts, B. W., \& Ando, J. (2012). Can low Behavioral Activation System predict depressive mood? An application of non-normal structural equation modeling. Japanese Psychological Research, 54(2), 170-181. https://doi.org/10.1111/j.1468-5884.2011.00492.x

* - Takahashi, Y., Roberts, B. W., Yamagata, S., \& Kijima, N. (2015). Personality traits show differential relations with anxiety and depression in a nonclinical sample. Psychologia: An

NOTE: This is a postprint of the study Katz, B. A., Matanky, K., Aviram, G., \& Yovel, I. (2020). Reinforcement sensitivity, depression and anxiety: A meta-analysis and meta-analytic structural equation model. Clinical Psychology Review, 101842, doi: 
International Journal of Psychological Sciences, 58(1), 15-26. https://doi.org/10.2117/psysoc.2015.15

$\dagger$ - Tanaka, E., Sakamoto, S., Kijima, N., \& Kitamura, T. (1998). Different personalities between depression and anxiety. Journal of Clinical Psychology, 54(8), 1043-1051. https://doi.org/10.1002/(SICI)1097-4679

$\dagger$ - Taubitz, L. E., Pedersen, W. S., \& Larson, C. L. (2015). BAS reward responsiveness: A unique predictor of positive psychological functioning. Personality and Individual Differences, 80, 107-112. https://doi.org/10.1016/j.paid.2015.02.029

* - Thierry, N., Willeit, M., Praschak-Rieder, N., Zill, P., Hornik, K., Neumeister, A., ... Kasper, S. (2004). Serotonin transporter promoter gene polymorphic region (5-HTTLPR) and personality in female patients with seasonal affective disorder and in healthy controls. European Neuropsychopharmacology, 14(1), 53-58. https://doi.org/10.1016/S0924-977X(03)00064-6

Torrubia, R., Avila, C., \& Caseras, X. (2008). Reinforcement sensitivity scales. In P. J. Corr (Ed.), The Reinforcement Sensitivity Theory of Personality. Cambridge: Cambridge University Press.

* - Torrubia, R., Ávila, C., Moltó, J., \& Caseras, X. (2001). The Sensitivity to Punishment and Sensitivity to Reward Questionnaire (SPSRQ) as a measure of Gray's anxiety and impulsivity dimensions. Personality and Individual Differences, 31(6), 837-862. https://doi.org/10.1016/S0191-8869(00)00183-5

Treadway, M. T., Bossaller, N. A., Shelton, R. C., \& Zald, D. H. (2012). Effort-based decision-making in major depressive disorder: A translational model of motivational anhedonia. Journal of Abnormal Psychology, 121(3), 553-558. https://doi.org/10.1037/a0028813

Trew, J. L. (2011). Exploring the roles of approach and avoidance in depression: an integrative model. Clinical Psychology Review, 31(7), 1156-1168. https://doi.org/10.1016/j.cpr.2011.07.007

* - Tse, W. S., Rochelle, T. L., \& Cheung, J. C. K. (2011). The relationship between personality, social functioning, and depression: A structural equation modeling analysis. International Journal of Psychology, 46(3), 234-240. https://doi.org/10.1080/00207594.2011.554553

* - Ubl, B., Kuehner, C., Kirsch, P., Ruttorf, M., Flor, H., \& Diener, C. (2015). Neural reward processing in individuals remitted from major depression. Psychological Medicine, 45(16), 3549-3558. https://doi.org/10.1017/S0033291715001452

Urosević, S., Abramson, L. Y., Harmon-Jones, E., \& Alloy, L. B. (2008). Dysregulation of the behavioral approach system (BAS) in bipolar spectrum disorders: review of theory and evidence. Clinical Psychology Review, 28(7), 1188-1205. https://doi.org/10.1016/j.cpr.2008.04.004

* - Uzieblo, K., Verschuere, B., \& Crombez, G. (2007). The Psychopathic Personality Inventory: Construct validity of the twofactor structure. Personality and Individual Differences, 43(4), 657-667. https://doi.org/10.1016/j.paid.2007.01.008

* - Van der Gucht, E., Morriss, R., Lancaster, G., Kinderman, P., \& Bentall, R. P. (2009). Psychological processes in bipolar affective disorder: negative cognitive style and reward processing. British Journal of Psychiatry, 194(2), 146-151. https://doi.org/10.1192/bjp.bp.107.047894

* - Van Meter, A. R., \& Youngstrom, E. A. (2015). A tale of two diatheses: Temperament, BIS, and BAS as risk factors for mood disorder. Journal of Affective Disorders, 180, 170-178. https://doi.org/10.1016/j.jad.2015.03.053

Vautier, S., \& Pohl, S. (2009). Do Balanced Scales Assess Bipolar Constructs? The Case of the STAI Scales. Psychological Assessment, 21(2), 187-193. https://doi.org/10.1037/a0015312

* - Vergara, C., \& Roberts, J. E. (2011). Motivation and goal orientation in vulnerability to depression. Cognition and Emotion, 25(7 PG-1281-1290), 1281-1290. https://doi.org/10.1080/02699931.2010.542743

* - Vervoort, L., Wolters, L. H., Hogendoorn, S. M., de Haan, E., Boer, F., \& Prins, P. J. M. (2010). Sensitivity of Gray's Behavioral Inhibition System in clinically anxious and non-anxious children and adolescents. Personality and Individual Differences. Vervoort, Leentje: University of Amsterdam, Department of Clinical Psychology, Roeterstraat 15, Amsterdam, Netherlands, 1018 WB, 1.vervoort@uva.nl: Elsevier Science. https://doi.org/10.1016/j.paid.2009.12.021

Viswesvaran, C., \& Ones, D. S. (1995). Theory testing: Combining psychometric meta-analysis and structural equations modeling THEORY TESTING: COMBINING PSYCHOMETRIC META-ANALYSIS AND STRUCTURAL EQUATIONS MODELING. Personnel Psychology, 48(4), 865-885. https://doi.org/10.1111/j.1744-6570.1995.tb01784.x

* - Voth, E. M., Claes, L., Georgiadou, E., Selle, J., Trotzke, P., Brand, M., ... Muller, A. (2014). Reactive and regulative temperament in patients with compulsive buying and non-clinical controls measured by self-report and performance-based tasks, 55(7 PG-1505-12), 1505-1512.

https://doi.org/10.1016/j.comppsych.2014.05.011

* - Wachleski, C., Salum, G. A., Blaya, C., Kipper, L., Paludo, A., Salgado, A. P., \& Manfro, G. G. (2008). Harm avoidance and self-directedness as essential features of panic disorder patients. Comprehensive Psychiatry, 49(5 PG-476-481), 476481. https://doi.org/10.1016/j.comppsych.2008.03.003

* - Wagener, A., Baeyens, C., \& Blairy, S. (2016). Depressive symptomatology and the influence of the behavioral avoidance and activation: A gender-specific investigation. Journal of Affective Disorders, 193(PG-123-129), 123-129. https://doi.org/10.1016/j.jad.2015.12.040

* - Wang, J., Qin, W., Liu, B., Zhou, Y., Wang, D., Zhang, Y., ... Yu, C. (2014). Neural mechanisms of oxytocin receptor gene mediating anxiety-related temperament. Brain Structure \& Function, 219(5 PG-1543-1554), 1543-1554. https://doi.org/10.1007/s00429-013-0584-9

* - Wang, S., Mason, J., Charney, D., \& Yehuda, R. (1997). Relationships between hormonal profile and novelty seeking in combat-related posttraumatic stress disorder. Biological Psychiatry, 41(2 PG-145-151), 145-151. https://doi.org/10.1016/S0006-3223(95)00648-6

Watkins, E. R. (2008). Constructive and unconstructive repetitive thought. Psychological Bulletin, 134(2), 163-206. https://doi.org/http://dx.doi.org/10.1037/0033-2909.134.2.163

Watson, D. (2004). Stability versus change, dependability versus error: Issues in the assessment of personality over time. Journal of Research in Personality, 38(4), 319-350, 10.1016/j.jrp.2004.03.001

Watson, D. (2009). Differentiating the Mood and Anxiety Disorders: A Quadripartite Model. Annual Review of Clinical Psychology, 5(1), 221-247. https://doi.org/10.1146/annurev.clinpsy.032408.153510

Watson, D., Clark, L. a., \& Tellegen, A. (1988). Development and validation of brief measures of positive and negative affect:

NOTE: This is a postprint of the study Katz, B. A., Matanky, K., Aviram, G., \& Yovel, I. (2020). Reinforcement sensitivity, depression and anxiety: A meta-analysis and meta-analytic structural equation model. Clinical Psychology Review, 101842, doi: 
The PANAS scales. Journal of Personality and Social Psychology, 54(6), 1063-1070. https://doi.org/10.1037//00223514.54.6.1063

Watson, D., Clark, L. A., Weber, K., Assenheimer, J. S., Strauss, M. E., \& McCormick, R. A. (1995). Testing a tripartite model: II. Exploring the symptom structure of anxiety and depression in student, adult, and patient samples. Journal of Abnormal Psychology, 104(1), 3-14. https://doi.org/10.1037/0021843X.104.1.3

Watson, D., \& Naragon-Gainey, K. (2010). On the specificity of positive emotional dysfunction in psychopathology: Evidence from the mood and anxiety disorders and schizophrenia/schizotypy. Clinical Psychology Review, 30(7), 839-848. https://doi.org/10.1016/j.cpr.2009.11.002

Watson, D., Stasik, S. M., Ellickson-Larew, S., \& Stanton, K. (2015). Extraversion and psychopathology: A facet-level analysis. Journal of Abnormal Psychology, 124(2), 432-446. https://doi.org/10.1037/abn0000051

Watson, D., Weber, K., Assenheimer, J. S., Clark, L. A., Strauss, M. E., \& McCormick, R. A. (1995). Testing a tripartite model: I. Evaluating the convergent and discriminant validity of anxiety and depression symptom scales. Journal of Abnormal Psychology, 104(1), 3-14. https://doi.org/10.1037/0021843X.104.1.3

* - Westlye, L. T., Bjørnebekk, A., Grydeland, H., Fjell, A. M., \& Walhovd, K. B. (2011). Linking an anxiety-related personality trait to brain white matter microstructure: Diffusion tensor imaging and Harm Avoidance. Archives of General Psychiatry, 68(4), 369-377. https://doi.org/10.1001/archgenpsychiatry. 2011.24

* - Wiborg, I. M., Falkum, E., Dahl, A. A., \& Gullberg, C. (2005). Is harm avoidance an essential feature of patients with panic disorder? Comprehensive Psychiatry, 46(4), 311-314. https://doi.org/10.1016/j.comppsych.2004.08.009

$\dagger$ - Wichelns, G. A., Renna, M. E., \& Mennin, D. S. (2016). Preliminary validation of subjective anchor scales for worry and rumination. Cognitive Therapy and Research, 40(5), 645-660. https://doi.org/10.1007/s10608-016-9779-8

Widiger, T. A., Sellbom, M., Chmielewski, M., Clark, L. A., DeYoung, C. G., Kotov, R., ... Wright, A. G. C. (2018). Personality in a Hierarchical Model of Psychopathology. Clinical Psychological Science, 216770261879710. https://doi.org/10.1177/2167702618797105

* - Windle, M. (1994). Temperamental inhibition and activation: Hormonal and psychosocial correlates and associated psychiatric disorders. Personality and Individual Differences, 17(1), 61-70. https://doi.org/10.1016/0191-8869(94)90262-3

Wothke, W. (1993). Nonpositive definite matrices in strucutral modeling. In Testing structural equation models (pp. 256293). Newbury Park, CA: Sage.

Wright, N. E., Scerpella, D., \& Lisdahl, K. M. (2016). Marijuana use is associated with behavioral approach and depressive symptoms in adolescents and emerging adults. PLOS ONE, 11(11), e0166005. https://doi.org/10.1371/journal.pone. 0166005

* - Wu, P.-J., Chang, S.-M., Lu, M.-K., Chen, W. J., Yang, Y.-K., Tzung-LiehYeh, ... Kuo, P.-H. (2012). The profile and familiality of personality traits in mood disorder families. Journal of
Affective Disorders, 138(3), 367-374. https://doi.org/10.1016/j.jad.2012.01.015

* - Wytykowska, A., Fajkowska, M., Domaradzka, E., \& Jankowski, K. S. (2017). Construct validity of the Polish version of the reinforcement sensitivity theory-personality questionnaire. Personality and Individual Differences, 109, 172-180. https://doi.org/10.1016/j.paid.2016.12.054

* - Yen, J.-Y., Yen, C.-F., Chen, C.-S., Wang, P.-W., Chang, Y.H., \& Ko, C.-H. (2012). Social anxiety in online and real-life interaction and their associated factors. Cyberpsychology, Behavior, and Social Networking, 15(1 PG-7-12), 7-12. https://doi.org/10.1089/cyber.2011.0015

* - Young, L. T., Bagby, R. M., Cooke, R. G., Parker, J. D. A., Levitt, A. J., \& Joffe, R. T. (1995). A comparison of Tridimensional Personality Questionnaire dimensions in bipolar disorder and unipolar depression. Psychiatry Research, $58(2$ PG-139-143), 139-143. https://doi.org/10.1016/01651781(95)02684-O

Zald, D. H., \& Treadway, M. T. (2017). Reward Processing, Neuroeconomics, and Psychopathology. Annual Review of Clinical Psychology, 13(1), 471-495. https://doi.org/10.1146/annurevclinpsy-032816-044957

Zaninotto, L., Solmi, M., Toffanin, T., Veronese, N., Cloninger, C. R., \& Correll, C. U. (2016). A meta-analysis of temperament and character dimensions in patients with mood disorders: Comparison to healthy controls and unaffected siblings. Journal of Affective Disorders, 194(January), 84-97. https://doi.org/10.1016/j.jad.2015.12.077

* - Zaninotto, L., Souery, D., Calati, R., Di Nicola, M., Montgomery, S., Kasper, S., ... Janiri, L. (2015). Temperament and character profiles in bipolar I, bipolar II and major depressive disorder: Impact over illness course, comorbidity pattern and psychopathological features of depression. Journal of Affective Disorders, 184(PG-51-59), 51-59.

https://doi.org/10.1016/j.jad.2015.05.036

* - Zhao, J., Cheng, J., Harris, M., \& Vigo, R. (2015). Anxiety and intertemporal decision making: The effect of the behavioral inhibition system and the moderation effects of trait anxiety on both state anxiety and socioeconomic status. Personality and Individual Differences, 87(PG-236-241), 236-241. https://doi.org/10.1016/j.paid.2015.08.018

* - Zhao, J., Harris, M., \& Vigo, R. (2016). Anxiety and moral judgment: The shared deontological tendency of the behavioral inhibition system and the unique utilitarian tendency of trait anxiety. Personality and Individual Differences, 95(PG29-33), 29-33. https://doi.org/10.1016/j.paid.2016.02.024

Zinbarg, R. E., \& Yoon, K. L. (2008). RST and clinical disorders: Anxiety and depression. In P. J. Corr (Ed.), The Reinforcement Sensitivity Theory of Personality (pp. 360-397). Cambridge: Cambridge University Press.

* - Zvolensky, M. J., Feldner, M. T., Eifert, G. H., \& Stewart, S. H. (2001). Evaluating differential predictions of emotional reactivity during repeated $20 \%$ carbon dioxide-enriched air challenge. Cognition \& Emotion, 15(6), 767-786. https://doi.org/10.1080/02699930143000284

Zvolensky, M. J., Vujanovic, a. a., Bernstein, a., \& Leyro, T. (2010). Distress tolerance: Theory, measurement, and relations to psychopathology. Current Directions in Psychological Science, 19(6), 406-410. https://doi.org/10.1177/096372141038

NOTE: This is a postprint of the study Katz, B. A., Matanky, K., Aviram, G., \& Yovel, I. (2020). Reinforcement sensitivity, depression and anxiety: A meta-analysis and meta-analytic structural equation model. Clinical Psychology Review, 101842, doi: 
Table 1. Studies on the bivariate relationships between reinforcement sensitivity, depression and anxiety (Study 1)

\begin{tabular}{|c|c|c|c|c|c|c|c|c|c|c|c|c|}
\hline ID_Text & $\mathrm{N}$ & $\begin{array}{l}\text { Perc } \\
\text { Wom }\end{array}$ & Age & $\begin{array}{l}\text { Disorder } \\
\text { cluster }\end{array}$ & Clinical status & RST Scales & $\begin{array}{l}\text { Pub sta- } \\
\text { tus }\end{array}$ & $\begin{array}{l}\text { Data } \\
\text { type }\end{array}$ & $\begin{array}{c}g \\
\text { BAS }\end{array}$ & $\begin{array}{c}v g \\
\text { BAS }\end{array}$ & $\begin{array}{c}g \\
\text { BIS }\end{array}$ & $\begin{array}{l}v g \\
\text { BIS }\end{array}$ \\
\hline Aarts et al. (2010) & 32 & .88 & 18.81 & Anxiety & Healthy & BIS/BAS & $\mathrm{Y}$ & $d$ & .13 & .12 & .84 & .13 \\
\hline $\begin{array}{l}\text { Abbate-Daga et al. } \\
\text { (2014) }\end{array}$ & 59 & 1.00 & 25.08 & Depression & Healthy & TCI & $\mathrm{N}$ & $r$ & .23 & .07 & 1.13 & .08 \\
\hline Alfimova et al. (2014) & 266 & .59 & 30.80 & Depression & Healthy & TCI-HA & $\mathrm{Y}$ & $r$ & NA & NA & 1.00 & .02 \\
\hline \multirow[t]{2}{*}{ Alonso et al., (2008) } & 76 & .37 & 32.30 & Anxiety & Outpatients & TCI & $\mathrm{Y}$ & $d$ & -.85 & .06 & 1.71 & .07 \\
\hline & 44 & .41 & 30.70 & Anxiety & Episode/Acute & $\mathrm{TCI}$ & $\mathrm{Y}$ & $d$ & -.70 & .09 & 2.52 & .16 \\
\hline Ammerman et al. (2016) & 1,912 & .63 & 20.89 & Depression & Healthy & SPSRQ & $\mathrm{Y}$ & $r$ & .39 & .00 & .75 & .00 \\
\hline Applegate et al. (2009) & 516 & .66 & 21.75 & Depression & Healthy & BIS/BAS & $\mathrm{Y}$ & $r$ & -.45 & .01 & .41 & .01 \\
\hline Avila et al. (2001) & 45 & 1.00 & 19.02 & Anxiety & Healthy & SPSRQ & $\mathrm{Y}$ & $r$ & -.06 & .09 & 1.08 & .10 \\
\hline Baggio et al. (2015) & 4,778 & .00 & 20.00 & Depression & Healthy & BIS/BAS & $\mathrm{N}$ & $r$ & .05 & .00 & -.43 & .00 \\
\hline Bajraktarov et al. (2017) & 40 & NA & NA & Depression & Episode/Acute & TCI & $\mathrm{Y}$ & $d$ & -1.01 & .11 & 1.96 & .14 \\
\hline Balsamo (2013) & 230 & .90 & 20.90 & Depression & Healthy & TCI-R & $\mathrm{Y}$ & $r$ & -.19 & .02 & -.32 & .02 \\
\hline \multirow[t]{2}{*}{ Battaglia et al. (1996) } & 68 & .63 & 36.10 & Other & Remission & TPQ & $\mathrm{Y}$ & $d$ & .17 & .07 & 1.08 & .08 \\
\hline & 71 & .63 & 36.10 & Anxiety & Remission & TPQ & $\mathrm{Y}$ & $d$ & .44 & .07 & 1.21 & .08 \\
\hline Battaglia et al. (1998) & 63 & 1.00 & 34.60 & Anxiety & Remission & TPQ & $\mathrm{Y}$ & $d$ & .08 & .07 & 1.08 & .08 \\
\hline Bensaeed et al. (2014) & 167 & .54 & 33.80 & Depression & Remission & TCI & $\mathrm{Y}$ & $d$ & -.57 & .03 & .24 & .03 \\
\hline Bergdahl et al. (2003) & 74 & .84 & NA & Anxiety & Episode/Acute & TCI & $\mathrm{Y}$ & $d$ & .87 & .06 & -.19 & .05 \\
\hline Berger et al. (2014) & 314 & .54 & 33.70 & Anxiety & Healthy & BIS/BAS-BIS & $\mathrm{Y}$ & $r$ & NA & NA & -.77 & .01 \\
\hline Bey et al. (2017) & 326 & .60 & 33.60 & Anxiety & Episode/Acute & TCI-HA & $\mathrm{Y}$ & $d$ & NA & NA & 4.28 & .04 \\
\hline
\end{tabular}




\begin{tabular}{|c|c|c|c|c|c|c|c|c|c|c|c|c|}
\hline ID_Text & $\mathrm{N}$ & $\begin{array}{l}\text { Perc } \\
\text { Wom }\end{array}$ & Age & $\begin{array}{l}\text { Disorder } \\
\text { cluster }\end{array}$ & Clinical status & RST Scales & $\begin{array}{l}\text { Pub sta- } \\
\text { tus }\end{array}$ & $\begin{array}{l}\text { Data } \\
\text { type }\end{array}$ & $\begin{array}{c}g \\
\text { BAS }\end{array}$ & $\begin{array}{c}v g \\
\text { BAS }\end{array}$ & $\begin{array}{c}g \\
\text { BIS }\end{array}$ & $\begin{array}{l}v g \\
\text { BIS }\end{array}$ \\
\hline Bodas et al. (2017) & 385 & .52 & 40.60 & Anxiety & Healthy & BIS/BAS & $\mathrm{Y}$ & $r$ & .04 & .01 & .89 & .01 \\
\hline Booth et al. (2009) & 454 & .80 & 21.40 & Anxiety & Healthy & BIS/BAS & $\mathrm{Y}$ & $r$ & -.35 & .01 & .64 & .01 \\
\hline $\begin{array}{l}\text { Borgomaneri et al. } \\
\text { (2017) }\end{array}$ & 26 & .42 & 23.20 & Anxiety & Healthy & BIS/BAS & $\mathrm{N}$ & $r$ & .28 & .15 & .39 & .15 \\
\hline Brailean et al. (2014) & 85 & NA & NA & Depression & Episode/Acute & BIS/BAS & $\mathrm{Y}$ & $d$ & -.50 & .05 & .76 & .05 \\
\hline Brown et al. (1992) & 1,060 & .51 & 44.90 & Other & Outpatients & TPQ & $\mathrm{Y}$ & $d$ & .48 & .03 & 1.80 & .03 \\
\hline Buchman et al. (2014) & 40 & NA & 80.40 & Depression & Healthy & TCI-HA & $\mathrm{Y}$ & $r$ & NA & NA & .81 & .10 \\
\hline $\begin{array}{l}\text { Carver et al. (2009); } \\
\text { Study } 1\end{array}$ & 235 & .57 & 19.50 & Depression & Healthy & BIS/BAS & $\mathrm{Y}$ & $r$ & .06 & .02 & .41 & .02 \\
\hline $\begin{array}{l}\text { Carver et al. (2009); } \\
\text { Study } 2\end{array}$ & 394 & .67 & 19.50 & Depression & Healthy & BIS/BAS & $\mathrm{Y}$ & $r$ & .11 & .01 & .45 & .01 \\
\hline Caseras et al. (2003) & 538 & .78 & 19.94 & Anxiety & Healthy & $\begin{array}{c}\text { TPQ; SPSRQ; } \\
\text { BIS/BAS; } \\
\text { GRAPES; } \\
\text { MS-BIS }\end{array}$ & $\mathrm{Y}$ & $r$ & -.27 & .01 & 1.34 & .01 \\
\hline Celikel et al. (2009) & 132 & .77 & 31.39 & Depression & Outpatients & TCI & $\mathrm{Y}$ & $d$ & -.67 & .03 & 1.11 & .04 \\
\hline Chang et al. (2013) & 932 & .49 & 40.26 & Depression & Remission & TPQ & $\mathrm{Y}$ & $d$ & -.10 & .00 & .05 & .00 \\
\hline Chang et al. (2013a) & 250 & .58 & 37.66 & Anxiety & Outpatients & TPQ & $\mathrm{Y}$ & $d$ & -.17 & .03 & .78 & .03 \\
\hline Chang et al. (2013b) & 224 & .41 & NA & Anxiety & Episode/Acute & TPQ & $\mathrm{Y}$ & $d$ & .29 & .04 & .56 & .04 \\
\hline Chatterjee et al. (1997) & 40 & .00 & 27.10 & Anxiety & Episode/Acute & TCI & $\mathrm{Y}$ & $d$ & -1.65 & .13 & 4.15 & .31 \\
\hline Chen et al. (2011) & 469 & .50 & 41.70 & Depression & Healthy & TCI & $\mathrm{Y}$ & $r$ & .05 & .01 & -.61 & .01 \\
\hline Cheung et al. (2006) & 74 & .65 & 74.80 & Depression & Episode/Acute & TCI-HA & $\mathrm{Y}$ & $d$ & NA & NA & .67 & .06 \\
\hline Claes et al. (2011) & 211 & 1.00 & 22.56 & Depression & Healthy & BIS/BAS & $\mathrm{N}$ & $r$ & .37 & .02 & .48 & .02 \\
\hline
\end{tabular}




\begin{tabular}{|c|c|c|c|c|c|c|c|c|c|c|c|c|}
\hline ID_Text & $\mathrm{N}$ & $\begin{array}{l}\text { Perc } \\
\text { Wom }\end{array}$ & Age & $\begin{array}{l}\text { Disorder } \\
\text { cluster }\end{array}$ & Clinical status & RST Scales & $\begin{array}{l}\text { Pub sta- } \\
\text { tus }\end{array}$ & $\begin{array}{l}\text { Data } \\
\text { type }\end{array}$ & $\begin{array}{l}g \\
\text { BAS }\end{array}$ & $\begin{array}{l}v g \\
\text { BAS }\end{array}$ & $\begin{array}{c}g \\
\text { BIS }\end{array}$ & $\begin{array}{l}v g \\
\text { BIS }\end{array}$ \\
\hline Cloninger et al. (1998) & 804 & .57 & 46.00 & Depression & Healthy & TCI & $\mathrm{Y}$ & $r$ & -.12 & .00 & 1.12 & .01 \\
\hline Contractor et al. (2013) & 308 & .64 & 42.51 & Anxiety & Healthy & SPSRQ & Y & $r$ & .26 & .01 & .69 & .01 \\
\hline Cooper et al. (2008) & 327 & .66 & 21.86 & Anxiety & Healthy & SPSRQ-S & $\mathrm{Y}$ & $r$ & -.02 & .01 & 2.07 & .02 \\
\hline Cooper et al. (2014) & 38 & .47 & 24.39 & Depression & Healthy & BIS/BAS & $\mathrm{Y}$ & $r$ & .05 & .10 & .04 & .10 \\
\hline Corr et al. (2016) & 362 & .76 & 23.34 & Anxiety & Healthy & RST-PQ & Y & $r$ & .04 & .01 & .91 & .01 \\
\hline \multirow[t]{2}{*}{ Cowley et al. (1993) } & 29 & NA & 30.42 & Anxiety & Episode/Acute & TPQ & Y & $d$ & -.62 & .15 & 1.34 & .17 \\
\hline & 22 & NA & 32.53 & Anxiety & Episode/Acute & TPQ & Y & $d$ & -.33 & .17 & 1.52 & .22 \\
\hline Cremers et al. (2015) & 40 & .45 & 28.40 & Anxiety & Episode/Acute & $\begin{array}{c}\text { BIS/BAS-BIS, } \\
\text { RR }\end{array}$ & Y & $d$ & -.38 & .10 & 1.59 & .13 \\
\hline $\begin{array}{l}\text { Cruz-Fuentes et al. } \\
\text { (2004) }\end{array}$ & 108 & .57 & 34.00 & Anxiety & Episode/Acute & TCI & Y & $d$ & -.61 & .04 & 1.36 & .05 \\
\hline Dalbudak et al. (2013) & 319 & .73 & 21.29 & Anxiety & Episode/Acute & TCI & Y & $d$ & -.14 & .02 & .52 & .02 \\
\hline Davenport et al. (2012) & 134 & 1.00 & 22.00 & Anxiety & Healthy & SPSRQ-SR & Y & $r$ & .65 & .03 & NA & NA \\
\hline $\begin{array}{l}\text { de la Torre-Luque et al. } \\
\text { (2016) }\end{array}$ & 50 & .62 & 13.00 & Anxiety & Episode/Acute & SPSRQ-J & Y & $d$ & NA & NA & 2.40 & .14 \\
\hline $\begin{array}{l}\text { DelDonno et al. (2015); } \\
\text { Study } 1\end{array}$ & 54 & .76 & 28.98 & Depression & Episode/Acute & $\begin{array}{l}\text { BIS/BAS- } \\
\text { BIS,RR,D }\end{array}$ & $\mathrm{Y}$ & $d$ & -1.34 & .09 & 1.91 & .11 \\
\hline $\begin{array}{l}\text { DelDonno et al. (2015); } \\
\text { Study } 2\end{array}$ & 60 & .63 & 21.25 & Depression & Remission & $\begin{array}{l}\text { BIS/BAS- } \\
\text { BIS,RR,D }\end{array}$ & Y & $d$ & -.10 & .07 & .13 & .07 \\
\hline De Pascalis et al. (2013) & 51 & 1.00 & 24.60 & Anxiety & Healthy & BIS/BAS & $\mathrm{Y}$ & $r$ & .28 & .08 & 1.16 & .09 \\
\hline Dennis (2007) & 36 & .72 & 21.42 & Anxiety & Healthy & BIS/BAS-BIS & $\mathrm{Y}$ & $r$ & NA & NA & 1.81 & .15 \\
\hline Derntl et al. (2011) & 30 & .60 & 33.50 & Depression & Episode/Acute & BIS/BAS- BAS & Y & $d$ & -2.05 & .20 & 3.68 & .35 \\
\hline
\end{tabular}




\begin{tabular}{|c|c|c|c|c|c|c|c|c|c|c|c|c|}
\hline ID_Text & $\mathrm{N}$ & $\begin{array}{c}\text { Perc } \\
\text { Wom }\end{array}$ & Age & $\begin{array}{l}\text { Disorder } \\
\text { cluster }\end{array}$ & Clinical status & RST Scales & $\begin{array}{l}\text { Pub sta- } \\
\text { tus }\end{array}$ & $\begin{array}{l}\text { Data } \\
\text { type }\end{array}$ & $\begin{array}{c}g \\
\text { BAS }\end{array}$ & $\begin{array}{c}v g \\
\text { BAS }\end{array}$ & $\begin{array}{c}g \\
\text { BIS }\end{array}$ & $\begin{array}{c}v g \\
\text { BIS }\end{array}$ \\
\hline \multirow{2}{*}{ Díaz et al. (1993) } & 89 & .00 & 27.60 & Anxiety & Healthy & SPSRQ-SP & $\mathrm{Y}$ & $r$ & NA & NA & 1.61 & .06 \\
\hline & 82 & 1.00 & 27.60 & Anxiety & Healthy & SPSRQ-SP & $\mathrm{Y}$ & $r$ & NA & NA & 1.00 & .05 \\
\hline Dinovo et al. (2011) & 477 & .50 & 19.20 & Depression & Healthy & BIS/BAS & $\mathrm{Y}$ & $r$ & .56 & .01 & .49 & .01 \\
\hline Dodd et al. (2011) & 175 & .88 & 19.75 & Depression & Healthy & BIS/BAS & $\mathrm{Y}$ & $r$ & .11 & .02 & .63 & .02 \\
\hline \multirow[t]{2}{*}{ Dufey et al. (2011) } & 233 & 1.00 & 20.08 & Anxiety & Healthy & SPSRQ & $\mathrm{Y}$ & $r$ & .16 & .02 & 1.51 & .02 \\
\hline & 201 & .00 & 20.08 & Anxiety & Healthy & SPSRQ & $\mathrm{Y}$ & $r$ & .51 & .02 & 1.67 & .03 \\
\hline Duley et al. (2007) & 38 & .34 & 21.35 & Anxiety & Healthy & BIS/BAS & $\mathrm{Y}$ & $d$ & -.30 & .11 & 2.47 & .19 \\
\hline Ekinci et al. (2012) & 160 & .56 & 34.20 & Depression & Remission & TCI & $\mathrm{Y}$ & $d$ & -.12 & .02 & 1.50 & .03 \\
\hline Elovainio et al. (2004) & 2,149 & .59 & 31.40 & Depression & Healthy & TCI & $\mathrm{Y}$ & $r$ & -.02 & .00 & 1.12 & .00 \\
\hline Ettelt et al. (2008) & 150 & .67 & 37.70 & Anxiety & Episode/Acute & TPQ-HA & $\mathrm{Y}$ & $d$ & NA & NA & 1.24 & .03 \\
\hline Farmer et al. (2009) & 591 & .57 & 51.00 & Depression & Healthy & TCI & $\mathrm{Y}$ & $r$ & -.05 & .01 & .80 & .01 \\
\hline Gazioglu et al. (2014) & 73 & .56 & 35.10 & Depression & Healthy & TCI & $\mathrm{Y}$ & $r$ & NA & NA & 1.05 & .06 \\
\hline Gil (2005) & 180 & .58 & 23.40 & Anxiety & Episode/Acute & TPQ & $\mathrm{Y}$ & $d$ & -.32 & .04 & .31 & .04 \\
\hline $\begin{array}{l}\text { Gillath et al. (2009); } \\
\text { Study } 1\end{array}$ & 83 & .77 & 19.00 & Anxiety & Healthy & BIS/BAS & $\mathrm{N}$ & $r$ & -.12 & .05 & .59 & .05 \\
\hline $\begin{array}{l}\text { Gillath et al. (2009); } \\
\text { Study } 2\end{array}$ & 101 & .66 & 20.00 & Anxiety & Healthy & BIS/BAS & $\mathrm{N}$ & $r$ & -.25 & .04 & 1.38 & .05 \\
\hline \multirow[t]{2}{*}{ Goekoop et al. (2011) } & 164 & NA & 68.00 & Depression & Episode/Acute & TCI & $\mathrm{Y}$ & $d$ & -.24 & .02 & 1.50 & .03 \\
\hline & 127 & NA & 68.00 & Depression & Remission & TCI & $\mathrm{Y}$ & $d$ & .11 & .04 & .86 & .04 \\
\hline Gökdağ et al. (2016) & 255 & NA & NA & Depression & Episode/Acute & TCI & $\mathrm{Y}$ & $d$ & .01 & .02 & 1.37 & .02 \\
\hline Gomez et al. (2005) & 358 & .55 & 24.06 & Anxiety & Healthy & $\begin{array}{l}\text { BIS/BAS; } \\
\text { GRAPES }\end{array}$ & $\mathrm{Y}$ & $r$ & -.63 & .01 & 1.62 & .01 \\
\hline
\end{tabular}




\begin{tabular}{|c|c|c|c|c|c|c|c|c|c|c|c|c|}
\hline ID_Text & $\mathrm{N}$ & $\begin{array}{l}\text { Perc } \\
\text { Wom }\end{array}$ & Age & $\begin{array}{l}\text { Disorder } \\
\text { cluster }\end{array}$ & Clinical status & RST Scales & $\begin{array}{l}\text { Pub sta- } \\
\text { tus }\end{array}$ & $\begin{array}{l}\text { Data } \\
\text { type }\end{array}$ & $\begin{array}{c}g \\
\text { BAS }\end{array}$ & $\begin{array}{c}v g \\
\text { BAS }\end{array}$ & $\begin{array}{c}g \\
\text { BIS }\end{array}$ & $\begin{array}{l}v g \\
\text { BIS }\end{array}$ \\
\hline Greenwood et al. (2013) & 135 & .62 & 45.00 & Depression & Remission & TCI & $\mathrm{N}$ & $d$ & NA & NA & 1.02 & .07 \\
\hline Gudiño (2013) & 148 & .56 & 11.43 & Anxiety & Healthy & BIS/BAS & Y & $r$ & .55 & .03 & .71 & .03 \\
\hline Hagenaars (2016) & 1,154 & .63 & 50.48 & Anxiety & Healthy & BIS/BAS-BIS & $\mathrm{Y}$ & $r$ & NA & NA & .82 & .00 \\
\hline \multirow[t]{2}{*}{ Halvorsen et al. (2009) } & 105 & .45 & 47.40 & Depression & Episode/Acute & TCI & $\mathrm{Y}$ & $d$ & -.56 & .04 & 2.08 & .06 \\
\hline & 138 & .48 & 46.91 & Depression & Remission & TCI & Y & $d$ & -.06 & .03 & .97 & .04 \\
\hline Han et al. (2006) & 277 & .00 & 17.36 & Anxiety & Healthy & TCI & Y & $r$ & -.10 & .01 & 2.49 & .03 \\
\hline Hannan et al. (2013) & 282 & .63 & 19.68 & Anxiety & Healthy & $\mathrm{J} 5$ & Y & $r$ & -.22 & .01 & .25 & .01 \\
\hline Hansenne et al. (2001) & 128 & .50 & 37.79 & Depression & Episode/Acute & TCI & Y & $d$ & -.40 & .03 & 2.08 & .05 \\
\hline \multirow[t]{2}{*}{ Hansenne et al. (2009) } & 108 & .59 & 44.50 & Depression & Episode/Acute & TCI-R & Y & $d$ & -.91 & .04 & 1.94 & .05 \\
\hline & 40 & .75 & 47.50 & Depression & Remission & TCI-R & Y & $d$ & -.39 & .10 & .97 & .11 \\
\hline $\begin{array}{l}\text { Harmon-Jones et al. } \\
\text { (1997) }\end{array}$ & 37 & 1.00 & 18.50 & Anxiety & Healthy & BIS/BAS & Y & $r$ & -1.01 & .12 & .66 & .11 \\
\hline Hasler et al. (2010) & 208 & .67 & 19.23 & Depression & Episode/Acute & BIS/BAS & Y & $r$ & -1.18 & .02 & 1.12 & .02 \\
\hline \multirow[t]{2}{*}{ Hellerstein et al. (2000) } & 178 & .00 & 42.00 & Depression & Episode/Acute & TPQ & Y & $d$ & .17 & .02 & 1.75 & .03 \\
\hline & 532 & .50 & 42.00 & Depression & Episode/Acute & TPQ & $\mathrm{Y}$ & $d$ & .31 & .01 & 1.54 & .01 \\
\hline Highsmith et al., (2017) & 18 & .56 & 20.40 & Anxiety & Healthy & BIS/BAS-FS & Y & $r$ & -1.15 & .24 & 1.62 & .27 \\
\hline Hirano et al. (2002) & 163 & .58 & 42.59 & Depression & Episode/Acute & TCI & $\mathrm{Y}$ & $d$ & -.34 & .03 & 1.69 & .04 \\
\hline Holmes et al. (2012) & 1,050 & NA & 21.37 & Anxiety & Healthy & $\begin{array}{c}\text { TCI-HA; } \\
\text { BIS/BAS-BIS }\end{array}$ & $\mathrm{Y}$ & $r$ & NA & NA & 1.40 & .00 \\
\hline Hoyer et al. (2013) & 88 & .45 & 26.95 & Anxiety & Episode/Acute & TPQ & Y & $d$ & .34 & .05 & .46 & .05 \\
\hline Hur et al. (2009) & 112 & .66 & 38.70 & Depression & Episode/Acute & TCI & Y & $d$ & -.30 & .04 & .87 & .04 \\
\hline
\end{tabular}




\begin{tabular}{|c|c|c|c|c|c|c|c|c|c|c|c|c|}
\hline ID_Text & $\mathrm{N}$ & $\begin{array}{l}\text { Perc } \\
\text { Wom }\end{array}$ & Age & $\begin{array}{l}\text { Disorder } \\
\text { cluster }\end{array}$ & Clinical status & RST Scales & $\begin{array}{l}\text { Pub sta- } \\
\text { tus }\end{array}$ & $\begin{array}{l}\text { Data } \\
\text { type }\end{array}$ & $\begin{array}{c}g \\
\text { BAS }\end{array}$ & $\begin{array}{l}v g \\
\text { BAS }\end{array}$ & $\begin{array}{c}g \\
\text { BIS }\end{array}$ & $\begin{array}{l}v g \\
\text { BIS }\end{array}$ \\
\hline Izci et al. (2014) & 122 & .67 & 35.70 & Anxiety & Outpatients & TCI & $\mathrm{Y}$ & $d$ & -.14 & .03 & .41 & .03 \\
\hline Iidaka et al. (2006) & 56 & .46 & 22.30 & Depression & Healthy & TCI-HA & $\mathrm{Y}$ & $r$ & NA & NA & .81 & .08 \\
\hline $\begin{array}{l}\text { C. J. Jackson (2009); } \\
\text { Study } 1\end{array}$ & 972 & .72 & 22.00 & Anxiety & Healthy & $\mathrm{J}-5$ & $\mathrm{Y}$ & $r$ & .00 & .00 & 1.04 & .00 \\
\hline $\begin{array}{l}\text { C. J. Jackson (2009); } \\
\text { Study } 2\end{array}$ & 190 & .61 & 18.89 & Anxiety & Healthy & J5; BIS/BAS & $\mathrm{Y}$ & $r$ & -.36 & .00 & .84 & .00 \\
\hline Jarmolowicz (2014) & 100 & .49 & 30.70 & Depression & Healthy & BIS/BAS & $\mathrm{Y}$ & $r$ & -.14 & .04 & .41 & .04 \\
\hline \multirow[t]{2}{*}{ N. Jiang et al. (2003) } & 162 & .74 & 19.40 & Anxiety & Healthy & TCI & $\mathrm{Y}$ & $r$ & -.23 & .02 & 1.66 & .03 \\
\hline & 89 & .49 & 23.20 & Anxiety & Healthy & TCI & $\mathrm{Y}$ & $r$ & -.32 & .04 & 1.78 & .06 \\
\hline Y. Jiang et al. (2014) & 225 & .68 & 19.52 & Anxiety & Healthy & $\begin{array}{l}\text { BIS/BAS; } \\
\text { RST-PQ }\end{array}$ & $\mathrm{Y}$ & $r$ & -.55 & .02 & 1.25 & .02 \\
\hline Johnson et al. (2003) & 1,296 & .47 & 19.00 & Anxiety & Other & $\begin{array}{c}\text { BIS/BAS-FS } \\
\text { and RR }\end{array}$ & $\mathrm{Y}$ & $d$ & .09 & .01 & NA & NA \\
\hline $\begin{array}{l}\text { Johnson et al. (2006); } \\
\text { Study } 1\end{array}$ & 138 & .68 & 18.00 & Depression & Healthy & BIS/BAS & $\mathrm{Y}$ & $r$ & -.21 & .03 & .41 & .03 \\
\hline $\begin{array}{l}\text { Johnson et al. (2006); } \\
\text { Study } 2\end{array}$ & 285 & .68 & 18.00 & Depression & Healthy & BIS/BAS & $\mathrm{Y}$ & $r$ & -.07 & .01 & .28 & .01 \\
\hline Jokela et al. (2011) & 1,591 & .57 & 37.80 & Depression & Healthy & TCI & $\mathrm{Y}$ & $r$ & -.05 & .00 & 1.58 & .00 \\
\hline Jones et al. (2008) & 231 & .79 & 28.52 & Depression & Healthy & BIS/BAS & $\mathrm{Y}$ & $r$ & -.15 & .02 & .48 & .02 \\
\hline Josefsson et al. (2007) & 136 & 1.00 & 35.63 & Depression & Outpatients & TCI & $\mathrm{Y}$ & $d$ & -.37 & .03 & 1.49 & .04 \\
\hline Joyce et al. (2010) & 412 & .67 & 48.20 & Depression & Not specified & TCI & $\mathrm{Y}$ & $d$ & -.08 & .01 & .94 & .01 \\
\hline Jung et al. (2011) & 40 & .35 & 25.23 & Anxiety & Episode/Acute & BIS/BAS & $\mathrm{Y}$ & $d$ & -.40 & .10 & .76 & .10 \\
\hline Jylhä et al. (2011) & 398 & .69 & NA & Depression & Episode/Acute & TCI-R & $\mathrm{Y}$ & $d$ & -.54 & .01 & 1.08 & .01 \\
\hline
\end{tabular}




\begin{tabular}{|c|c|c|c|c|c|c|c|c|c|c|c|c|}
\hline ID_Text & $\mathrm{N}$ & $\begin{array}{l}\text { Perc } \\
\text { Wom }\end{array}$ & Age & $\begin{array}{l}\text { Disorder } \\
\text { cluster }\end{array}$ & Clinical status & RST Scales & $\begin{array}{l}\text { Pub sta- } \\
\text { tus }\end{array}$ & $\begin{array}{l}\text { Data } \\
\text { type }\end{array}$ & $\begin{array}{c}g \\
\text { BAS }\end{array}$ & $\begin{array}{l}v g \\
\text { BAS }\end{array}$ & $\begin{array}{c}g \\
\text { BIS }\end{array}$ & $\begin{array}{l}v g \\
\text { BIS }\end{array}$ \\
\hline $\begin{array}{l}\text { Kambouropoulos et al. } \\
\text { (2014) }\end{array}$ & 218 & .73 & 32.84 & Anxiety & Healthy & J5 - FFFS & $\mathrm{Y}$ & $r$ & NA & NA & .63 & .02 \\
\hline Kaneda et al. (2011) & 166 & .66 & 44.38 & Depression & Episode/Acute & TCI & $\mathrm{Y}$ & $d$ & -.69 & .03 & 1.45 & .03 \\
\hline Kang et al. (2015) & 120 & .00 & 20.48 & Anxiety & Healthy & TCI & $\mathrm{Y}$ & $r$ & NA & NA & .36 & .03 \\
\hline Kasch et al. (2002) & 89 & .69 & 34.60 & Depression & Episode/Acute & BIS/BAS & $\mathrm{Y}$ & $d$ & -1.55 & .07 & 1.15 & .06 \\
\hline $\begin{array}{l}\text { Kashdan et al. (2006); } \\
\text { Study } 1\end{array}$ & 104 & .55 & NA & Anxiety & Healthy & BIS/BAS & $\mathrm{Y}$ & $r$ & -.36 & .04 & 1.65 & .05 \\
\hline $\begin{array}{l}\text { Kashdan et al. (2006); } \\
\text { Study } 2\end{array}$ & 90 & .50 & 19.38 & Anxiety & Healthy & BIS/BAS & $\mathrm{Y}$ & $r$ & -.36 & .04 & 1.00 & .05 \\
\hline Kerremans et al. (2010) & 239 & .47 & 16.60 & Depression & Healthy & BIS/BAS & $\mathrm{N}$ & $r$ & -.47 & .02 & .54 & .02 \\
\hline Keune et al. (2012) & 35 & .69 & 24.14 & Depression & Healthy & BIS/BAS & $\mathrm{Y}$ & $r$ & -.10 & .11 & .06 & .11 \\
\hline S. W. Kim et al. (2001) & 81 & .27 & 41.45 & Anxiety & Outpatients & TPQ & $\mathrm{Y}$ & $d$ & -.15 & .05 & 1.60 & .06 \\
\hline S. J. Kim et al. (2009) & 315 & .38 & 34.59 & Anxiety & Episode/Acute & TCI & $\mathrm{Y}$ & $d$ & -.05 & .01 & 1.28 & .02 \\
\hline Kimbrel et al. (2008) & 128 & 1.00 & 18.84 & Anxiety & Healthy & SPSRQ & $\mathrm{Y}$ & $r$ & -.14 & .03 & 1.42 & .04 \\
\hline Kimbrel et al. (2012) & 207 & .67 & 19.10 & Anxiety & Healthy & BIS/BAS & $\mathrm{Y}$ & $r$ & -.25 & .02 & 1.51 & .02 \\
\hline \multirow[t]{2}{*}{ Kimura et al. (2000) } & 117 & .00 & 43.40 & Depression & Remission & TCI & $\mathrm{Y}$ & $d$ & -.31 & .03 & 1.57 & .04 \\
\hline & 168 & 1.00 & 43.40 & Depression & Remission & TCI & $\mathrm{Y}$ & $d$ & -.20 & .02 & 1.12 & .03 \\
\hline Kircanski et al. (2013) & 152 & 1.00 & 44.00 & Depression & Remission & BIS/BAS & $\mathrm{Y}$ & $d$ & -.50 & .03 & .71 & .03 \\
\hline Knyazev et al. (2003) & 47 & .87 & 23.69 & Anxiety & Healthy & GWPQ & $\mathrm{Y}$ & $r$ & .30 & .08 & 1.44 & .10 \\
\hline Knyazev et al. (2004) & 345 & .73 & 20.00 & Anxiety & Healthy & $\begin{array}{l}\text { GWPQ; } \\
\text { BIS/BAS }\end{array}$ & $\mathrm{Y}$ & $r$ & .11 & .01 & 1.00 & .01 \\
\hline
\end{tabular}




\begin{tabular}{|c|c|c|c|c|c|c|c|c|c|c|c|c|}
\hline ID_Text & $\mathrm{N}$ & $\begin{array}{l}\text { Perc } \\
\text { Wom }\end{array}$ & Age & $\begin{array}{l}\text { Disorder } \\
\text { cluster }\end{array}$ & Clinical status & RST Scales & $\begin{array}{l}\text { Pub sta- } \\
\text { tus }\end{array}$ & $\begin{array}{l}\text { Data } \\
\text { type }\end{array}$ & $\stackrel{g}{\text { BAS }}$ & $\begin{array}{c}v g \\
\text { BAS }\end{array}$ & $\begin{array}{c}g \\
\text { BIS }\end{array}$ & $\begin{array}{l}v g \\
\text { BIS }\end{array}$ \\
\hline $\begin{array}{l}\text { Knyazev, Bocharov et } \\
\text { al. (2008) }\end{array}$ & 292 & .41 & 15.50 & Anxiety & Healthy & GWPQ & $\mathrm{Y}$ & $r$ & .16 & .01 & 1.18 & .02 \\
\hline $\begin{array}{l}\text { Knyazev, Levin et al. } \\
\text { (2008) }\end{array}$ & 51 & .69 & 20.00 & Anxiety & Healthy & $\begin{array}{c}\text { GWPQ; } \\
\text { BIS/BAS-BIS }\end{array}$ & Y & $r$ & NA & NA & 1.23 & .09 \\
\hline Kramer et al. (2015) & 120 & .53 & 44.09 & Anxiety & Episode/Acute & J5 & Y & $d$ & -.58 & .04 & -.31 & .04 \\
\hline \multirow[t]{2}{*}{ Kushner et al. (2000) } & 49 & 1.00 & 47.00 & Anxiety & Healthy & TPQ & $\mathrm{Y}$ & $r$ & .51 & .08 & 1.60 & .11 \\
\hline & 24 & .00 & 23.50 & Anxiety & Healthy & TPQ & $\mathrm{Y}$ & $r$ & .25 & .16 & 2.49 & .28 \\
\hline \multirow[t]{4}{*}{ Kusunoki et al. (2000) } & 26 & .00 & 35.20 & Anxiety & Remission & TCI & Y & $d$ & -.48 & .16 & 2.31 & .26 \\
\hline & 39 & 1.00 & 35.20 & Anxiety & Remission & TCI & $\mathrm{Y}$ & $d$ & -.39 & .11 & 2.28 & .18 \\
\hline & 25 & .00 & 36.00 & Depression & Remission & TCI & $\mathrm{Y}$ & $d$ & -.13 & .17 & 1.74 & .23 \\
\hline & 39 & 1.00 & 36.00 & Depression & Remission & TCI & $\mathrm{Y}$ & $d$ & .15 & .11 & 1.20 & .13 \\
\hline Landman et al. (2016) & 59 & .00 & 37.90 & Anxiety & Healthy & BIS/BAS-BIS & Y & $r$ & NA & NA & 1.03 & .07 \\
\hline Lee et al. (2012) & 344 & .62 & 42.75 & Depression & Not specified & TCI & $\mathrm{Y}$ & $d$ & -.15 & .04 & .98 & .04 \\
\hline Leikas et al. (2007) & 1,270 & .51 & 45.76 & Anxiety & Healthy & BIS/BAS & $\mathrm{Y}$ & $r$ & .26 & .00 & .80 & .00 \\
\hline Lemaire et al. (2014) & 101 & .49 & 43.90 & Anxiety & Healthy & TPQ & $\mathrm{N}$ & $r$ & -.10 & .04 & 1.78 & .05 \\
\hline Lemogne et al. (2009) & 60 & .50 & 23.45 & Depression & Healthy & $\mathrm{TCI}$ & $\mathrm{N}$ & $r$ & -.15 & .07 & .47 & .07 \\
\hline $\begin{array}{l}\text { Levinson et al. (2011); } \\
\text { Study } 1\end{array}$ & 723 & .68 & 19.14 & Anxiety & Healthy & BIS/BAS & $\mathrm{Y}$ & $r$ & -.44 & .01 & .80 & .01 \\
\hline Li et al. (2015) & 330 & .58 & 16.95 & Depression & Healthy & BIS/BAS & $\mathrm{Y}$ & $r$ & .08 & .01 & .63 & .01 \\
\hline Lochner et al. (2007) & 109 & .70 & 35.80 & Anxiety & Episode/Acute & TCI-NS and HA & $\mathrm{Y}$ & $d$ & -.44 & .04 & 1.06 & .05 \\
\hline Lorian et al. (2010) & 55 & .73 & 20.24 & Anxiety & Healthy & BIS/BAS-BIS & $\mathrm{Y}$ & $r$ & NA & NA & 1.40 & .09 \\
\hline Lovallo et al. (2014) & 314 & .57 & 23.50 & Depression & Healthy & TPQ & $\mathrm{N}$ & $r$ & -.33 & .01 & .93 & .01 \\
\hline
\end{tabular}




\begin{tabular}{|c|c|c|c|c|c|c|c|c|c|c|c|c|}
\hline ID_Text & $\mathrm{N}$ & $\begin{array}{l}\text { Perc } \\
\text { Wom }\end{array}$ & Age & $\begin{array}{l}\text { Disorder } \\
\text { cluster }\end{array}$ & Clinical status & RST Scales & $\begin{array}{l}\text { Pub sta- } \\
\text { tus }\end{array}$ & $\begin{array}{l}\text { Data } \\
\text { type }\end{array}$ & $\begin{array}{c}g \\
\text { BAS }\end{array}$ & $\begin{array}{l}v g \\
\text { BAS }\end{array}$ & $\begin{array}{c}g \\
\text { BIS }\end{array}$ & $\begin{array}{l}v g \\
\text { BIS }\end{array}$ \\
\hline Lövdahl et al. (2010) & 26 & .85 & 33.60 & Depression & Not specified & TCI & Y & $d$ & .27 & .18 & .78 & .20 \\
\hline Lyoo et al. (2003) & 70 & .37 & 28.70 & Anxiety & Episode/Acute & TCI & Y & $d$ & -.43 & .06 & 1.20 & .07 \\
\hline Lyvers et al. (2014a) & 106 & .63 & 21.21 & Anxiety & Healthy & SPSRQ & Y & $r$ & .58 & .04 & .62 & .04 \\
\hline Lyvers et al. (2014b) & 113 & .69 & 22.11 & Anxiety & Healthy & SPSRQ & Y & $r$ & .65 & .04 & .67 & .04 \\
\hline Maack et al. (2012) & 91 & .63 & 24.78 & Anxiety & Episode/Acute & BIS/BAS & Y & $d$ & -.15 & .08 & 1.17 & .09 \\
\hline Maack et al. (2015) & 291 & .75 & 20.38 & Anxiety & Healthy & BIS/BAS & Y & $r$ & -.13 & .01 & .47 & .01 \\
\hline Mansell et al. (2008) & 191 & .84 & 20.00 & Depression & Healthy & BIS/BAS & Y & $r$ & .09 & .02 & .70 & .02 \\
\hline Marchesi et al. (2006) & 142 & .69 & 36.00 & Anxiety & Episode/Acute & TCI & Y & $d$ & -.15 & .03 & .83 & .03 \\
\hline Mardaga et al. (2009) & 40 & .55 & 42.80 & Depression & Episode/Acute & $\begin{array}{l}\text { TCI-R; } \\
\text { BIS/BAS }\end{array}$ & Y & $d$ & -.03 & .10 & 1.27 & .12 \\
\hline Mardaga et al. (2014) & 38 & .71 & 42.80 & Depression & Episode/Acute & TCI-R & Y & $d$ & -.67 & .11 & .75 & .11 \\
\hline $\begin{array}{l}\text { Marteinsdottir et al. } \\
(2003)\end{array}$ & 431 & NA & 33.50 & Anxiety & Episode/Acute & TCI-R & Y & $d$ & -.32 & .03 & 1.19 & .04 \\
\hline Meerkerk et al. (2010) & 1,369 & .63 & 42.00 & Depression & Episode/Acute & TCI & Y & $d$ & -.44 & .00 & 1.12 & .00 \\
\hline Mertol et al. (2012) & 79 & .57 & 41.50 & Anxiety & Outpatients & TCI & $\mathrm{Y}$ & $d$ & 2.31 & .08 & 5.50 & .24 \\
\hline \multirow[t]{2}{*}{ Minaya et al. (2009) } & 82 & .67 & 34.20 & Depression & Outpatients & TCI & $\mathrm{Y}$ & $d$ & -.31 & .05 & .55 & .05 \\
\hline & 87 & .67 & 34.20 & Other & Outpatients & TCI & $\mathrm{Y}$ & $d$ & .27 & .05 & .45 & .05 \\
\hline Minelli et al. (2009) & 327 & .59 & 50.30 & Other & Episode/Acute & TCI & $\mathrm{Y}$ & $d$ & -.41 & .02 & 1.06 & .02 \\
\hline Mitchell et al. (2006) & 184 & .70 & 18.92 & Anxiety & Healthy & $\begin{array}{l}\text { BIS/BAS; } \\
\text { SPSRQ }\end{array}$ & $\mathrm{Y}$ & $r$ & .16 & .02 & .86 & .02 \\
\hline \multirow[t]{2}{*}{ Mitsui et al. (2013) } & 479 & .00 & 18.70 & Depression & Episode/Acute & TCI & $\mathrm{Y}$ & $d$ & .18 & .04 & .79 & .04 \\
\hline & 203 & 1.00 & 18.55 & Depression & Episode/Acute & TCI & $\mathrm{Y}$ & $d$ & .12 & .07 & .91 & .07 \\
\hline
\end{tabular}




\begin{tabular}{|c|c|c|c|c|c|c|c|c|c|c|c|c|}
\hline ID_Text & $\mathrm{N}$ & $\begin{array}{l}\text { Perc } \\
\text { Wom }\end{array}$ & Age & $\begin{array}{l}\text { Disorder } \\
\text { cluster }\end{array}$ & Clinical status & RST Scales & $\begin{array}{l}\text { Pub sta- } \\
\text { tus }\end{array}$ & $\begin{array}{l}\text { Data } \\
\text { type }\end{array}$ & $\begin{array}{c}g \\
\text { BAS }\end{array}$ & $\begin{array}{c}v g \\
\text { BAS }\end{array}$ & $\begin{array}{c}g \\
\text { BIS }\end{array}$ & $\begin{array}{c}v g \\
\text { BIS }\end{array}$ \\
\hline & 489 & .00 & 18.70 & Depression & Episode/Acute & TCI & $\mathrm{Y}$ & $d$ & .00 & .03 & .63 & .03 \\
\hline & 250 & 1.00 & 18.40 & Depression & Episode/Acute & TCI & $\mathrm{Y}$ & $d$ & .25 & .02 & .24 & .02 \\
\hline Miyoshi et al. (2016) & 85 & .45 & 26.24 & Depression & Episode/Acute & TCI & $\mathrm{Y}$ & $d$ & -2.68 & .13 & 5.89 & .30 \\
\hline $\begin{array}{l}\text { Mommersteeg et al. } \\
\text { (2011) }\end{array}$ & 92 & .07 & 28.50 & Anxiety & Episode/Acute & TCI & $\mathrm{N}$ & $d$ & .63 & .26 & .81 & .26 \\
\hline Mörtberg et al. (2007) & 459 & .51 & 34.90 & Anxiety & Episode/Acute & TCI & $\mathrm{Y}$ & $d$ & -.32 & .02 & 1.89 & .02 \\
\hline Movius (2005) & 98 & .52 & 19.00 & Anxiety & Healthy & BIS/BAS & $\mathrm{Y}$ & $r$ & -.17 & .04 & .97 & .05 \\
\hline \multirow[t]{2}{*}{ Mueller et al. (2011) } & 286 & 1.00 & 22.90 & Depression & Healthy & BIS/BAS & $\mathrm{Y}$ & $r$ & .39 & .01 & .56 & .01 \\
\hline & 124 & .00 & 22.90 & Depression & Healthy & BIS/BAS & $\mathrm{Y}$ & $r$ & .47 & .03 & .51 & .03 \\
\hline Mulder et al. (1994) & 148 & .51 & 41.50 & Depression & Episode/Acute & TPQ & $\mathrm{Y}$ & $d$ & -.43 & .03 & 3.47 & .07 \\
\hline Müller et al. (2005) & 202 & NA & NA & Anxiety & Healthy & BIS/BAS & $\mathrm{Y}$ & $r$ & -.18 & .02 & .92 & .02 \\
\hline Naito et al. (2000) & 220 & .50 & 20.90 & Depression & Healthy & TCI & $\mathrm{Y}$ & $r$ & .00 & .02 & 1.21 & .02 \\
\hline \multirow[t]{2}{*}{ Nery et al. (2009) } & 75 & .33 & 38.10 & Depression & Episode/Acute & TCI & $\mathrm{Y}$ & $d$ & .46 & .06 & 2.05 & .08 \\
\hline & 45 & .33 & 39.10 & Depression & Remission & TCI & $\mathrm{Y}$ & $d$ & .35 & .10 & .48 & .10 \\
\hline Nicholls et al. (2014) & 350 & .71 & 34.21 & Anxiety & Healthy & SPSRQ & $\mathrm{N}$ & $r$ & .05 & .01 & 2.55 & .02 \\
\hline $\begin{array}{l}\text { Norris et al. (2011); } \\
\text { Study } 1\end{array}$ & 65 & 1.00 & NA & Depression & Healthy & BIS/BAS & $\mathrm{Y}$ & $r$ & .08 & .06 & 1.30 & .07 \\
\hline North et al. (2012) & 151 & .48 & 43.00 & Anxiety & Episode/Acute & TCI-NS and HA & $\mathrm{N}$ & $d$ & .26 & .03 & .85 & .03 \\
\hline $\begin{array}{l}\text { Nowakowska et al. } \\
\text { (2005) }\end{array}$ & 71 & .45 & 33.60 & Depression & Remission & TCI & $\mathrm{Y}$ & $d$ & .49 & .08 & 1.26 & .10 \\
\hline Nyman et al. (2011) & 3,902 & .50 & 16.00 & Depression & Remission & TCI & $\mathrm{Y}$ & $d$ & .10 & .00 & .67 & .00 \\
\hline O’Connor et al. (2014) & 402 & .78 & 32.49 & Anxiety & Healthy & BIS/BAS & $\mathrm{Y}$ & $r$ & -.58 & .01 & 1.42 & .01 \\
\hline
\end{tabular}




\begin{tabular}{|c|c|c|c|c|c|c|c|c|c|c|c|c|}
\hline ID_Text & $\mathrm{N}$ & $\begin{array}{l}\text { Perc } \\
\text { Wom }\end{array}$ & Age & $\begin{array}{l}\text { Disorder } \\
\text { cluster }\end{array}$ & Clinical status & RST Scales & $\begin{array}{l}\text { Pub sta- } \\
\text { tus }\end{array}$ & $\begin{array}{l}\text { Data } \\
\text { type }\end{array}$ & $\begin{array}{l}g \\
\text { BAS }\end{array}$ & $\begin{array}{l}v g \\
\text { BAS }\end{array}$ & $\begin{array}{c}g \\
\text { BIS }\end{array}$ & $\begin{array}{l}v g \\
\text { BIS }\end{array}$ \\
\hline Panayiotou et al. (2014) & 127 & .82 & 21.22 & Anxiety & Healthy & SPSRQ & $\mathrm{Y}$ & $r$ & .45 & .03 & 1.49 & .04 \\
\hline Peirson et al. (2001) & 471 & .76 & 19.19 & Depression & Healthy & TCI & $\mathrm{Y}$ & $r$ & -.05 & .01 & .98 & .01 \\
\hline Perich et al. (2011) & 69 & .75 & 41.18 & Depression & Remission & BIS/BAS & $\mathrm{Y}$ & $d$ & -.40 & .06 & .21 & .06 \\
\hline \multirow[t]{2}{*}{ Perkins et al. (2006) } & 83 & 1.00 & 29.03 & Anxiety & Healthy & BIS/BAS & Y & $r$ & .01 & .05 & .99 & .05 \\
\hline & 58 & .00 & 29.03 & Anxiety & Healthy & BIS/BAS & Y & $r$ & .25 & .07 & .80 & .07 \\
\hline Perkins et al. (2007) & 101 & .41 & 20.00 & Anxiety & Healthy & BIS/BAS & $\mathrm{Y}$ & $r$ & -1.06 & .04 & 1.14 & .05 \\
\hline $\begin{array}{l}\text { Perkins et al. (2010); } \\
\text { Study } 1\end{array}$ & 173 & .54 & 23.90 & Anxiety & Healthy & BIS/BAS & Y & $r$ & -.05 & .02 & 1.29 & .03 \\
\hline $\begin{array}{l}\text { Perkins et al. (2010); } \\
\text { Study } 2\end{array}$ & 97 & .77 & 23.05 & Anxiety & Healthy & BIS/BAS & Y & $r$ & -.15 & .04 & .90 & .04 \\
\hline Pfohl et al. (1990) & 60 & .63 & 38.00 & Anxiety & Episode/Acute & TPQ & Y & $d$ & -.41 & .07 & 2.12 & .10 \\
\hline Pickett et al. (2011) & 851 & 1.00 & 19.48 & Anxiety & Healthy & BIS/BAS & Y & $r$ & .03 & .00 & .49 & .00 \\
\hline Pinciotti et al. (2017) & 322 & .72 & 21.30 & Anxiety & Healthy & J5-FFFS & Y & $r$ & NA & NA & -.46 & .01 \\
\hline \multirow[t]{2}{*}{ Pinto-Meza et al. (2006) } & 30 & NA & 22.00 & Depression & Episode/Acute & SPSRQ & Y & $d$ & -1.55 & .17 & 1.45 & .16 \\
\hline & 50 & NA & 35.00 & Depression & Remission & SPSRQ & Y & $d$ & -.92 & .10 & .00 & .09 \\
\hline Prochwicz et al. (2016) & 492 & .89 & 21.58 & Depression & Healthy & TCI & $\mathrm{Y}$ & $r$ & .02 & .01 & 1.06 & .01 \\
\hline Putman et al. (2010) & 28 & 1.00 & 22.70 & Anxiety & Healthy & BIS/BAS-BIS & $\mathrm{Y}$ & $r$ & NA & NA & 2.22 & .22 \\
\hline Reimold et al. (2008) & 29 & .45 & 46.30 & Depression & Episode/Acute & TCI & $\mathrm{Y}$ & $d$ & -.21 & .14 & 2.35 & .24 \\
\hline Richman et al. (1997) & 515 & .00 & 45.10 & Anxiety & Episode/Acute & TPQ & $\mathrm{Y}$ & $d$ & .62 & .02 & 1.97 & .02 \\
\hline $\begin{array}{l}\text { M. A. Richter et al. } \\
\text { (1996) }\end{array}$ & 64 & .41 & 35.50 & Anxiety & Episode/Acute & TPQ & $\mathrm{Y}$ & $d$ & -.31 & .06 & 1.29 & .07 \\
\hline J. Richter et al. (2000) & 192 & 62 & 44.80 & Depression & Episode/Acute & TCI & $\mathrm{Y}$ & $d$ & -.92 & .03 & 1.46 & .03 \\
\hline
\end{tabular}




\begin{tabular}{|c|c|c|c|c|c|c|c|c|c|c|c|c|}
\hline ID_Text & $\mathrm{N}$ & $\begin{array}{l}\text { Perc } \\
\text { Wom }\end{array}$ & Age & $\begin{array}{l}\text { Disorder } \\
\text { cluster }\end{array}$ & Clinical status & RST Scales & $\begin{array}{l}\text { Pub sta- } \\
\text { tus }\end{array}$ & $\begin{array}{l}\text { Data } \\
\text { type }\end{array}$ & $\stackrel{g}{\text { BAS }}$ & $\begin{array}{l}v g \\
\text { BAS }\end{array}$ & $\begin{array}{c}g \\
\text { BIS }\end{array}$ & $\begin{array}{l}v g \\
\text { BIS }\end{array}$ \\
\hline \multirow[t]{2}{*}{ J. Richter et al. (2003) } & 466 & .00 & 36.84 & Depression & Episode/Acute & TCI & $\mathrm{Y}$ & $d$ & -.44 & .01 & 1.21 & .01 \\
\hline & 837 & 1.00 & 38.28 & Depression & Episode/Acute & TCI & Y & $d$ & -.37 & .01 & .99 & .01 \\
\hline Rönnlund et al. (2011) & 255 & .48 & 75.00 & Depression & Healthy & TCI-HA & Y & $r$ & NA & NA & .77 & .02 \\
\hline $\begin{array}{l}\text { Rybakowski et al. } \\
(2004)\end{array}$ & 60 & 1.00 & 15.90 & Depression & Healthy & TCI & $\mathrm{Y}$ & $r$ & -.13 & .07 & 1.41 & .08 \\
\hline Salter (2013) & 36 & .14 & 43.10 & Depression & Healthy & TCI-HA & Y & $r$ & NA & NA & -.74 & .11 \\
\hline \multirow[t]{2}{*}{ Sasayama et al. (2011) } & 122 & .00 & 35.19 & Depression & Outpatients & TCI & $\mathrm{Y}$ & $d$ & -.67 & .04 & 1.84 & .05 \\
\hline & 122 & 1.00 & 37.93 & Depression & Outpatients & TCI & Y & $d$ & -.53 & .04 & 1.56 & .04 \\
\hline Sato et al. (1999) & 141 & .25 & 47.43 & Depression & Outpatients & TCI & $\mathrm{Y}$ & $d$ & -.22 & .03 & 1.92 & .04 \\
\hline Saviotti et al. (1991) & 66 & .82 & 30.70 & Anxiety & Remission & TPQ & Y & $d$ & -.07 & .06 & 2.05 & .09 \\
\hline Segarra et al. (2014) & 329 & .55 & 20.23 & Anxiety & Healthy & BIS/BAS & Y & $r$ & .14 & .01 & 1.21 & .01 \\
\hline Shachar et al. (2014) & 1,362 & .53 & 14.44 & Anxiety & Healthy & JTCI-HA & Y & $r$ & NA & NA & .65 & .00 \\
\hline Sharma et al. (2017) & 58 & .52 & 36.72 & Depression & Not specified & BIS/BAS-RR & Y & $d$ & -.67 & .07 & NA & NA \\
\hline Slessareva et al. (2004) & 146 & NA & NA & Depression & Healthy & BIS & Y & $r$ & NA & NA & .43 & .03 \\
\hline $\begin{array}{l}\text { Smillie et al. (2007); } \\
\text { Study } 1\end{array}$ & 60 & .62 & 20.60 & Anxiety & Healthy & BIS/BAS & $\mathrm{Y}$ & $r$ & -.99 & .07 & 1.41 & .08 \\
\hline $\begin{array}{l}\text { Smillie et al. (2007); } \\
\text { Study } 2\end{array}$ & 81 & .65 & 20.70 & Anxiety & Healthy & BIS/BAS & $\mathrm{Y}$ & $r$ & .32 & .05 & 1.34 & .06 \\
\hline \multirow[t]{2}{*}{ Smith et al. (2005) } & 39 & .00 & 21.20 & Depression & Remission & TCI & $\mathrm{Y}$ & $d$ & .55 & .11 & 1.63 & .14 \\
\hline & 102 & 1.00 & 21.20 & Depression & Remission & TCI & $\mathrm{Y}$ & $d$ & -.04 & .04 & 1.54 & .05 \\
\hline Soler et al. (2014) & 145 & .93 & 34.49 & Depression & Not specified & SPSRQ & $\mathrm{Y}$ & $d$ & .14 & .03 & .93 & .03 \\
\hline Stein et al. (2001) & 55 & .62 & 41.71 & Anxiety & Episode/Acute & TPQ & $\mathrm{Y}$ & $d$ & .01 & .07 & .58 & .07 \\
\hline
\end{tabular}




\begin{tabular}{|c|c|c|c|c|c|c|c|c|c|c|c|c|}
\hline ID_Text & $\mathrm{N}$ & $\begin{array}{l}\text { Perc } \\
\text { Wom }\end{array}$ & Age & $\begin{array}{l}\text { Disorder } \\
\text { cluster }\end{array}$ & Clinical status & RST Scales & $\begin{array}{l}\text { Pub sta- } \\
\text { tus }\end{array}$ & $\begin{array}{l}\text { Data } \\
\text { type }\end{array}$ & $\begin{array}{c}g \\
\text { BAS }\end{array}$ & $\begin{array}{c}v g \\
\text { BAS }\end{array}$ & $\begin{array}{c}g \\
\text { BIS }\end{array}$ & $\begin{array}{l}v g \\
\text { BIS }\end{array}$ \\
\hline Stewart et al. (2008) & 872 & .61 & 20.89 & Anxiety & Healthy & TPQ & $\mathrm{N}$ & $r$ & -.16 & .00 & 2.29 & .01 \\
\hline \multirow{2}{*}{$\begin{array}{l}\text { M. Takahashi et al. } \\
\text { (2013) }\end{array}$} & 122 & .25 & 37.33 & Depression & Episode/Acute & TCI & $\mathrm{Y}$ & $d$ & -.59 & .04 & 1.85 & .05 \\
\hline & 118 & .27 & 37.76 & Depression & Remission & TCI & $\mathrm{Y}$ & $d$ & -.25 & .04 & .71 & .05 \\
\hline $\begin{array}{l}\text { Y. Takahashi et al. } \\
\text { (2012); Study } 1\end{array}$ & 489 & NA & 19.68 & Depression & Healthy & BIS/BAS-BAS & $\mathrm{Y}$ & $r$ & -.34 & .01 & NA & NA \\
\hline $\begin{array}{l}\text { Y. Takahashi et al. } \\
\text { (2012); Study } 2\end{array}$ & 109 & NA & 20.31 & Depression & Healthy & BIS/BAS-BAS & $\mathrm{Y}$ & $r$ & -.72 & .04 & NA & NA \\
\hline $\begin{array}{l}\text { Y. Takahashi et al. } \\
\text { (2015) }\end{array}$ & 319 & .69 & 18.77 & Depression & Healthy & BIS/BAS & $\mathrm{Y}$ & $r$ & -.14 & .01 & .75 & .01 \\
\hline Thierry et al. (2004) & 132 & 1.00 & 32.80 & Anxiety & Outpatients & TCI & $\mathrm{Y}$ & $d$ & -.50 & .03 & 1.56 & .04 \\
\hline $\begin{array}{l}\text { Torrubia et al. (2001); } \\
\text { Study 3a }\end{array}$ & 96 & .00 & 20.14 & Anxiety & Healthy & SPSRQ & $\mathrm{Y}$ & $r$ & -.06 & .04 & 1.84 & .06 \\
\hline $\begin{array}{l}\text { Torrubia et al. (2001); } \\
\text { Study 3b }\end{array}$ & 276 & 1.00 & 20.14 & Anxiety & Healthy & SPSRQ & $\mathrm{Y}$ & $r$ & .20 & .01 & 1.46 & .02 \\
\hline Tse et al. (2011) & 902 & .47 & 24.55 & Depression & Healthy & TCI-HA & $\mathrm{Y}$ & $r$ & NA & NA & .72 & .00 \\
\hline Ubl et al. (2015) & 46 & .65 & 41.96 & Depression & Remission & TPQ & $\mathrm{Y}$ & $d$ & -.25 & .08 & 1.41 & .11 \\
\hline Uzieblo et al. (2007) & 431 & .58 & 18.81 & Anxiety & Healthy & BIS/BAS & $\mathrm{Y}$ & $r$ & .22 & .01 & 1.06 & .01 \\
\hline $\begin{array}{l}\text { Van der Gucht et al. } \\
\text { (2009) }\end{array}$ & 44 & .66 & 46.72 & Depression & Episode/Acute & BIS/BAS & $\mathrm{Y}$ & $d$ & -.26 & .10 & .94 & .11 \\
\hline Van Meter et al. (2015) & 313 & .62 & 19.85 & Depression & Not specified & BIS/BAS & $\mathrm{Y}$ & $d$ & -.55 & .05 & .08 & .05 \\
\hline Vangberg 2012) & 1,239 & .51 & 16.80 & Depression & Healthy & JTCI & $\mathrm{Y}$ & $r$ & -.25 & .00 & 1.35 & .00 \\
\hline Vergara et al. (2011) & 83 & .57 & 19.35 & Depression & Healthy & SPSRQ & $\mathrm{Y}$ & $r$ & .18 & .05 & 1.00 & .05 \\
\hline
\end{tabular}




\begin{tabular}{|c|c|c|c|c|c|c|c|c|c|c|c|c|}
\hline ID_Text & $\mathrm{N}$ & $\begin{array}{l}\text { Perc } \\
\text { Wom }\end{array}$ & Age & $\begin{array}{l}\text { Disorder } \\
\text { cluster }\end{array}$ & Clinical status & RST Scales & $\begin{array}{l}\text { Pub sta- } \\
\text { tus }\end{array}$ & $\begin{array}{l}\text { Data } \\
\text { type }\end{array}$ & $\stackrel{g}{\text { BAS }}$ & $\begin{array}{c}v g \\
\text { BAS }\end{array}$ & $\begin{array}{c}g \\
\text { BIS }\end{array}$ & $\begin{array}{l}v g \\
\text { BIS }\end{array}$ \\
\hline \multirow[t]{2}{*}{ Vervoort et al. (2010) } & 70 & .00 & 13.11 & Anxiety & Outpatients & BIS/BAS & $\mathrm{Y}$ & $d$ & .06 & .07 & 1.01 & .08 \\
\hline & 105 & 1.00 & 13.11 & Anxiety & Outpatients & BIS/BAS & Y & $d$ & -.75 & .04 & .48 & .04 \\
\hline Voth et al. (2014) & 31 & .81 & 39.07 & Depression & Healthy & BIS/BAS & $\mathrm{N}$ & $r$ & .14 & .12 & .51 & .13 \\
\hline Wachleski et al. (2008) & 270 & .74 & 38.10 & Anxiety & Outpatients & TCI & $\mathrm{Y}$ & $d$ & .07 & .01 & 1.54 & .02 \\
\hline Wagener et al. (2016) & 504 & .74 & 36.10 & Depression & Healthy & BIS/BAS & Y & $r$ & -.09 & .01 & 1.03 & .01 \\
\hline S. Wang et al. (1997) & 363 & .00 & 42.40 & Anxiety & Episode/Acute & TPQ & Y & $d$ & -4.08 & .05 & 1.61 & .03 \\
\hline J. Wang et al. (2014) & 323 & .48 & 23.75 & Depression & Healthy & TPQ-HA & Y & $r$ & NA & NA & .79 & .01 \\
\hline Westlye et al. (2011) & 263 & .57 & 50.00 & Depression & Healthy & TPQ-HA & Y & $r$ & NA & NA & .95 & .02 \\
\hline Wiborg et al. (2005) & 182 & .72 & 35.42 & Anxiety & Outpatients & TPQ & Y & $d$ & .19 & .03 & 1.26 & .03 \\
\hline Windle (1994) & 4,462 & NA & 37.83 & Depression & Healthy & $\begin{array}{c}\text { MS-BIS; } \\
\text { MMPI-MAC }\end{array}$ & Y & $r$ & -.24 & .00 & 1.62 & .00 \\
\hline Wright et al. (2016) & 42 & .52 & 21.10 & Depression & Healthy & BIS/BAS & $\mathrm{N}$ & $r$ & .22 & .09 & -.17 & .09 \\
\hline Wu et al. (2012) & 152 & .70 & 44.51 & Depression & Outpatients & TPQ & Y & $d$ & -.01 & .03 & 1.87 & .04 \\
\hline $\begin{array}{l}\text { Wytykowska et al. } \\
\text { (2017); Study } 1\end{array}$ & 1,512 & .54 & 39.41 & Anxiety & Healthy & RST-PQ & Y & $r$ & -.42 & .00 & 1.06 & .00 \\
\hline $\begin{array}{l}\text { Wytykowska et al. } \\
\text { (2017); Study } 2\end{array}$ & 124 & .59 & 38.23 & Depression & Episode/Acute & RST-PQ & Y & $d$ & -2.08 & .05 & 1.96 & .05 \\
\hline Yen et al. (2012) & 2,282 & .52 & 20.96 & Anxiety & Not specified & BIS/BAS & $\mathrm{Y}$ & $d$ & .57 & .01 & 1.32 & .01 \\
\hline \multirow[t]{2}{*}{ Young et al. (1995) } & 47 & .00 & 38.90 & Depression & Outpatients & TPQ & $\mathrm{Y}$ & $d$ & -.45 & .08 & 1.04 & .09 \\
\hline & 65 & 1.00 & 38.80 & Depression & Outpatients & TPQ & $\mathrm{Y}$ & $d$ & .14 & .06 & .38 & .06 \\
\hline Zaninotto et al. (2015) & 165 & .65 & 44.86 & Depression & Episode/Acute & TCI & $\mathrm{N}$ & $d$ & -.32 & .03 & .42 & .03 \\
\hline Zhao et al. (2015) & 108 & .61 & 19.28 & Anxiety & Healthy & BIS/BAS-BIS & Y & $r$ & NA & NA & .86 & .04 \\
\hline
\end{tabular}




\begin{tabular}{|c|c|c|c|c|c|c|c|c|c|c|c|c|}
\hline ID_Text & $\mathrm{N}$ & $\begin{array}{l}\text { Perc } \\
\text { Wom }\end{array}$ & Age & $\begin{array}{l}\text { Disorder } \\
\text { cluster }\end{array}$ & Clinical status & RST Scales & $\begin{array}{l}\text { Pub sta- } \\
\text { tus }\end{array}$ & $\begin{array}{l}\text { Data } \\
\text { type }\end{array}$ & $\begin{array}{c}g \\
\text { BAS }\end{array}$ & $\begin{array}{c}v g \\
\text { BAS }\end{array}$ & $\stackrel{g}{g}$ BIS & $\begin{array}{c}v g \\
\text { BIS }\end{array}$ \\
\hline \multirow[t]{2}{*}{ Zhao et al. (2016) } & 98 & 1.00 & NA & Anxiety & Healthy & BIS/BAS-BIS & $\mathrm{N}$ & $r$ & NA & NA & .85 & .04 \\
\hline & 62 & .00 & NA & Anxiety & Healthy & BIS/BAS-BIS & $\mathrm{N}$ & $r$ & NA & NA & .48 & .06 \\
\hline Zvolensky et al. (2001) & 60 & .57 & NA & Anxiety & Healthy & BIS/BAS & $\mathrm{Y}$ & $r$ & .16 & .07 & 1.44 & .08 \\
\hline
\end{tabular}

Note. BIS/BAS: Behavioral Inhibition System/Behavioral Activation scale, BIS/BAS- Dr FS and RR: BIS/BAS subscales Drive Fun Seeking and Reward Responsiveness, GRAPES: Generalized Reward and Punishment Expectancy Scales, GWPQ: Gray-Wilson Personality Questionnaire, J5: Jackson 5, J5-FFFS: J5 Fight Flight Freeze Scale, JTCI: Junior Temperament and Character Inventory, JTCI-HA: JTCI Harm Avoidance Subscale, MMPI-MAC: Minnesota Multiphasic Personality Inventory's MAC scale, MS-BIS: MacAndrew \& Steele's (1991) Behavior Inhibition Scale, RST-PQ: Reinforcement Sensitivity Theory Personality Questionnaire, SPSRQ: Sensitivity to Punishment, Sensitivity to Reward Questionnaire, TPQ: Tridimensional Personality Questionnaire, TCI: Temperament and Character Inventory, TCI-HA and NS: TCI Harm Avoidance and Novelty Seeking subscales, TCI-R: Revised TCI.

Note. Data type indicates the type of effect size selected. $d=$ standard mean difference; $r=$ correlation. 
Table 2a. Analysis summary of BAS and categorical moderators

\begin{tabular}{lcccc}
\hline Moderator & $k$ & Hedges' g & $95 \% \mathrm{CI}$ & $\begin{array}{c}\text { Test of subgroup differ- } \\
\text { ences }\end{array}$ \\
\hline $\begin{array}{l}\text { Main Effect } \\
\text { Disorder }\end{array}$ & 228 & -.16 & {$[-.21 ;-.11]$} & \\
$\quad \begin{array}{l}\text { Depression } \\
\text { Anxiety }\end{array}$ & 116 & -.21 & {$[-.28 ;-.15]$} & $Q(1)=3.83, p=.05$ \\
$\quad 108$ & -.11 & {$[-.19 ;-.02]$} & \\
$\begin{array}{l}\text { Diagnostic Method } \\
\quad \text { Clinical diagnosis }\end{array}$ & 111 & -.28 & {$[-.38 ;-.19]$} & \\
$\quad$ Self-report & 117 & -.06 & {$[-.12 .-00]$} & \\
$\quad$ Source & & & & \\
$\quad \begin{array}{l}\text { Published } \\
\text { Unpublished }\end{array}$ & 208 & -.17 & {$[-.23 ;-.12]$} & \\
& 20 & -.06 & {$[-.18 ; .05]$} & \\
\hline
\end{tabular}

Table 2b. Analysis summary of BIS and categorical moderators

\begin{tabular}{lcccc}
\hline Moderator & $k$ & Hedges'g & $95 \% \mathrm{CI}$ & $\begin{array}{c}\text { Test of subgroup differ- } \\
\text { ences }\end{array}$ \\
\hline $\begin{array}{l}\text { Main Effect } \\
\text { Disorder }\end{array}$ & 255 & 1.11 & {$[1.02 ; 1.19]$} & \\
$\quad \begin{array}{l}\text { Depression } \\
\text { Anxiety }\end{array}$ & 125 & .99 & {$[.87 ; 1.12]$} & \\
$\quad$ Diagnostic Method & 126 & 1.21 & {$[1.10 ; 1.32]$} & \\
$\quad$ Clinical diagnosis & 114 & 1.29 & {$[1.17 ; 1.42]$} & \\
$\quad$ Self-report & 141 & .96 & {$[.85 ; 1.07]$} & \\
$\quad \begin{array}{l}\text { Source } \\
\quad \text { Published }\end{array}$ & & & & \\
$\quad$ Unpublished & 232 & 1.12 & {$[1.04 ; 1.19]$} & \\
\hline
\end{tabular}

NOTE: This is a postprint of the study Katz, B. A., Matanky, K., Aviram, G., \& Yovel, I. (2020). Reinforcement sensitivity, depression and anxiety: A meta-analysis and meta-analytic structural equation model. Clinical Psychology Review, 101842, doi: $10.1016 /$ j.cpr.2020.101842. See online article for final text. 
Table 3a. Random-effects models of significant moderators of BAS

\begin{tabular}{|c|c|c|c|c|c|c|c|}
\hline \multirow[b]{2}{*}{ Moderator } & \multicolumn{4}{|c|}{ Univariate metaregression } & \multicolumn{3}{|c|}{ Multivariate metaregression } \\
\hline & Beta & SE & $95 \% \mathrm{CI}$ & $R^{2}$ & Beta & SE & $95 \% \mathrm{CI}$ \\
\hline Disorder & $-.12^{*}$ & .05 & {$[-.22 ;-.02]$} & .000 & -.07 & .08 & {$[-.22 ; .08]$} \\
\hline Publication status & -.13 & .09 & {$[-.31 ; .05]$} & .000 & & & \\
\hline Assessment method & $-.22^{* * *}$ & .05 & {$[-.32 ;-.11]$} & .037 & $-.24^{* *}$ & .07 & {$[-.38 ;-.09]$} \\
\hline $\mathrm{N}$ & .00 & .00 & {$[-.00 ; .00]$} & .000 & & & \\
\hline Age & $-.01^{*}$ & .00 & {$[-.01 ;-.00]$} & .020 & .00 & .00 & {$[-.01 ; .01]$} \\
\hline Percent women & .16 & .10 & {$[-.05 ; .36]$} & .000 & & & \\
\hline
\end{tabular}

Note. Disorder: $0=$ anxiety, $1=$ depression; Publication status: $0=$ unpublished, $1=$ published; Clinical status: $0=$ healthy, $1=$ clinical; $\mathrm{N}=$ sample size of study; Age = mean age of participants; Percent women: Percent of sample that was female.

$*-p<.05 ; * *-p<.01 ; * * *-p<.001$

Table 3b. Random-effects models of significant moderators of BIS

\begin{tabular}{|c|c|c|c|c|c|c|c|}
\hline \multirow[t]{2}{*}{ Moderator } & \multicolumn{4}{|c|}{ Univariate metaregression } & \multicolumn{3}{|c|}{ Multivariate metaregression } \\
\hline & Beta & SE & $\overline{95 \%} \mathrm{CI}$ & $R^{2}$ & Beta & SE & $95 \% \mathrm{CI}$ \\
\hline Disorder & $-.22^{* *}$ & .09 & {$[-.39 ;-.06]$} & .022 & $-.31^{* * *}$ & .10 & {$[-.50 ;-.12]$} \\
\hline Publication status & .26 & .14 & {$[-.01 ; .54]$} & .136 & & & \\
\hline Assessment method & $.34^{* * *}$ & .09 & {$[.17 ; .51]$} & .025 & $.40^{* * * *}$ & .10 & {$[.20 ; .60]$} \\
\hline $\mathrm{N}$ & -.00 & .00 & {$[-.00 ; .00]$} & .027 & & & \\
\hline Age & .01 & .00 & {$[-.00 ; .00]$} & .051 & & & \\
\hline Percent women & $-.38^{*}$ & .16 & {$[-.69 ;-.07]$} & .061 & $-.32^{* *}$ & .16 & {$[-.60 ;-.01]$} \\
\hline
\end{tabular}

Note. Disorder: $0=$ anxiety, $1=$ depression; Publication status: $0=$ unpublished, $1=$ published; Clinical status: 0 = healthy, 1 = clinical; $\mathrm{N}=$ sample size of study; Age = mean age of participants; Percent women: Percent of sample that was female.

$*-p<.05 ; * *-p<.01 ; * * *-p<.001$ 
Table 4. Intercorrelation of the Study 1 moderator variables

\begin{tabular}{|c|c|c|c|c|c|c|c|c|}
\hline & g_BAS & g_BIS & $\mathrm{N}$ & Dep & Clin & Src & Age & Women \\
\hline g_BAS & - & & & & & & & \\
\hline g_BIS & $-.23^{* *}$ & - & & & & & & \\
\hline $\mathrm{N}$ & .09 & -.11 & - & & & & & \\
\hline Disorder & -.12 & $-.14^{*}$ & .09 & - & & & & \\
\hline Assessment & $-.19^{* *}$ & $.22^{* *}$ & $-.16^{*}$ & $.21^{* *}$ & - & & & \\
\hline Source & -.10 & .11 & -.04 & -.02 & $.14^{*}$ & - & & \\
\hline Age & -.09 & .10 & -.07 & $.27^{* *}$ & $.49^{* *}$ & .07 & - & \\
\hline Percent Women & .09 & $-.15^{*}$ & -.09 & .01 & -.09 & .02 & -.09 & - \\
\hline
\end{tabular}

Note. g_BAS = BAS effect size; g_BIS = BIS effect sizes measured in Hedges' $g ; \mathrm{N}=$ total N; Disorder is the pathology measure used with depression $=1$, anxiety $=0$; Assessment is the assessment strategy with self-report correlation $=0$, diagnosed-healthy comparison $=1$; Source is the source of the data with "published data" = 1 , "unpublished data" $=0$; Age is mean age; Percent Women is calculated as n_wom $/ \mathrm{n}$.

Note. $*<.05 ; * *<.01$ 
Table 5a. Clinical status-by-disorder for BAS

\begin{tabular}{|c|c|c|c|c|c|c|c|c|c|}
\hline \multirow[b]{2}{*}{ Moderator } & \multicolumn{3}{|c|}{ Total } & \multicolumn{3}{|c|}{ Depression } & \multicolumn{3}{|c|}{ Anxiety } \\
\hline & $k$ & Hedges' $g$ & $95 \% C I$ & $k$ & Hedges' $g$ & $95 \% \mathrm{CI}$ & $k$ & Hedges' $g$ & $95 \% C I$ \\
\hline Main Effect & 112 & -.29 & {$[-.39 ;-.20]$} & 65 & -.36 & {$[-.47 ;-.25]$} & 43 & -.22 & {$[-.43 ;-.01]$} \\
\hline \multicolumn{10}{|l|}{ Clinical status } \\
\hline Episode/Acute & 64 & -.43 & {$[-.58 ;-.29]$} & 35 & -.51 & {$[-.67 ;-.34]$} & 28 & -.33 & {$[-.61 ;-.04]$} \\
\hline Outpatients & 21 & -.12 & {$[-.34 ; .10]$} & 9 &.- .35 & {$[-.53 ;-.17]$} & 10 & -.02 & {$[-.32 ; .28]$} \\
\hline Euthymic/Remission & 27 & -.11 & {$[-.22 ;-.00]$} & 21 & -.14 & {$[-.26 ;-.01]$} & 5 & -.02 & {$[-.40 ; .37]$} \\
\hline
\end{tabular}

Note. Bolded effect sizes are significantly different from zero.

Table 5b. Clinical status-by-disorder for BIS

\begin{tabular}{|c|c|c|c|c|c|c|c|c|c|}
\hline \multirow[b]{2}{*}{ Moderator } & \multicolumn{3}{|c|}{ Total } & \multicolumn{3}{|c|}{ Depression } & \multicolumn{3}{|c|}{ Anxiety } \\
\hline & $k$ & Hedges' $g$ & $95 \% C I$ & $k$ & Hedges' $g$ & $95 \% \mathrm{CI}$ & $k$ & Hedges' $g$ & $95 \% C I$ \\
\hline Episode/Acute & 67 & 1.40 & {$[1.24 ; 1.57]$} & 37 & 1.64 & {$[1.41 ; 1.87]$} & 30 & 1.31 & {$[.98 ; 1.65]$} \\
\hline Outpatients & 21 & 1.36 & {$[1.07 ; 1.65]$} & 9 & 1.32 & {$[.96 ; 1.68]$} & 10 & 1.48 & {$[.99 ; 1.97]$} \\
\hline Euthymic/Remission & 28 & 1.01 & {$[.80 ; 1.23]$} & 22 & .87 & {$[.65 ; 1.10]$} & 5 & 1.70 & {$[1.18 ; 2.23]$} \\
\hline
\end{tabular}

Note. All effect sizes are significantly different from zero. 
Table 6. Studies on the inter-relationships between reinforcement sensitivity, depression and anxiety (Study 2)

\begin{tabular}{|c|c|c|c|c|c|c|c|c|c|}
\hline ID_Text & $\mathrm{N}$ & $\begin{array}{l}\text { Published } \\
\text { data? }\end{array}$ & $\begin{array}{c}\text { RST } \\
\text { Scales }\end{array}$ & $\begin{array}{l}\text { BAS-depres- } \\
\text { sion }\end{array}$ & BAS-anxiety & $\begin{array}{l}\text { BIS-de- } \\
\text { pression }\end{array}$ & $\begin{array}{c}\text { BIS- } \\
\text { Anxiety }\end{array}$ & $\begin{array}{l}\text { BAS- } \\
\text { BIS }\end{array}$ & $\begin{array}{c}\text { Depression- } \\
\text { Anxiety }\end{array}$ \\
\hline Albrecht et al. (2016) & 204 & $\mathrm{Y}$ & BIS/BAS & -.02 & .10 & .27 & .30 & -.14 & .58 \\
\hline Ak et al. (2012) & 55 & $\mathrm{~N}$ & TCI & -.14 & -.10 & .27 & .10 & .80 & .65 \\
\hline Atkinson et al. (2012) & 448 & $\mathrm{~N}$ & BIS/BAS & -.04 & -.10 & .28 & .22 & .10 & .71 \\
\hline Beevers et al. (2002) & 171 & $\mathrm{Y}$ & BIS/BAS & -.21 & .07 & .20 & .24 & .11 & .27 \\
\hline Brook et al. (2016) & 1,132 & $\mathrm{~N}$ & BIS/BAS & -.27 & .07 & .41 & .42 & -.04 & .37 \\
\hline Brunborg et al. (2010) & 61 & Y & BIS/BAS & -.02 & .10 & .02 & .54 & .03 & .41 \\
\hline Brunborg et al. (2010) & 204 & $\mathrm{Y}$ & BIS/BAS & -.06 & -.12 & .27 & .30 & -.14 & .58 \\
\hline Ceschi et al. (2011) & 122 & Y & SPSRQ & -.21 & .07 & .44 & .35 & .14 & .29 \\
\hline Chen et al. (2011) & 556 & $\mathrm{Y}$ & $\begin{array}{c}\text { TCI; } \\
\text { BIS/BAS }\end{array}$ & -.09 & .17 & .46 & .37 & -.16 & .63 \\
\hline Choi et al. (2014) & 21 & $\mathrm{~N}$ & $\begin{array}{l}\text { BIS/BAS; } \\
\text { TCI }\end{array}$ & .28 & .33 & .58 & .59 & -.10 & .31 \\
\hline Dennis et al. (2007) & 67 & Y & $\begin{array}{c}\text { BIS/BAS- } \\
\text { BAS }\end{array}$ & .14 & .36 & .02 & .52 & -.07 & .55 \\
\hline Fayazi et al. (2017) & 453 & $\mathrm{Y}$ & $\mathrm{J}-5$ & -.09 & -.03 & .09 & .17 & .17 & .43 \\
\hline Feil et al. (2008) & 161 & $\mathrm{Y}$ & BIS/BAS & -.09 & .01 & .21 & .23 & .05 & .57 \\
\hline Gawęda et al. (2014) & 161 & Y & TCI & -.11 & -.13 & .54 & .47 & .17 & .57 \\
\hline Goncalves et al. (2010) & 595 & $\mathrm{Y}$ & TCI & -.11 & .09 & .43 & .43 & -.34 & .65 \\
\hline Hamill et al. (2015) & 467 & $\mathrm{Y}$ & BIS/BAS & -.01 & -.01 & .35 & .35 & .06 & .67 \\
\hline Harnett et al. (2016) & 452 & Y & $\mathrm{J}-5$ & -.15 & -.08 & .16 & .17 & -.04 & .58 \\
\hline Hundt et al. (2007) & 285 & $\mathrm{Y}$ & $\begin{array}{l}\text { BIS/BAS; } \\
\text { SPSRQ }\end{array}$ & .01 & .09 & .32 & .21 & .08 & .33 \\
\hline Hundt et al. (2013) & 293 & Y & BIS/BAS & -.14 & -.06 & .28 & .31 & .02 & .49 \\
\hline Izadpanah et al. (2017) & 274 & Y & ARES & -.16 & .02 & .43 & .31 & -.23 & .55 \\
\hline Jiménez-Murcia et al. (2015) & 50 & $\mathrm{~N}$ & TCI & .12 & -.02 & .41 & .35 & -.41 & .59 \\
\hline Jorm et al. (1998) & 2,725 & $\mathrm{~N}$ & BIS/BAS & .03 & -.29 & .29 & .23 & .20 & .77 \\
\hline \multirow[t]{2}{*}{ Jylhä et al. (2006) } & 184 & $\mathrm{Y}$ & TCI-R & -.06 & .10 & .58 & .57 & -.44 & .74 \\
\hline & 163 & Y & TCI-R & -.20 & -.03 & .49 & .52 & -.38 & .71 \\
\hline Katz et al. (2018) & 512 & $\mathrm{~N}$ & BIS/BAS & -.25 & -.10 & .34 & .32 & .02 & .60 \\
\hline Liao et al. (2017) & 87 & $\mathrm{~N}$ & TPQ & -.09 & -.14 & .40 & .41 & .04 & .48 \\
\hline Lu et al., (2012) & 184 & Y & TCI & -.17 & -.13 & .35 & .24 & -.12 & .53 \\
\hline Lyvers et al. (2016) & 86 & $\mathrm{Y}$ & SPSRQ & -.13 & -.09 & .37 & .34 & .18 & .73 \\
\hline
\end{tabular}




\begin{tabular}{|c|c|c|c|c|c|c|c|c|c|}
\hline ID_Text & $\mathrm{N}$ & $\begin{array}{c}\text { Published } \\
\text { data? }\end{array}$ & $\begin{array}{l}\text { RST } \\
\text { Scales }\end{array}$ & $\begin{array}{l}\text { BAS-depres- } \\
\text { sion }\end{array}$ & BAS-anxiety & $\begin{array}{l}\text { BIS-de- } \\
\text { pression }\end{array}$ & $\begin{array}{l}\text { BIS- } \\
\text { Anxiety }\end{array}$ & $\begin{array}{l}\text { BAS- } \\
\text { BIS }\end{array}$ & $\begin{array}{l}\text { Depression- } \\
\text { Anxiety }\end{array}$ \\
\hline Manfredi et al. (2011) & 307 & $\mathrm{Y}$ & TPQ & .03 & -.13 & .39 & .31 & -.28 & .53 \\
\hline Markarian et al. (2013) & 459 & $\mathrm{Y}$ & BIS/BAS & .08 & .34 & .21 & .23 & .01 & .67 \\
\hline Matsudaira et al. (2006) & 541 & Y & TCI & .01 & .05 & .26 & .44 & -.27 & .49 \\
\hline Park et al., (2013) & 201 & Y & BIS/BAS & -.09 & .02 & .38 & .19 & .09 & .55 \\
\hline Rubinart et al. (2017) & 20 & $\mathrm{~N}$ & TCI & .08 & -.16 & .17 & .13 & -.54 & .73 \\
\hline Sanders et al. (2015) & 170 & $\mathrm{Y}$ & BIS/BAS & -.09 & .07 & .40 & .28 & -.14 & -.33 \\
\hline Scott-Parker et al. (2012) & 761 & $\mathrm{Y}$ & SPSRQ & .05 & .12 & .43 & .39 & .08 & .70 \\
\hline $\begin{array}{l}\text { Rodríguez-Testal et al. } \\
\text { (2016) }\end{array}$ & 287 & $\mathrm{Y}$ & SRQ & -.34 & .09 & .43 & .42 & .14 & .66 \\
\hline Tanaka et al. (1998) & 223 & Y & TCI & .15 & .16 & .48 & .36 & -.23 & .64 \\
\hline Taubitz et al. (2015) & 497 & $\mathrm{~N}$ & $\mathrm{BIS} / \mathrm{BAS}$ & -.12 & -.19 & .36 & .56 & .07 & .73 \\
\hline Wichelns et al. (2016) & 115 & $\mathrm{Y}$ & BIS/BAS & .11 & .14 & .30 & .02 & .93 & .78 \\
\hline
\end{tabular}

Note. ARES: Action Regulating Emotion Systems scale, BIS/BAS: Behavioral Inhibition System/Behavioral Activation scale, J-5: Jackson 5, SPSRQ: Sensitivity to Punishment, Sensitivity to Reward Questionnaire, TCI: Temperament and Character Inventory, TCI-R: Revised TCI. 
Table 7. Meta analysis of correlations between reinforcement sensitivity, depression and anxiety

\begin{tabular}{lccc}
\hline Variables & $r$ & $95 \%$ CI & $p$ value \\
\hline BAS-BIS & .01 & $-.08 ; .09$ & .90 \\
BAS-Depression & -.07 & $-.10 ;-.03$ & .001 \\
BAS-Anxiety & .01 & $-.03 ; .05$ & .55 \\
BIS-Depression & .37 & $.32 ; .41$ & $<.0001$ \\
BIS-Anxiety & .35 & $.30 ; .39$ & $<.0001$ \\
Depression-Anxiety & .65 & $.57 ; .73$ & $<.0001$ \\
\hline
\end{tabular}

NOTE: This is a postprint of the study Katz, B. A., Matanky, K., Aviram, G., \& Yovel, I. (2020). Reinforcement sensitivity, depression and anxiety: A meta-analysis and meta-analytic structural equation model. Clinical Psychology Review, 101842, doi: 10.1016/j.cpr.2020.101842. See online article for final text. 
Table 8. Summary of model fit statistics for the alternative path models

\begin{tabular}{cccccccc}
\hline Model & & & & & RMSEA & \\
& $\chi^{2}$ & $d f$ & CFI & RMSEA & $90 \%$ CI & SRMR \\
\hline First model & 180.92 & 4 & .982 & .057 & $.050-.064$ & .070 \\
Second model & 181.29 & 5 & .982 & .051 & $.045-.057$ & .070 \\
Third model & 241.56 & 6 & .976 & .054 & $.048-.060$ & .073 \\
Fourth model & 182.84 & 6 & .982 & .047 & $.041-.053$ & .070
\end{tabular}

Note. $\mathrm{CFI}=$ comparative fit index; $\mathrm{RMSEA}=$ root-mean-square error of approximation; $\mathrm{CI}=$ confidence interval; SRMR = Standardized root mean square residual. 
Figure 1. Derivation of analysis samples

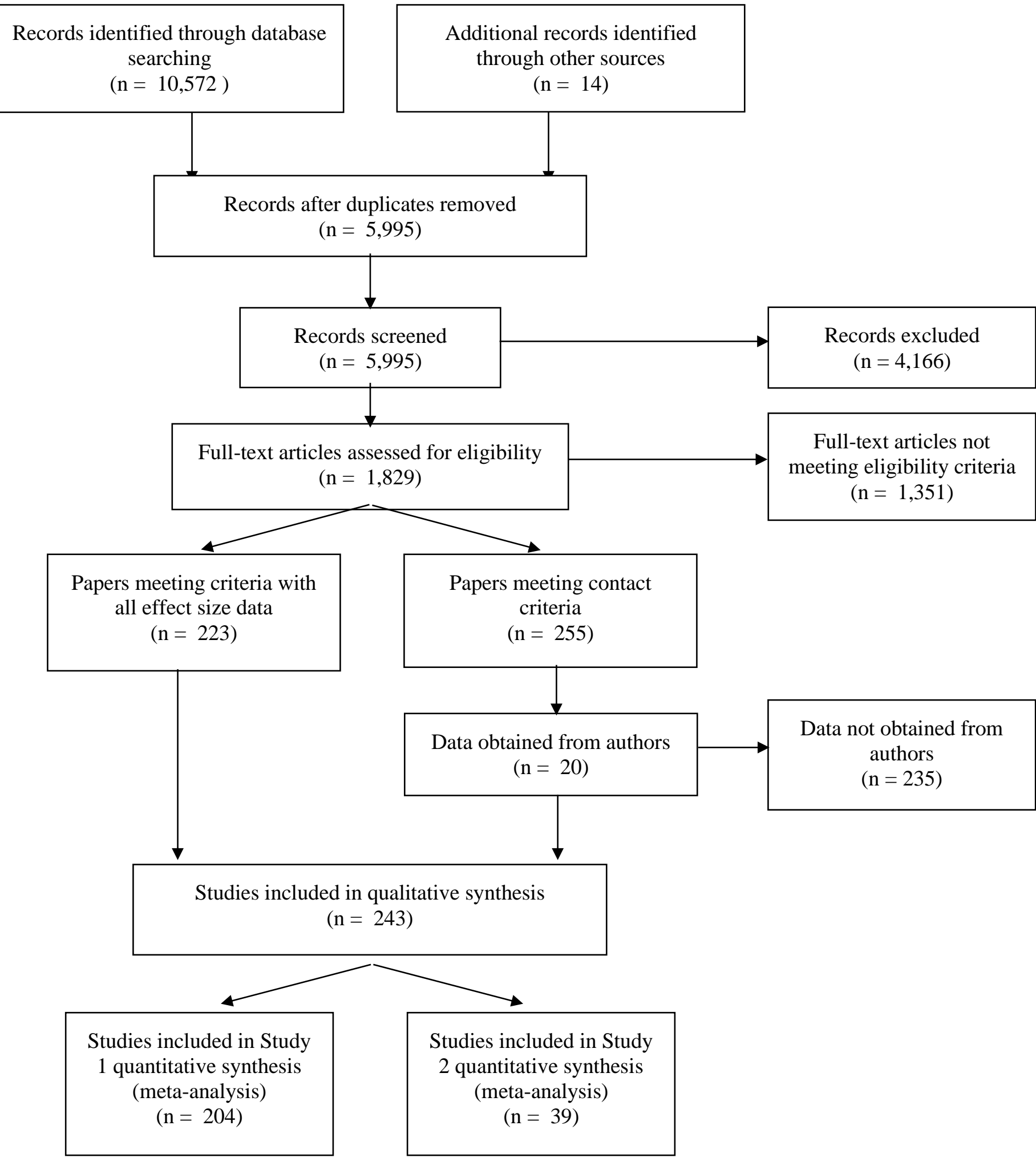


Figure 2a-b. Forest plot of BAS interaction between disorder and assessment method Figure 2a. Depression

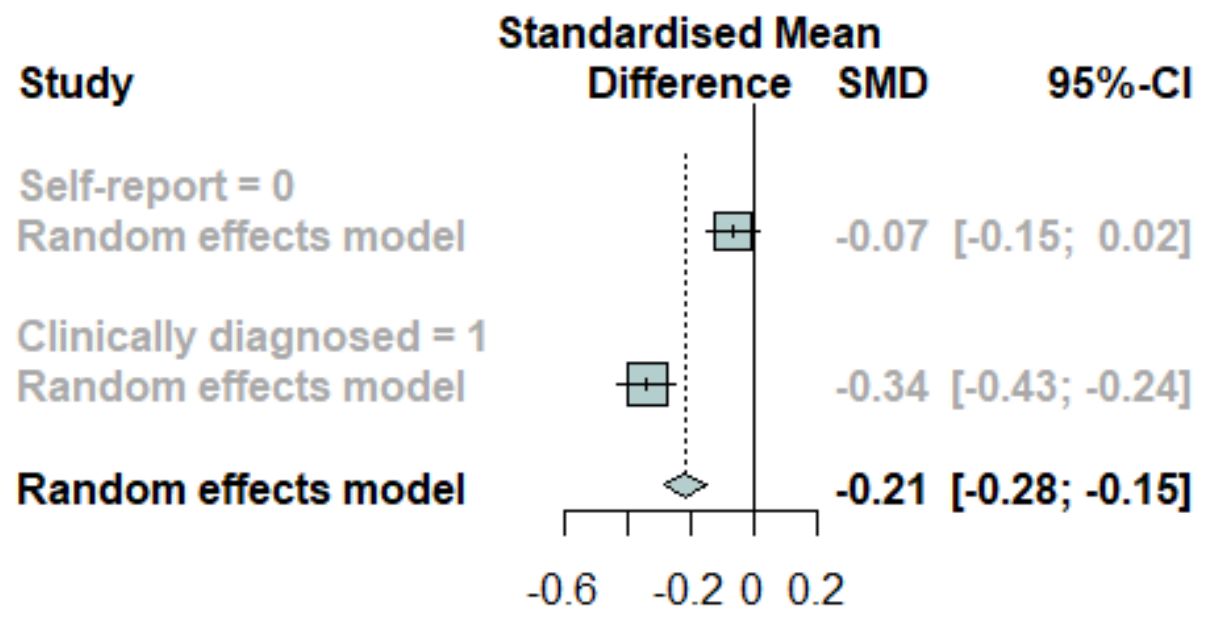

Figure 2b. Anxiety

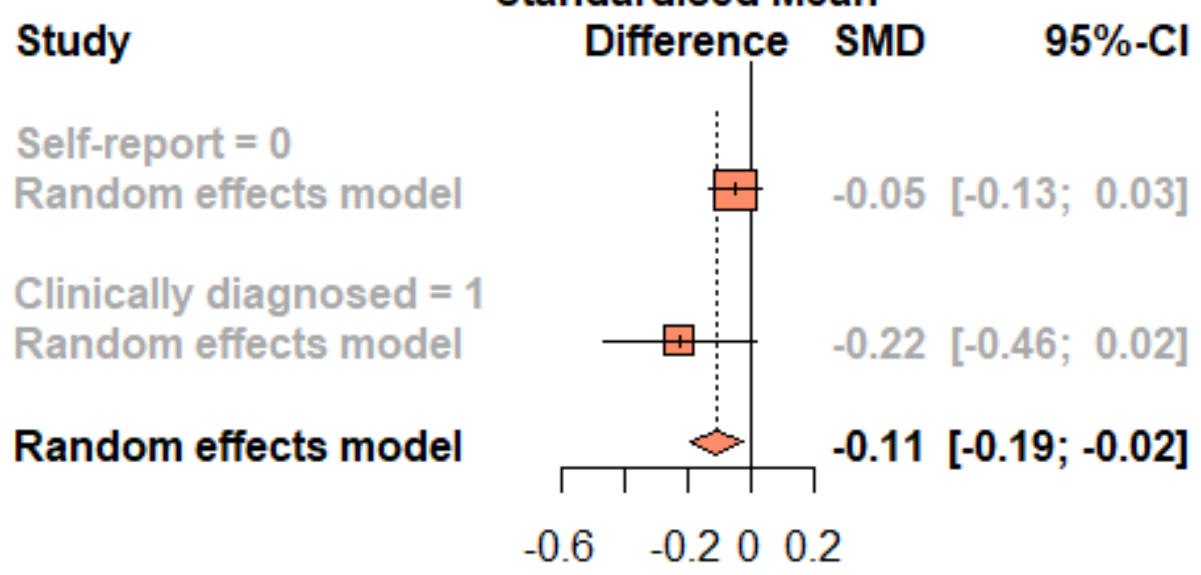


Figures 3a-b. Forest plot of BIS interaction between disorder and assessment method Figure 3a. Depression

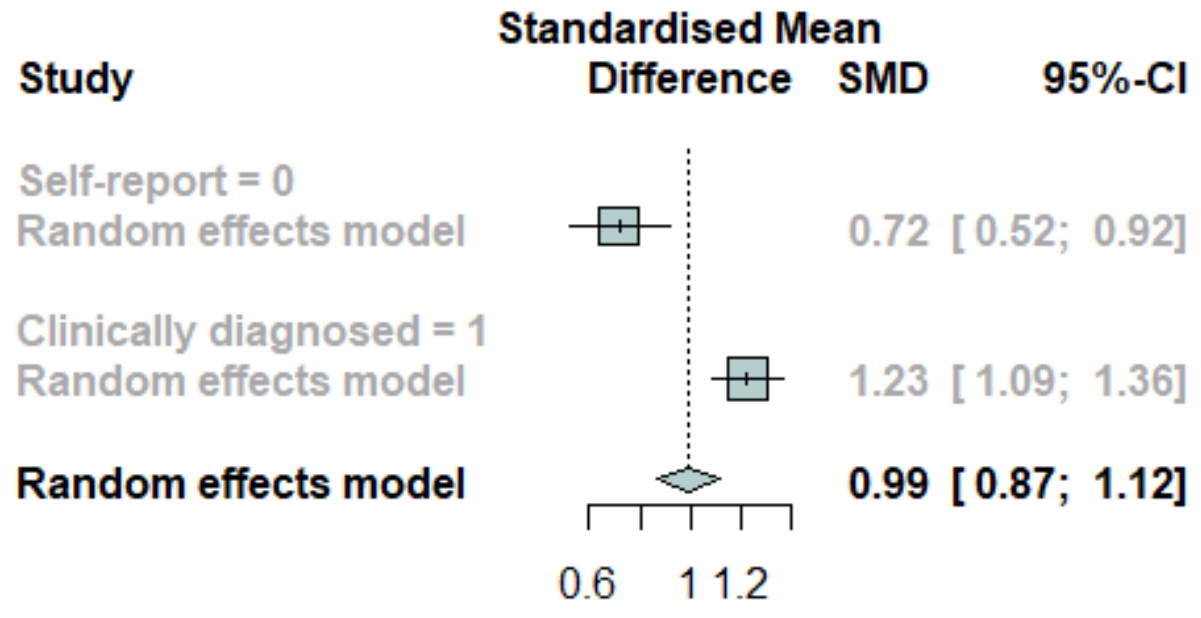

Figure 3b. Anxiety

\section{Study}

Self-report $=0$

Random effects model

Clinically diagnosed $=1$

Random effects model

Random effects model

\section{Standardised Mean}

Difference SMD $\quad 95 \%-\mathrm{Cl}$

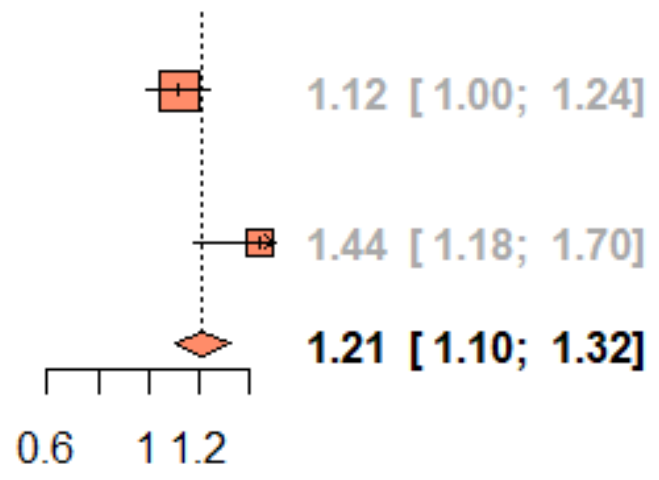


Figures 4a-b. Funnel plots of BAS and BIS effect sizes following the trim-and-fill procedure Figure 4a. Funnel plot of BAS effect sizes following the trim-and-fill procedure

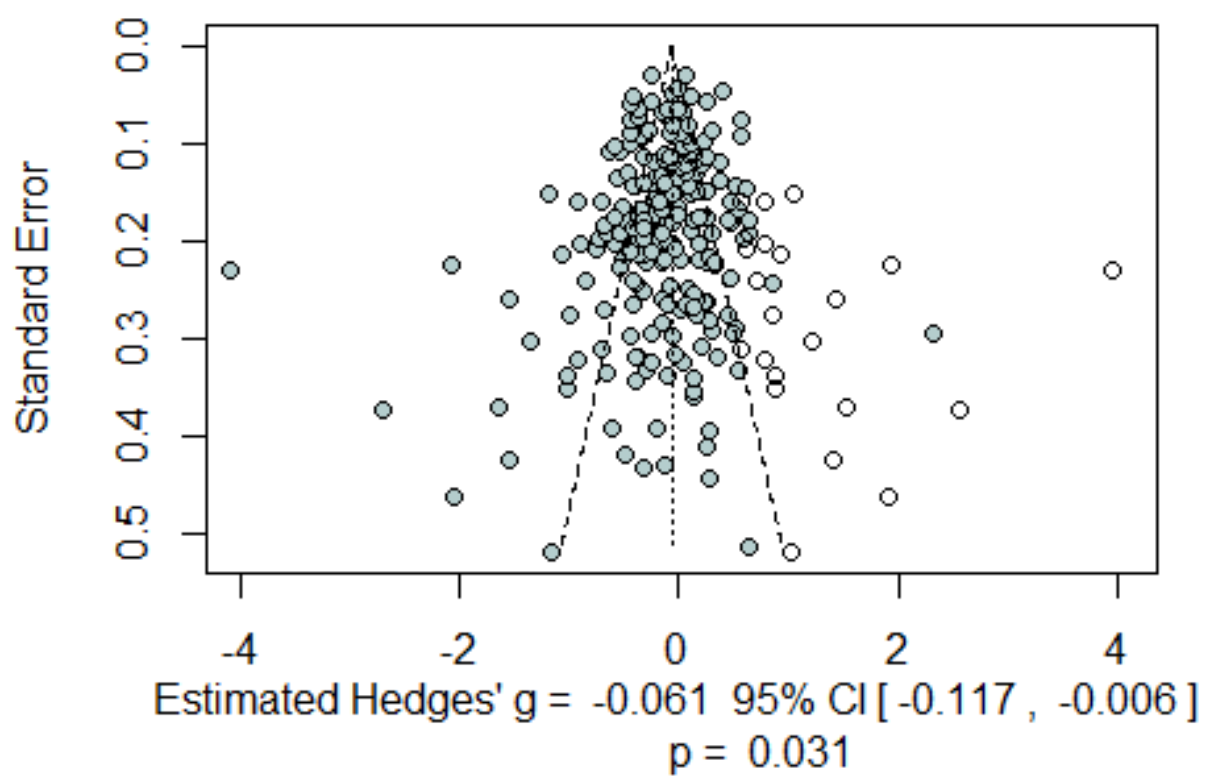

Figure $4 \mathrm{~b}$. Funnel plot of BIS effect sizes following the trim-and-fill procedure

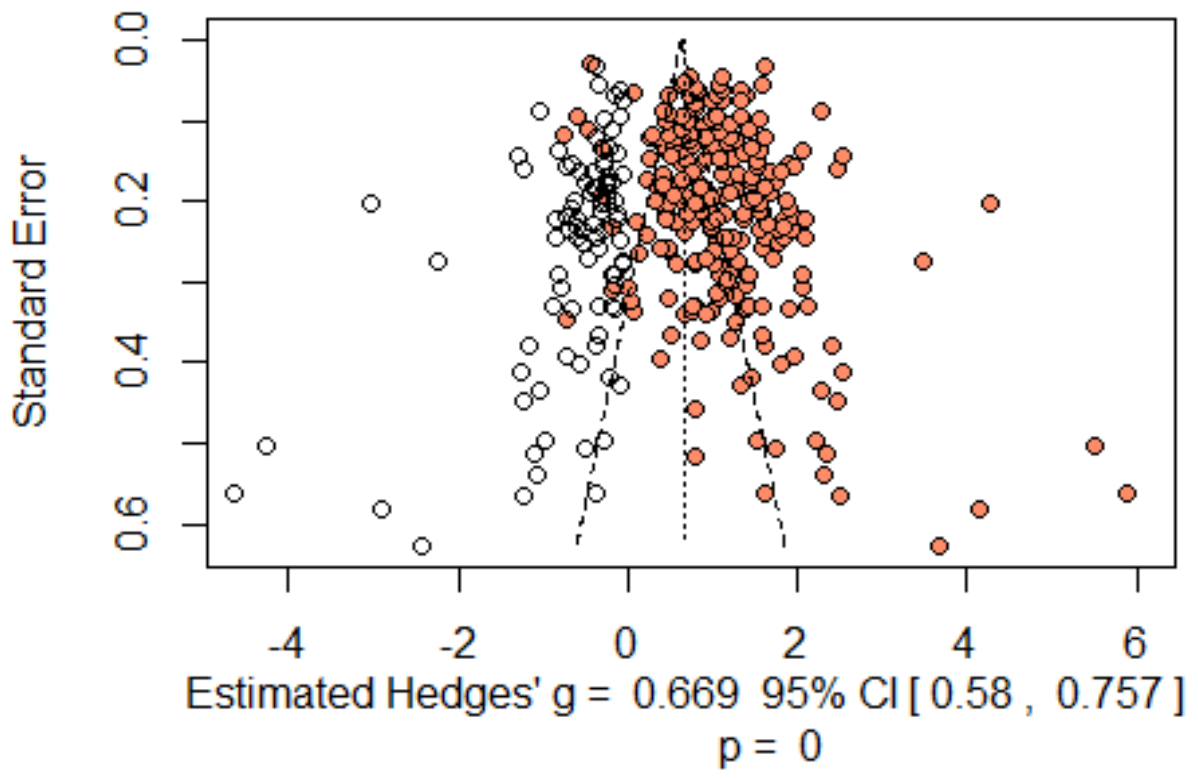

Note. Empty circles represent studies imputed by the trim-and-fill procedure. 
Figures 5a-b. Path models of reinforcement sensitivity predicting depression and anxiety Figure 5a. Original path model of reinforcement sensitivity predicting depression and anxiety

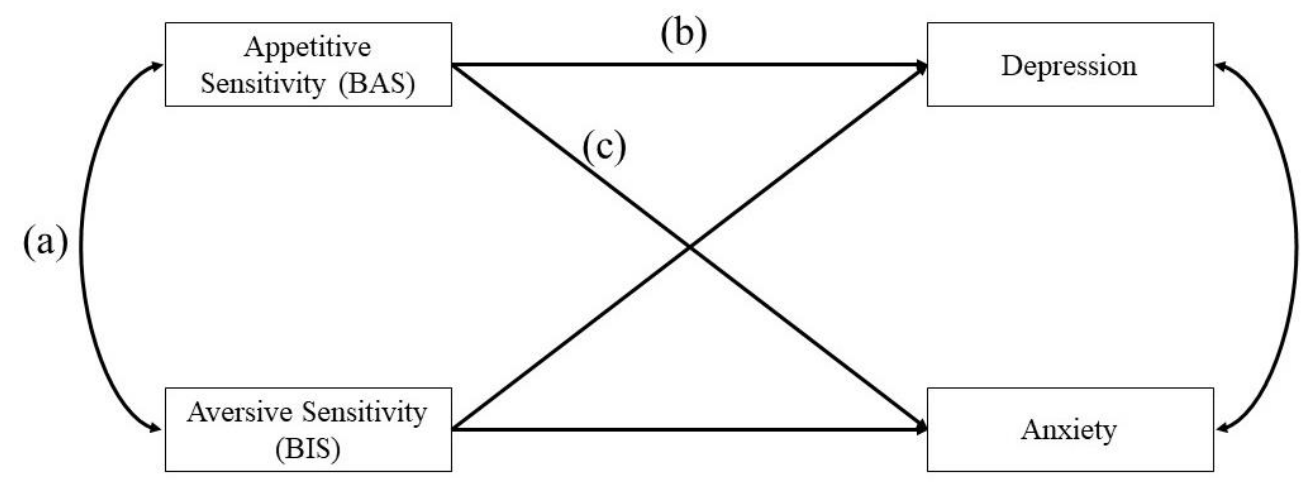

Note. Letters indicate paths that were removed in testing alternate models. (a) - removed in the second model. (b) - removed in the third model. (c) - removed in the fourth model.

Figure 5b. Final path model of reinforcement sensitivity predicting depression and anxiety

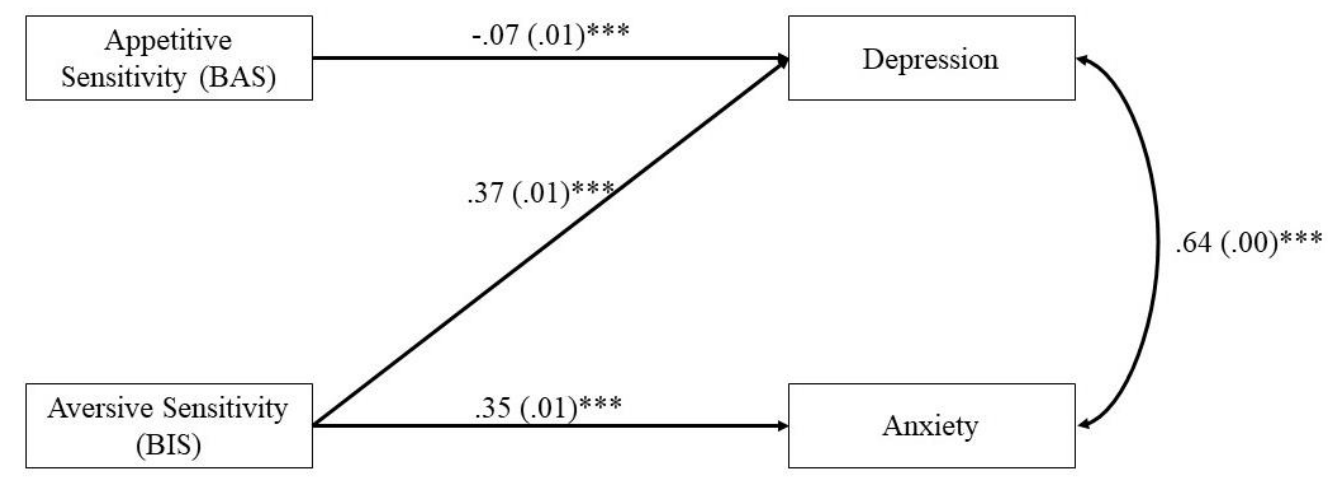

Note. $* * *-p<.001$ 